US-CL-CProperty of the United States Government
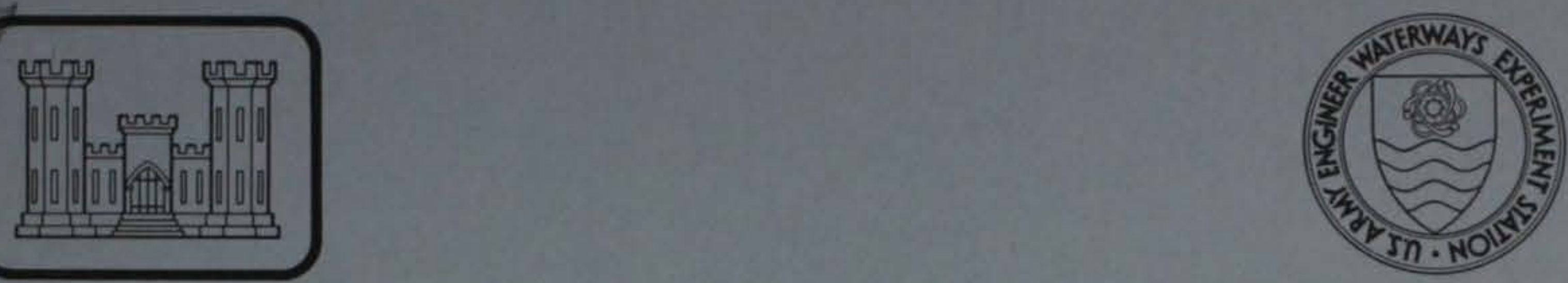

TECHNICAL REPORT SL-79-7

\title{
AN EFFECTIVE STRESS MODEL FOR GROUND MOTION CALCULATIONS
}

by

\author{
G. Y. Baladi \\ Structures Laboratory \\ U. S. Army Engineer Waterways Experiment Station \\ P. O. Box 631, Vicksburg, Miss. 39180
}

September 1979

Final Report

Approved For Public Release; Distribution Unlimited

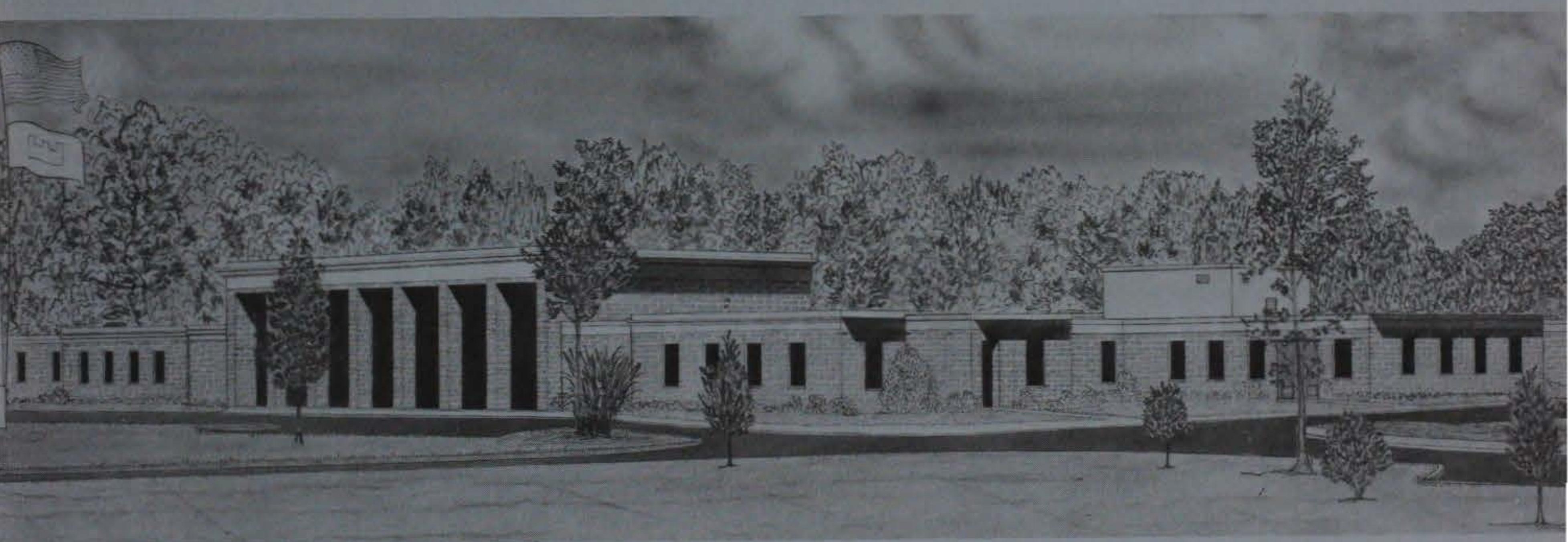

Prepared for Defense Nuclear Agency

Washington, D. C. 20305

Under DNA Subtask SB209, Work Unit 44

LBKAKY BRANCH

FECHNICAL INFORMATION CENTER

US ARMY ENGINEER WATERWAYS EXPERIMENT STATION

VICKSBURG. MISSISSIPE 


\begin{tabular}{|c|c|}
\hline REPORT DOCUMENTATION PAGE & $\begin{array}{c}\text { READ INSTRUCTIONS } \\
\text { BEFORE COMPLETING FORM }\end{array}$ \\
\hline $\begin{array}{l}\text { 1. REPORT NUMBER } \\
\text { Technical Report SL-79-7 }\end{array}$ & 3. RECIPIENT'S CATALOG NUMBER \\
\hline \multirow{2}{*}{$\begin{array}{l}\text { 4. TIE (and Subttio) } \\
\text { AN EFFECTIVE STRESS MODEL FOR GROUND MOTION } \\
\text { CALCULATIONS }\end{array}$} & $\begin{array}{l}\text { 5. TYPE OF REPORT \& PERIOD COVERED } \\
\text { Final report }\end{array}$ \\
\hline & 6. PERFORMING ORG. REPORT NUMBER \\
\hline $\begin{array}{l}\text { 7. AUTHOR(0) } \\
\text { G. Y. Baladi }\end{array}$ & 8. CONTRACT OR GRANT NUMBER(s) \\
\hline $\begin{array}{l}\text { 9. PERFORMING ORGANIZATION NAME AND ADDRESS } \\
\text { U. S. Army Engineer Waterways Experiment Station } \\
\text { Structures Laboratory } \\
\text { P. O. BOX } 631 \text {, Vicksburg, Miss. } 39180\end{array}$ & $\begin{array}{l}\text { 10. PROGRAM ELEMENT, PROJECT, TASK } \\
\text { AREA Q WORK UNIT NUMBERS } \\
\text { See Block } 18\end{array}$ \\
\hline \multirow{2}{*}{$\begin{array}{l}\text { 11. CONTROLLING OFFICE NAME AND ADDRESS } \\
\text { Director } \\
\text { Defense Nuclear Agency } \\
\text { Washington, D. C. } 20305\end{array}$} & $\begin{array}{l}\text { 12. REPORT DATE } \\
\text { September } 1979 \\
\end{array}$ \\
\hline & $\begin{array}{l}\text { 13. NUMBER OF PAGES } \\
115\end{array}$ \\
\hline \multirow[t]{2}{*}{ 14. MONITORING AGENCY NAME \& ADDRESS(if difforent from Controlling Office) } & $\begin{array}{l}\text { 15. SECURITY CLASS. (of thio roport) } \\
\text { Unclassified }\end{array}$ \\
\hline & $\begin{array}{l}\text { 15a. DECLASSIFICATION/DOWNGRADING } \\
\text { SCHEDULE }\end{array}$ \\
\hline
\end{tabular}

\section{DISTRIBUTION STATEMENT (of this Roport)}

Approved for public release; distribution unlimited.

17. DISTRIBUTION STATEMENT (of the abotract ontered in Block 20, if different from Report)

\section{SUPPLEMENTARY NOTES}

This research was sponsored by the Defense Nuclear Agency under DNA Subtask SB209, Work Unit 44, "Dynamic Pore Pressure Model."

19. KEY WORDS (Continue on reverse side If necessary and ldentify by block number)

Constitutive models

Ground motion

Ground shock

Stress-strain relations

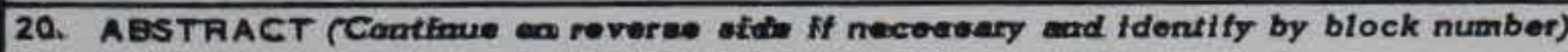

This report documents the development of a three-dimensional, elasticplastic, work-hardening constitutive model based on the theory of effective (intergranular) stress for the purpose of simulating the response of isotropic three-phase (partially saturated) earth materials. This model can be used to perform effective stress ground shock analyses. 


\section{ABSTRACT (Continued).}

The model is actually a marriage of two single-phase elastic-plastic models which simulate, respectively, the drained and undrained stress-strain behavior of earth media, and whose coefficients can all be determined experimentally using conventional laboratory testing techniques. Fitting the model, therefore, requires an extra set of laboratory tests (the drained tests) over that required to fit a contemporary (total stress) ground shock model.

For undrained applications (where only the applied total stresses are usually known), the model predicts total stresses and ground deformations as well as the effective stresses and pore pressures. Pore pressure is an output from the model, not an input. Laboratory pore pressure data obtained during conduct of the undrained tests, however, are extremely useful for verification of the model.

The model is examined under simulated drained and undrained laboratory test conditions to depict its various features and illustrate the techniques for fitting its functional coefficients. In addition, given a set of stress increments or a set of strain increments, two general methods are presented for exercising the model to compute the resultant total stresses, effective stresses, pore pressures, and deformations.

The feasibility of using the new model for effective stress ground shock analyses is demonstrated numerically by solving a simplified two-dimensional airslap problem for a saturated sand halfspace using an effective stress version of the LAYER code. The real power of this computational tool has yet to be investigated by applications against actual field experiments.

Appendix A reviews the fundamentals of elastic-plastic models. 


\section{PREFACE}

The investigation reported herein was conducted at the U. S. Army Engineer Waterways Experiment Station (WES) for the Defense Nuclear Agency under Nuclear Weapons Effects Subtask SB209, Work Unit 44, "Dynamic Pore Pressure Model."

This investigation was conducted and the report written by Dr. George Y. Baladi of the Geomechanics Division (GD), Structures Laboratory (SL), during the period October 1977-June 1979 under the general direction of Mr. Bryant Mather, Acting Chief, SL, and Dr. J. G. Jackson, Jr., Chief, GD.

COL John L. Cannon, CE, and COL Nelson P. Conover, CE, were Commanders and Directors of WES during the investigation and publication of this report. Mr. F. R. Brown was Technical Director. 
PREFACE

CONVERSION FACTORS, METRIC (SI) TO U. S. CUSTOMARY

UNITS OF MEASUREMENT

CHAPTER I INTRODUCTION . . . . . . . . . . . . . . . . . . . . 9

1.1 BACKGROUND ....................... . . . . 9

1.2 OBJECTIVE ....................... . . . . . . 11

1.3 SCOPE ...................... . . . 11

CHAPTER 2 EFFECTIVE STRESS CONCEPT AND MECHANICAL BEHAVIOR

OF SOIL . . . . . . . . . . . . . . . . 13

2.1 EFFECTIVE STRESS CONCEPT ................. 13

2.2 MECHANICAL BEHAVIOR OF SOIL . . . . . . . . . . . . 15

CHAPTER 3 ELASTIC-PLASTIC CONSTITUTIVE MODEL . . . . . . . . . 20

3.1 ELASTIC BEHAVIOR .................... 20

3.2 PLASTIC BEHAVIOR . . . . . . . . . . . . . . . . 22

3.3 SUMMARY ...................... . . . . . . 24

CHAPTER 4 THE TREATMENT OF A MULTIPHASE SYSTEM . . . . . . . . . 31

CHAPTER 5 BEHAVIOR OF THE MULTIPHASE CONSTITUTIVE MODEL

UNDER TRIAXIAL TEST CONDITIONS . . . . . . . . . . 37

5.1 INTRODUCTION . . . . . . . . . . . . . . . 37

5.2 HYDROSTATIC PHASE . . . . . . . . . . . . . 38

5.2.1 Drained Condition ............... 38

5.2.2 Undrained Condition ............... . 40

5.2.3 Computation of Effective Stress and Pore

Pressure ................... 41

5.3 SHEAR PHASE ...................... 42

5.3.1 Drained Condition .. . . . . . . . . . . 42

5.3.2 Undrained Conditions . . . . . . . . . . . . . 45

5.3.3 Effective Stress and Pore Pressure Computations . . . 46

CHAPTER 6 COMPARISONS OF LABORATORY TEST DATA WITH MODEL

PREDICTIONS . . . . . . . . . . . . . . 51

6.1 EXPERIMENTAL PROGRAM ............... . . . 51

6.2 MATERIAL CONSTANTS . . . . . . . . . . . . . . . . 52

6.3 COMPARISON OF TEST RESULTS WITH MODEL BEHAVIOR . . . . . 53

CHAPTER 7 APPLICATION OF THE MODEL FOR SOLVING GROUND

SHOCK PROBLEMS . . . . . . . . . . . . . . 70

7.1 INTRODUCTION . . . . . . . . . . . . . . . . . 70

7.2 COMPUTATIONAL DETAILS . . . . . . . . . . . . . 70

7.3 RESULTS . . . . . . . . . . . . . . . . . . 71 
CHAPTER 8 SUMMARY AND RECOMMENDATIONS . . . . . . . . . . . 86

8.1 SUMMARY . . . . . . . . . . . . . . . 86

8.2 RECOMMENDATIONS . . . . . . . . . . . . . . . . 86

REFERENCES . . . . . . . . . . . . . . . . . . . 87

APPENDIX A FUNDAMENTAL BASIS OF ELASTIC-PLASTIC

CONSTITUTIVE MODELS . . . . . . . . . . . . 91

A. 1 BASIC CONCEPTS FROM CONTINUUM MECHANICS . . . . . . . . . 91

A. 2 GENERAL DESCRIPTION OF ELASTIC-PLASTIC

CONSTITUTIVE MODELS . . . . . . . . . . . . . . . 93

A.2.1 Elastic Strain Increment Tensor . . . . . . . . . . . 96

A.2.2 Plastic Strain Increment Tensor . . . . . . . . . . . . 98

A.2.3 Total Strain Increment Tensor . . . . . . . . . . . 101

APPENDIX B NOTATION . . . . . . . . . . . . . . . . 103 


\section{LIST OF ILLUSTRATIONS}

Figure

Page

2.1 Typical behavior of a dry or drained soil under hydrostatic loading and unloading . . . . . .

2.2 Typical behavior of saturated soil tested under undrained triaxial test conditions . . . . . . . . . 18

2.3 Typical behavior of saturated soils tested under drained triaxial test conditions . . . . . . . . . . 19

3.1 Proposed relationship for isotropic compression test . . . . . . . . . . . . . . . 26

3.2 Elastic bulk modulus versus first invariant of the stess tensor . . . . . . . . . . . . . 27

3.3 Proposed relationship for triaxial shear test . . . . . . 28

3. 4 Elastic shear modulus versus second invariant of the stress deviation tensor and plastic volumetric strain . . . . . . . . . . . . . . . . . 29

3.5 Proposed yield surfaces for the elastic-plastic strain-hardening model . . . . . . . . . 30

5.1 Behavior of the model under drained hydrostatic compression . . . . . . . . . . . . . . . 48

5.2 Drained shear behavior predicted by the model for a conventional triaxial test and a constant mean normal stress test....................

5.3 Undrained shear behavior predicted by the model, showing the influence of the parameter $R$ on the effective stress path in a conventional undrained TX test............... . . . 50

6.1 Campbell Swamp sand grain size distribution curve . . . 57

6.2 Drained isotropic compression response, laboratory measurements versus model behavior, Group 1... . . . 58

6.3 Drained stress path for uniaxial (UX) strain and effective stress failure envelope, laboratory measurements versus model behavior, Group 1 . . . . .

6.4 Principal stress difference versus axial strain response from consolidated drained triaxial shear tests, laboratory measurements versus model behavior,

6.5 Drained and undrained isotropic compression response, laboratory measurements versus model behavior, Group 2. . . . . . . . . . . . . . . . . .

6.6 Drained and undrained stress path for uniaxial (UX) strain, laboratory measurements versus model behavior, Group 2... . . . . . . . . . . .

6.7 Principal stress difference versus axial strain response from consolidated drained triaxial shear tests, laboratory measurements versus model behavior, Group 2 . . . . . . . . . . . . . . . . . . 
6.8 Principal stress difference and excess pore pressure versus axial strain response from consolidated undrained triaxial shear tests, laboratory measurements versus model behavior,

6.9 Drained isotropic compression response, laboratory

6.10 Principal stress difference versus axial strain response from consolidated drained triaxial shear tests, laboratory measurements versus model behavior, Group 3

6.11 Effective stress paths for consolidated undrained triaxial shear tests, laboratory measurements versus model behavior, Group 3.............

6.12 Principal stress difference and excess pore pressure versus axial strain response from consolidated undrained triaxial shear tests, laboratory measurements versus model behavior, Group 3..............

6.13 Principal stress difference and excess pore pressure versus axial strain response from unconsolidated undrained triaxial shear tests, laboratory measurements versus model behavior, Group 3 ...........

7.1 Axisymmetric problem geometry . . . . . . . . . . .

7.2 Air overpressure versus time ............ . . 73

7.3 Stress-time histories; range 3.6 metres, depth 1.6

7.4 Stress-time histories; range 3.6 metres, depth 3.6

7.5 Stress-time histories; range 3.6 metres, depth 7.6

7.6 metres -time histories; range 15.6 metres, depth 1.6

7.7 Stress-time histories; range 15.6 metres, depth $3 . \dot{6}$

7.8 Stress-time histories; range 15.6 metres, depth 7.6

7.9 Vertical $(\mathrm{V})$ and radial $(U)$ particle velocity-time

7.10 Vertical (VD) and radial (RD) displacement-time histories; range 3.8 metres . . . . . . . . . . 81

7.11 Vertical (V) and radial (U) particle velocity-time histories; range 15.8 metres . . . . . . . . 82

7.12 Vertical (VD) and radial (RD) displacement-time histories; range 15.8 metres . . . . . . . . . . 83

7.13 Comparison of total and effective stress paths; range 3.6 metres . . . . . . . . . . . . . . . 84

7.14 Comparison of total and effective stress paths; range

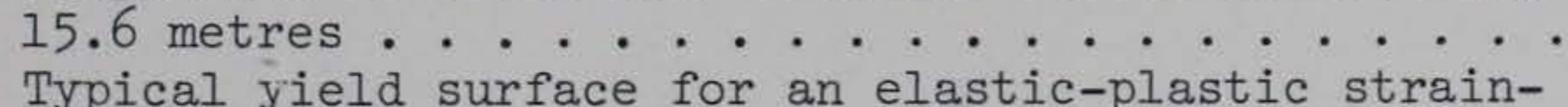

A.1 Typical yield surface for an elastic-plastic strainhardening model . . . . . . . . . . . . 102 


\section{LIST OF TABLES}

$\underline{\text { Table }}$

Page

3.1 Summary of the model parameters

4.1 Summary of the model parameters for a multiphase system ...................... 36

6.1 Numerical values of material constants for drained behavior of Campbell Swamp sand . . . . . . . . . 55

6.2 Numerical values of material constants for undrained behavior of Campbell Swamp sand . . . . . . . . 56 


\section{CONVERSION FACTORS, METRIC (SI) TO U. S. CUSTOMARY}

Units of measurement used in this report can be converted as follows: Multiply

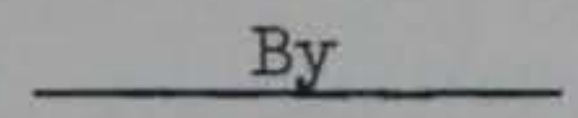

To Obtain

\section{Metric (SI) to U. S. Customary}

centimetres

centimetres per millisecond

grams per cubic centimetre

metres

metres per millisecond

millimetres

$$
\begin{aligned}
& 0.3937007 \\
& 0.3937007
\end{aligned}
$$

62.42797

3.280839

3.280839

0.03937007

U. S. Customary to Metric (SI)
bars
kilobars

100.00

100.00 kilopascals

megapascals 


\section{INTRODUCTION}

\subsection{BACKGROUND}

Earth materials are multiphase systems (Reference 1) that consist in general of solid particles (possibly cemented), water, and gas. The intrinsic response of such materials to externally applied loads is extremely complicated. To model this response for a particular material, one must resort to the theory of continuum mechanics and have available an appropriate constitutive relation. The solution of earth structure problems then becomes a mathematical formalism that can be achieved numerically or by other means.

In recent years, primarily under the sponsorship of the Defense Nuclear Agency (DNA), considerable progress has been made in the development of mathematical models for the study of ground shock effects in soil and/or rock media (References 2 through 12). The models are used in two-dimensional (2D) computer code calculations that help define the ground shock environment of current and planned hardened defense facilities. The requirement for more advanced models can be attributed to the desire for a better mathematical approximation of the observed stressstrain properties of earth materials. Consequently, several quite complicated nonlinear elastic-ideally plastic (References 2 through 4), variable moduli-type (References 5 through 8 ), and nonlinear elasticplastic work-hardening (References 9 through 12) constitutive models have been developed and used by the DNA soil and rock mechanics communities. A detailed summary of the advantages and disadvantages of each type of model is given in Reference 3. A brief historical development of these models is given in Reference 12. All of the above models are three-dimensional, either isotropic or transverse-isotropic, and can simulate to various degrees the observed highly nonlinear and hysteretic behavior of earth media, with some of them predicting shear-induced volume change; however, they all have in common that they can simulate only single-phase systems. 
Treatment of two-phase systems (water and solid) for fluidsaturated earth materials within the framework of elastic-plastic constitutive models was first attempted by Roscoe and his coworkers at Cambridge University (Reference 13). They successfully developed several two-dimensional models for describing the stress-strain-pore pressure response of saturated clay. The solid skeleton and the fluid constituent of their two-phase system (saturated clay) were assumed to be incompressible, thus allowing the treatment of undrained loading conditions by specifying $d \varepsilon_{k k}=0 \quad\left(d \varepsilon_{k k}=\right.$ increment of volumetric strain). ${ }^{1}$ The assumption of the incompressibility of the solid skeleton and the fluid constituent is reasonable since in most conventional geotechnical problems the loading conditions are static and the pressure levels of interest are very small. In 1976 and 1977, several isotropic two-phase constitutive models for saturated cohesionless soils were developed (References 14 and 15) at the U. S. Army Engineer Waterways Experiment Station (WES). These models also used the concept of $d \varepsilon_{\mathrm{kk}}=0$ to simulate undrained test conditions for fluid-saturated granular materials. In contrast to the Cambridge models (Reference 13), however, the WES models are three-dimensional and provide greater flexibility in fitting test data for a broad range of behavior. The models documented in References 13, 14, and 15 provide the means to perform effective stress analyses for problems involving static-type loading conditions. Because of their assumption that the solid skeleton and the water are incompressible (i.e., $d \varepsilon_{\mathrm{kk}}=0$ ), however, they are not suitable for problems involving transient or dynamic-type loading conditions, such as ground shock problems. The elimination of the assumption of incompressibility of the solid skeleton and water not only provides a means of solving dynamic problems but also provides a means for simulating partially saturated materials (i.e., solid skeleton, water, and gas). The model developed in this report closely parallels the developments reported in Reference 14 with the exception that the assumption of incompressibility of the solid skeleton and water is eliminated.

1 For convenience, symbols and abbreviations are listed and defined in the Notation (Appendix B). 
The development of the present model is based on the fact that current single-phase and two-phase constitutive models will each predict a different deformation path for a given stress loading, with the twophase model achieving the better agreement with physics and data. By implication, a two- or three-phase constitutive model will also predict better ground motion histories than the current crop of single-phase ground shock models. To what extent and in what situations remain to be seen.

\subsection{OBJECTIVE}

The overall objective of this study was to develop a completely general, three-dimensional, elastic-plastic, work-hardening constitutive relationship for simulating the behavior of isotropic three-phase earth materials.

\section{$1.3 \mathrm{SCOPE}$}

One of the constraints of this study was that the model should be in a form suitable for use with current finite-difference techniques (such as the LAYER code) for the computation of ground motions, total and effective stresses, and pore pressures produced within earth masses by explosion-induced ground shock. The work involved five steps:

(1) extending the mathematical model documented in Reference 14 to allow for volume changes, (2) fitting the model to available drained and undrained mechanical property test data, (3) validating the model by calculating the pore pressure responses for various laboratory test boundary conditions and comparing the predictions with actual test data, (4) devising an efficient numerical logic for calculating time histories of effective stress, pore pressure, and associated ground motions for blast-oriented problems, and (5) incorporating the model and its calculational logic into LAYER and performing a demonstration calculation.

The concept of effective stress and the mechanical behavior of soil are presented in Chapter 2. In Chapter 3, the development of a singlephase, elastic-plastic constitutive model, parallel to that reported in Reference 14, is presented. The application of this model to treat 
multiphase systems is explained in Chapter 4. The quantitative behavior of the multiphase model under simulated triaxial test conditions is examined in Chapter 5. Chapter 6 describes mathematical fits developed with available drained and undrained mechanical property test data for Campbell Swamp sand and presents comparisons of model-predicted responses with the measured laboratory behavior. The results of the 2D demonstration calculation are presented in Chapter 7 . Chapter 8 summarizes key aspects of the model and offers recommendations for its quantitative evaluation. Appendix A reviews the fundamental basis of elastic-plastic constitutive models and is included for reference purposes and future use. 


\section{CHAPTER 2}

EFFECTIVE STRESS CONCEPT AND MECHANICAL BEHAVIOR OF SOIL

Earth material, in its general form, is composed of a complex assemblage of discrete particles of varying shapes and orientation in a compact, possibly cemented, array. These particles may range in magnitude from the microscopic elements of a clay soil to the macroscopic boulders of a rock fill. The voids in the array may be filled with water or air and usually contain both. Before a constitutive model describing the behavior of these materials under an applied stress system can be developed, it is necessary to consider how these stresses are distributed among the several components comprising the aggregate and to understand, in general terms, the mechanical behavior of these assemblages. The emphasis throughout the remainder of this report will be on earth materials that are better described as soils than rocks; however, the model, in principle, is applicable to both.

\subsection{EFFECTIVE STRESS CONCEPT}

The normal stress components at a point in a soil body may be divided into two parts (Reference 16): The stress carried by the solid skeleton, referred to as the effective stress, and the stress carried by the pore fluid, referred to as the pore pressure. The pore pressure, in turn, can be divided into two additional parts: the stress carried by the water and the stress carried by the air. According to References 17,18 , and 19 , total stress ${ }^{1}$ can be expressed (in indicial notation) as

$$
\sigma_{i j}=\sigma_{i j}^{\prime}+\left[P_{a}-x\left(P_{a}-P_{w}\right)\right] \delta_{i j}
$$

1 Indices take on values of 1,2 , or 3. A repeated index is to be summed over its range. A comma between subscripts represents a derivative. Quantities are referred to rectangular Cartesian coordinates $\mathrm{x}_{i}$. 
where

$$
\begin{aligned}
& \sigma_{i j}=\text { total stress tensor } \\
& \sigma_{i j}^{\prime}=\text { effective stress tensor } \\
& P_{a}=\text { pore air pressure } \\
& x=\text { dimensionless quantity proportional to the pore volume } \\
& \text { occupied by the water phase }
\end{aligned}
$$

Equation 2.1 can be rewritten as

$$
\sigma_{i j}=\sigma_{i j}^{\prime}+u \delta_{i j}
$$

in which $u$ is the total pore pressure representing the combined effect of the pore air pressure and the pore water pressure, i.e.,

$$
u=P_{a}-x\left(P_{a}-P_{w}\right)
$$

For a fully saturated soil, $x=1$, and for a completely dry soil, $x=0$.

For a triaxial test performed on a cylindrical specimen $(r-\theta-z$ coordinate system), the stresses are (Equation 2.2)

$$
\begin{gathered}
\sigma_{z}=\sigma_{z}^{\prime}+u \\
\sigma_{\theta}=\sigma_{r}=\sigma_{\theta}^{\prime}+u=\sigma_{r}^{\prime}+u
\end{gathered}
$$

where $\sigma_{z}, \sigma_{r}$, and $\sigma_{\theta}$ are, respectively, the axial, radial, and tangential total stress components and $\sigma_{z}^{\prime}, \sigma_{r}^{\prime}$, and $\sigma_{\theta}^{\prime}$ are the corresponding effective stress components. The mechanical behavior of 
saturated and partially saturated soils tested under triaxial conditions is discussed in the following section.

\subsection{MECHANICAL BEHAVIOR OF SOIL}

The mechanical behavior of soils subjected to externally applied loads is quite complicated. Unlike the properties of most engineering materials, soil stress-strain properties are greatly affected by such factors as soil structure, degree of voids saturation, drainage conditions during loading, loading rate, loading history, and current stress state. In this report, the term soil structure is loosely used to recognize that "microvariables" such as grain size; grain size distribution; grain shape, surface texture, and mineralogy; and grain orientation, packing, and cementation, or bonding, all play an interrelated role in the complex mechanical response of soils. For practical purposes these microvariables are generally not individually characterized; rather "engineering" variables such as void ratio and relative density, which are more amenable to measurement and certainly more useful to analysts, and which account in a lumped sense for the interplay of many of the microvariables, are used to help characterize, understand, and predict the soils response.

Figure 2.1 shows a typical behavior of soil subjected to a hydrostatic state of stress. It is clear from this figure that soils, in general, exhibit a nonlinear compacting hydrostat.

Figure 2.2 shows a typical variety of stress-strain-pore pressure response curves manifested by saturated soils tested in undrained shear in a triaxial compression device. ${ }^{2}$ The three specimens were first isotropically consolidated to the same effective mean normal stress level (point 2), then sheared undrained. The shear curves marked "2 $\rightarrow$ $3^{\prime \prime}$ show the typical response of a normally consolidated clay or a very loose sand. The curves marked " $2 \rightarrow 5$ " show behavior typical of an overconsolidated clay or a very dense sand. Within the extreme limits of

These tests must include independent measurements of radial deformation. 
these loose and dense soil responses, there is a graduated response, typified herein by the curves marked $" 2 \rightarrow 4$." The latter response depends on the state of compaction (consolidation) of the material. It is clear from this figure that the effective stress is the only part of the total stress that affects soil shear strength.

Figure 2.3 shows typical (qualitative) stress-strain response curves for soils sheared under drained triaxial compression conditions; i.e., the curves marked "l" represent dense sand or overconsolidated clay, while the curves marked "2" depict response typical of loose sand or normally consolidated clay.

In Chapter 3 the mathematical development of a total-stress (singlephase), elastic-plastic, isotropic constitutive relationship that can qualitatively describe most of the behavior shown in Figures 2.1 through 2.3 is presented. This model is unable to simulate the postpeak work-softening shear response exhibited, for example, by material 1 in Figure 2.3. 


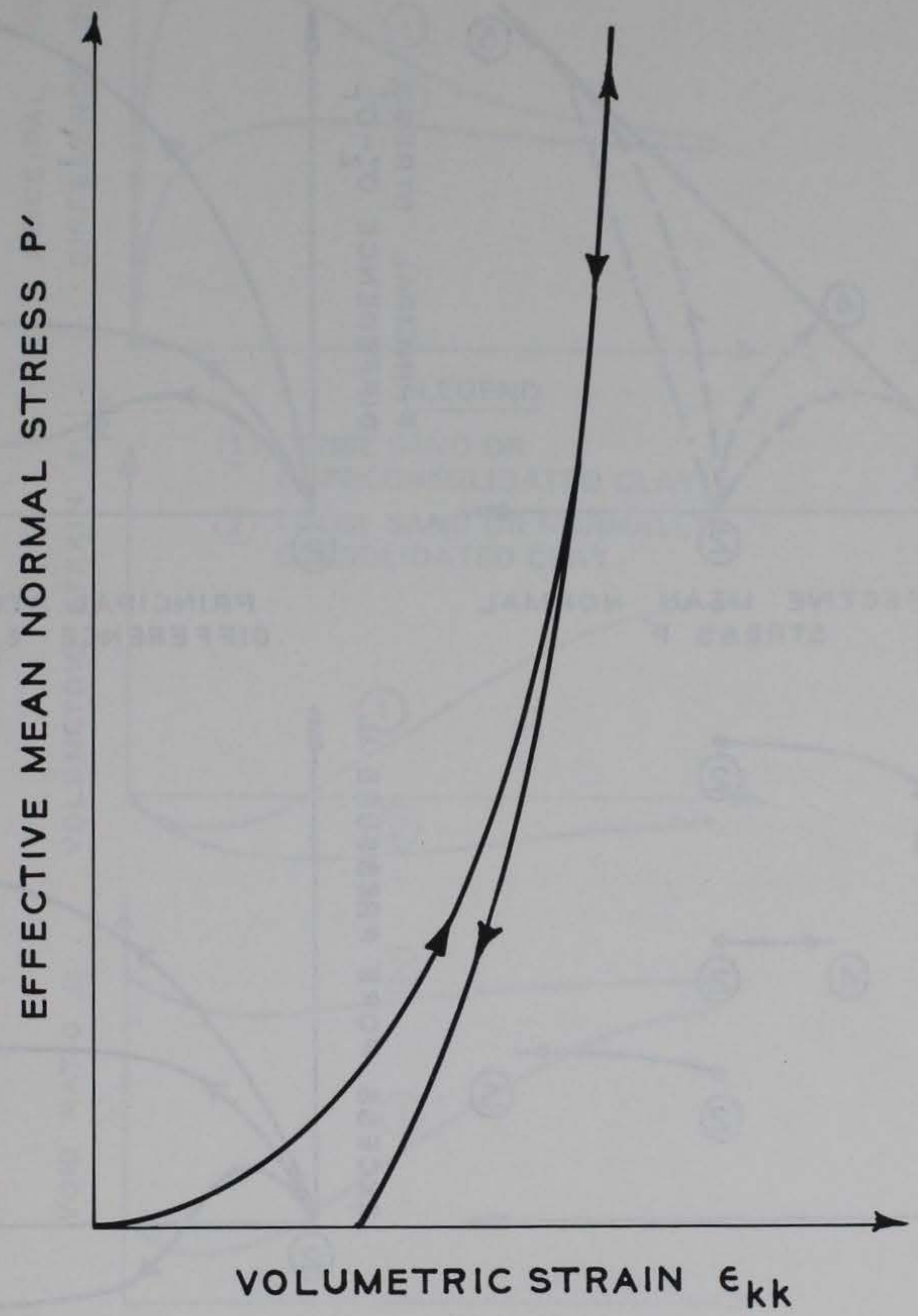

Figure 2.1 Typical behavior of a dry or drained soil under hydrostatic loading and unloading. 
- - - EFFECTIVE STRESS PATH

-.- - - TOTAL STRESS PATH

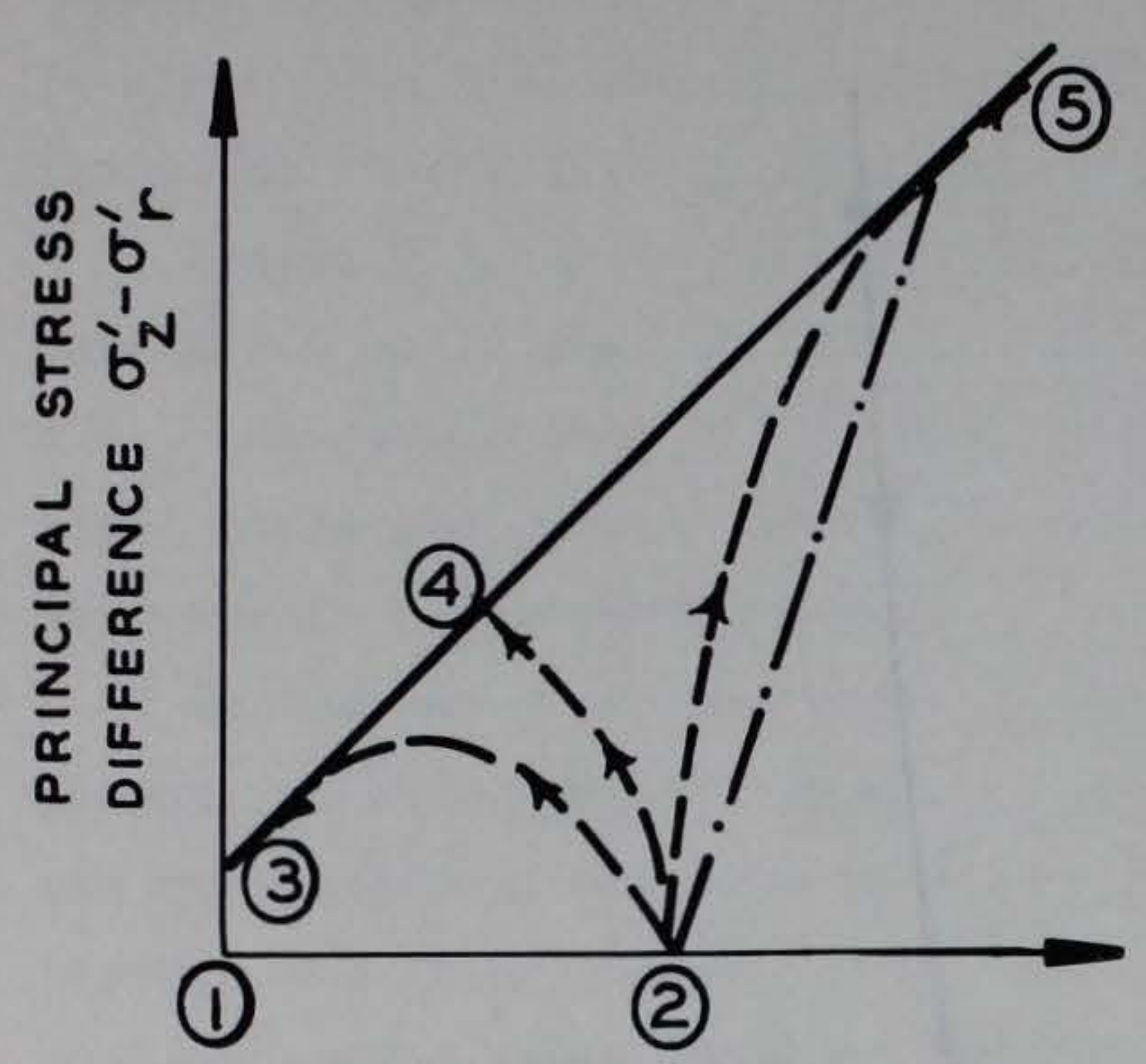

EFFECTIVE MEAN NORMAL STRESS P'

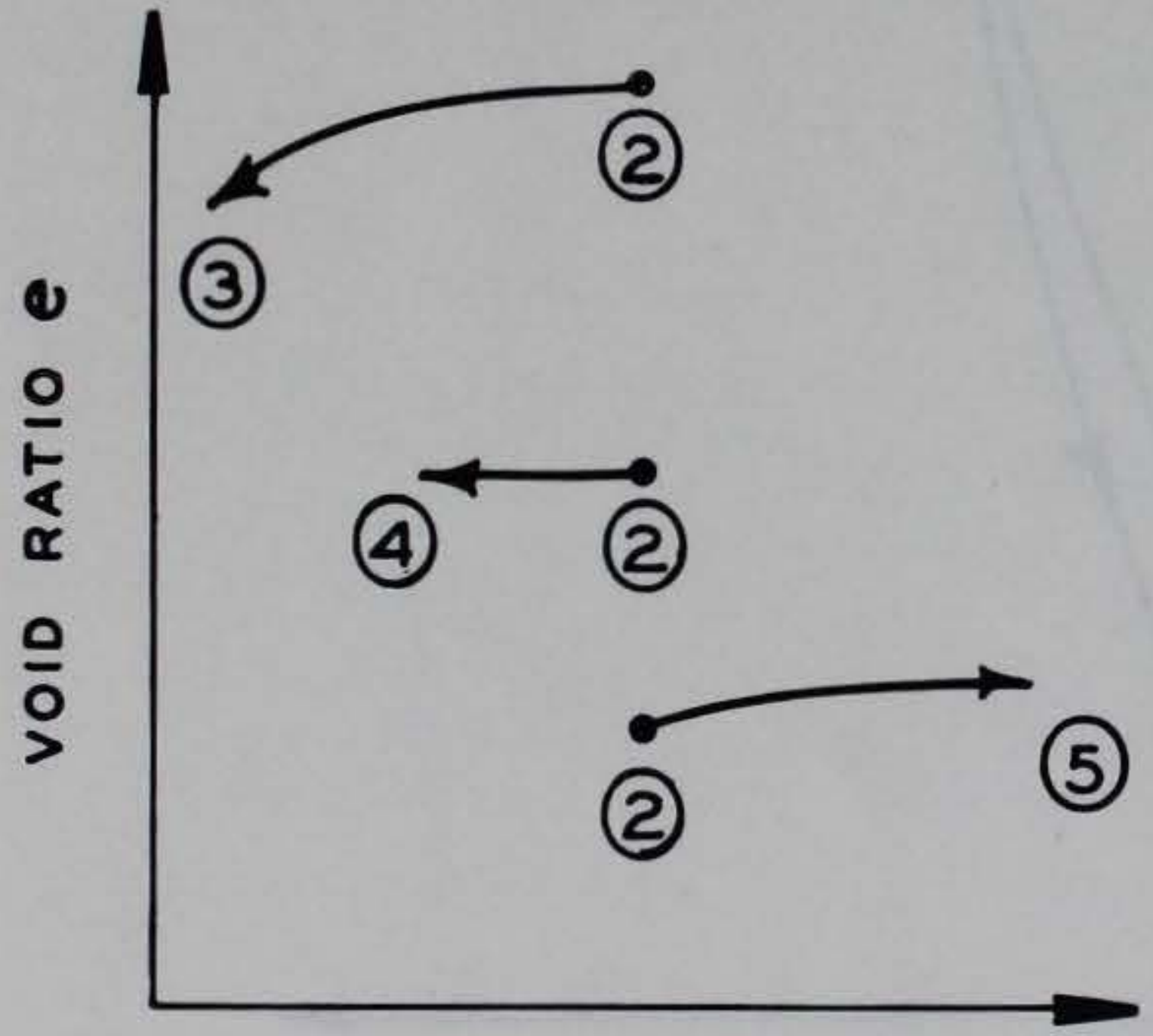

EFFECTIVE MEAN NORMAL STRESS $P^{\prime}$

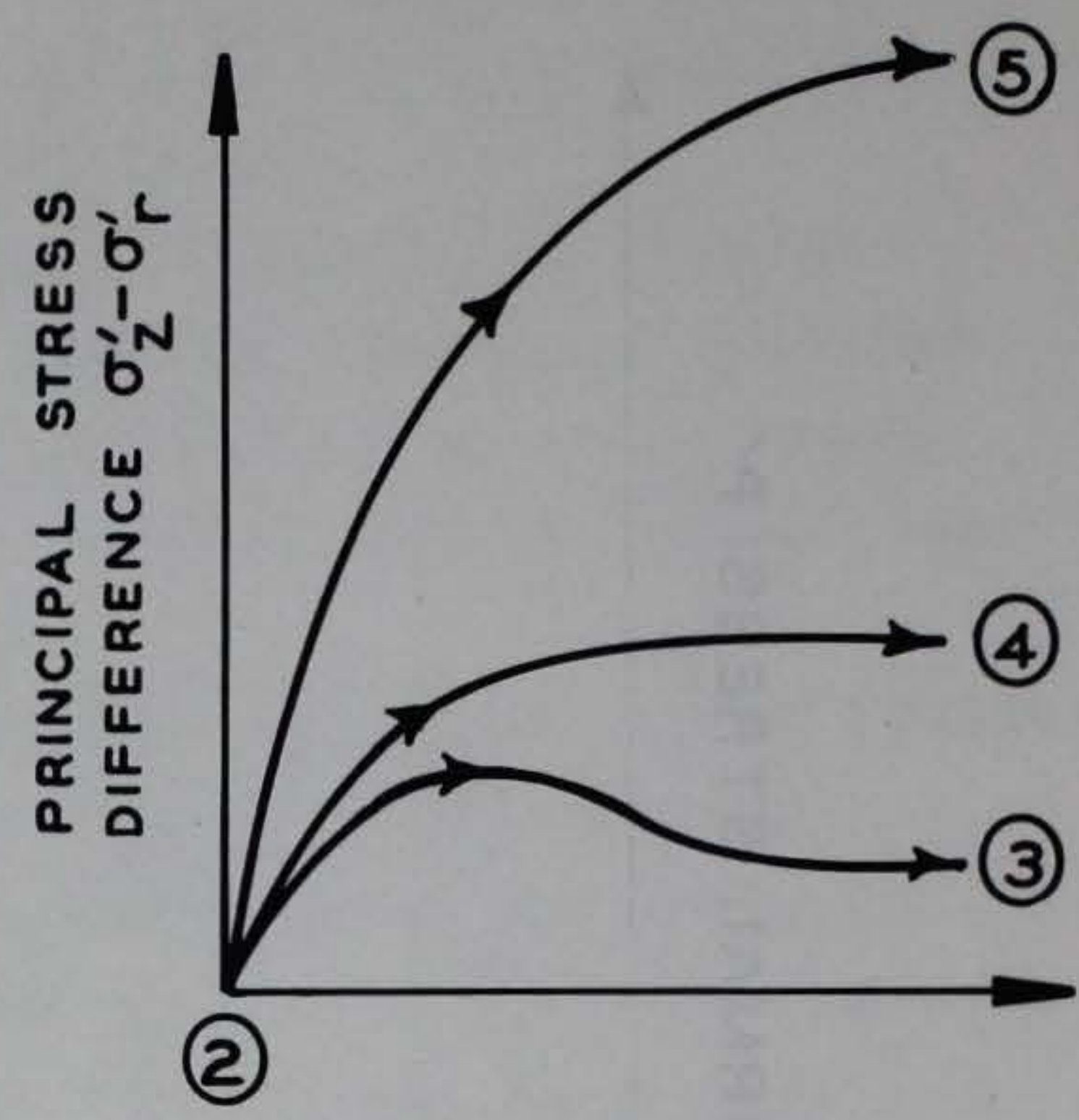

PRINCIPAL STRAIN DIFFERENCE $\epsilon_{z}-\epsilon_{r}$

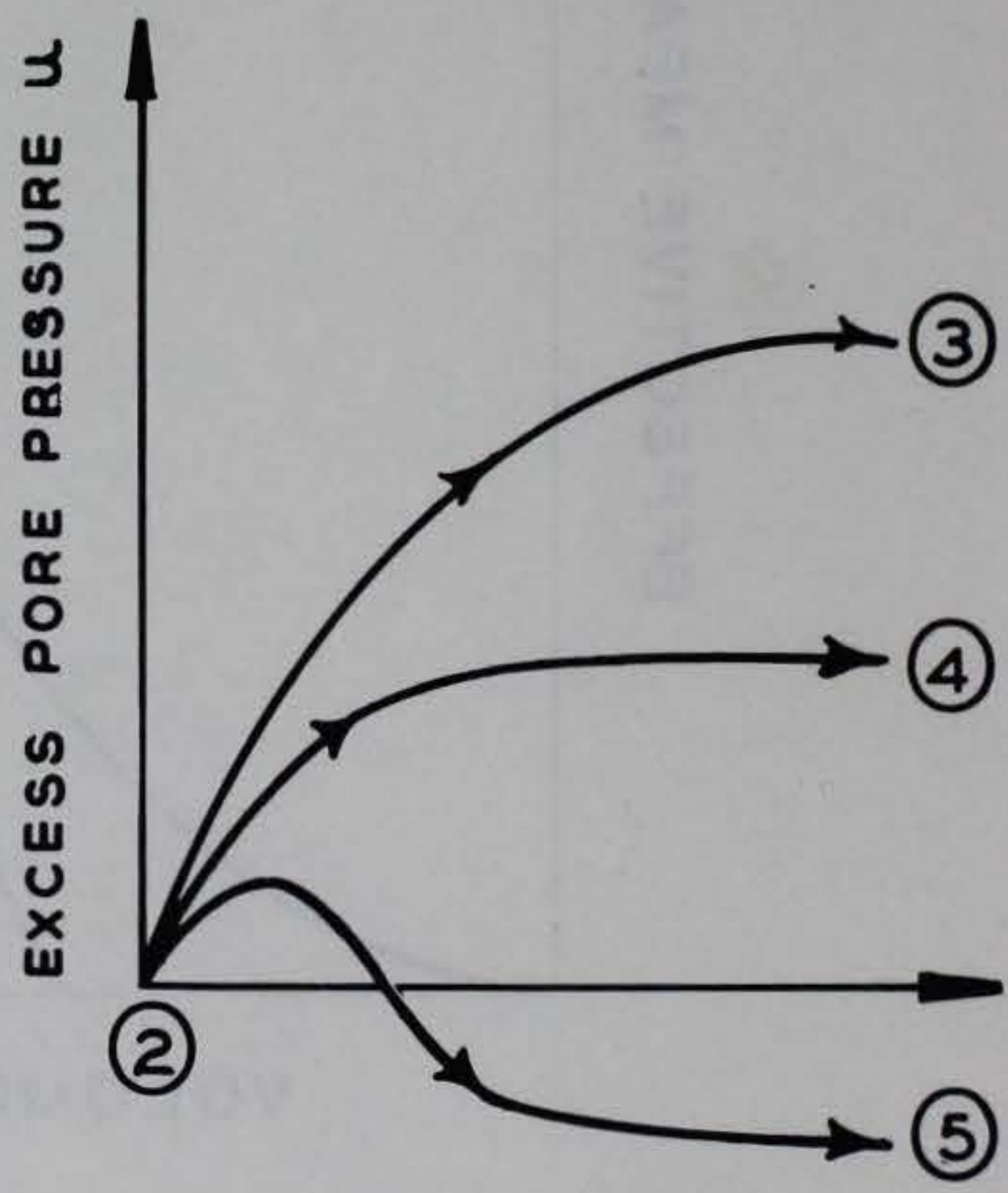

PRINCIPAL STRAIN DIFFERENCE $\epsilon_{z}-\epsilon_{r}$

Figure 2.2 Typical behavior of saturated soil tested under undrained triaxial test conditions. 

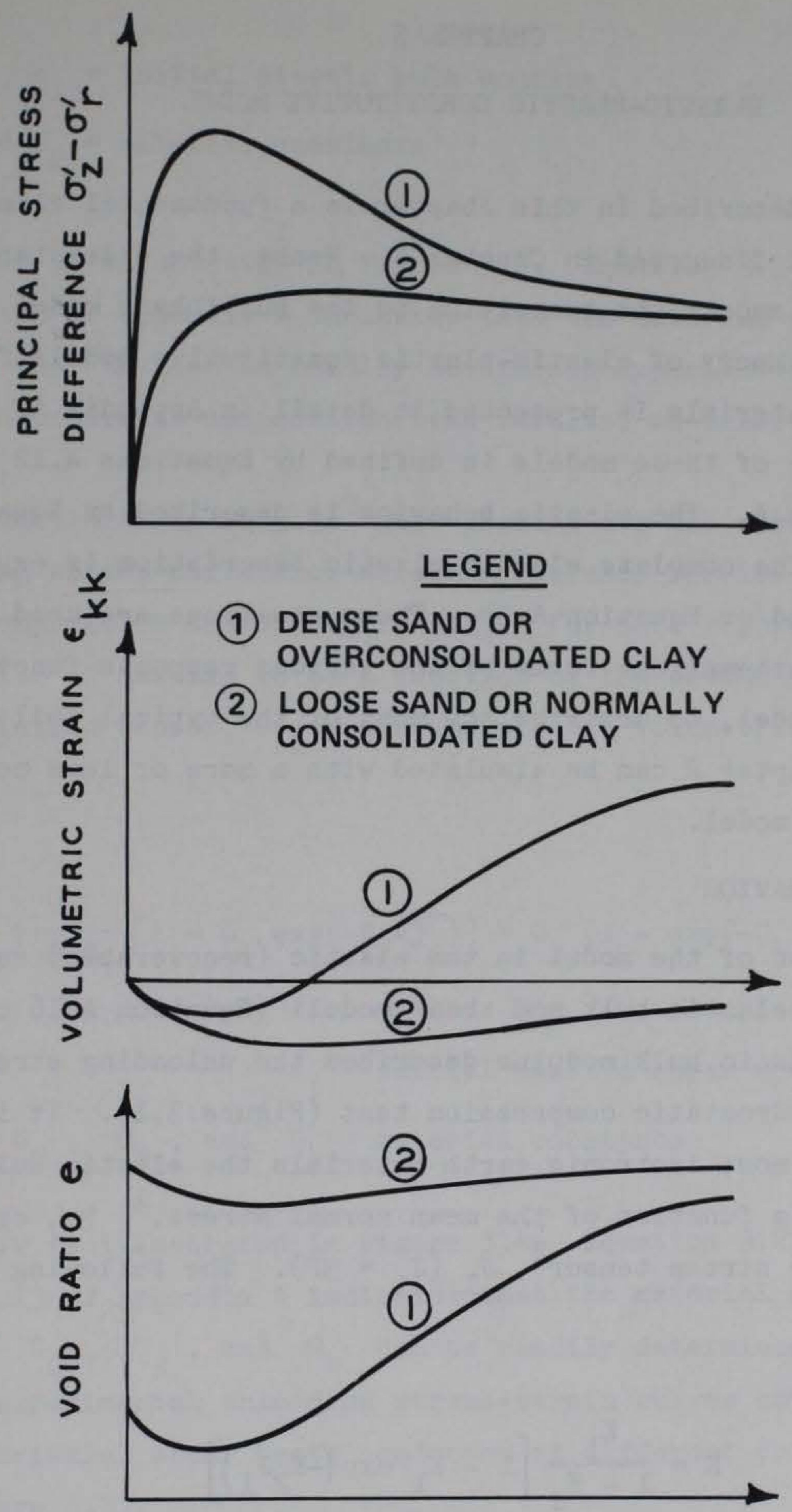

PRINCIPAL STRAIN DIFFERENCE $\epsilon_{z}-\epsilon_{r}$

Figure 2.3 Typical behavior of saturated soils tested under drained triaxial test conditions. 
ELASTIC-PLASTIC CONSTITUTIVE MODEL

The model described in this chapter is a fundamental element of the multiphase model discussed in Chapter 4. Hence, the understanding of this model will smooth the transition to the multiphase model.

The basic theory of elastic-plastic constitutive models for singlephase (solid) materials is presented in detail in Appendix A. The elastic behavior of these models is defined by Equations A.12 through A.16 of Appendix A. The plastic behavior is described by Equations A.17 through A.28. The complete elastic-plastic description is expressed by Equation A.29 and/or Equation A.30. These equations are used herein, with selected mathematical forms of the various response functions contained in the model, to describe how most of the typical soil responses presented in Chapter 2 can be simulated with a more or less conventional elastic-plastic model.

\subsection{ELASTIC BEHAVIOR}

The behavior of the model in the elastic (recoverable) range is governed by the elastic bulk and shear moduli (Equation A.16 of Appendix A). The elastic bulk modulus describes the unloading stress-strain response of a hydrostatic compression test (Figure 3.1). It is suggested that for most isotropic earth materials the elastic bulk modulus can be taken as a function of the mean normal stress, ${ }^{1} \mathrm{P}$, or the first invariant of the stress tensor ${ }^{2} \mathrm{~J}_{1}\left(\mathrm{~J}_{1}=3 \mathrm{P}\right)$. The following expression is chosen:

$$
K=\frac{K_{i}}{1-K_{1}}\left[1-K_{1} \exp \left(-K_{2} J_{1}\right)\right]
$$

${ }^{1}$ The elastic bulk modulus could also be a function of the plastic 2 volumetric strain.

In this report tension is considered as negative. 
where

$$
\mathrm{K}_{i}=\text { initial elastic bulk modulus }
$$

$\mathrm{K}_{1}$ and $\mathrm{K}_{2}=$ material constants

Equation 3.1 is illustrated in Figure 3.2. Equation 3.1 together with Equation A.13 of Appendix A indicates that the material constants $\mathrm{K}_{i}, \mathrm{~K}_{1}$, and $\mathrm{K}_{2}$ can be readily determined experimentally from the unloading hydrostatic compression test results, as illustrated in Figure 3.1 .

The elastic shear modulus ${ }^{3}$ must account for the curvature observed in unloading stress difference-strain difference results obtained from triaxial compression tests (Figure 3.3). For this report, the elastic shear modulus is assumed to be a function of the second invariant of the stress deviation tensor, $\bar{J}_{2}$, and the plastic volumetric strain, $\varepsilon_{\mathrm{kk}}^{\mathrm{P}}$ :

$$
G=\frac{G_{i}}{1-G_{1}}\left[1-G_{1} \exp \left(-G_{2} \sqrt{J_{2}}\right)\right]+G_{3}\left[1-\exp \left(-G_{4} \varepsilon_{k k}^{P}\right)\right]
$$

where

$$
G_{i}=\text { initial elastic shear modulus }
$$

$G_{1}, G_{2}, G_{3}$, and $G_{4}=$ material constants

Equation 3.2 is illustrated in Figure 3.4. Equation 3.2 together with Equation A.13 of Appendix A indicates that the material constants $G_{i}, G_{1}, G_{2}, G_{3}$, and $G_{4}$ can be readily determined from the slopes of experimental unloading stress-strain curves obtained from a series of triaxial shear tests conducted at different confining pressures (Figure 3.3).

3 The functional forms of the bulk and shear moduli (Equations 3.1 and 3.2) could include more terms and, hence, provide more flexibility in fitting the behavior of any specific material (cf. Reference 10). 


\subsection{PLASTIC BEHAVIOR}

For the plastic behavior, the loading function 6 (Equation A.9 of Appendix A) is assumed to be isotropic and to consist of two parts (Figure 3.5): an ultimate failure envelope which serves to limit the maximum shear stresses attainable by the material and an elliptically shaped strain-hardening yield surface that produces plastic volumetric and shear strains as it moves (Reference 10). The failure envelope portion of the loading function is assumed to be of the generalized Prager-Drucker type and is mathematically described by

$$
f\left(J_{1}, \sqrt{J_{2}}\right)=\sqrt{J_{2}}-\left[A-C \exp \left(-B J_{1}\right)\right]=0
$$

and the strain-hardening yield surface is described by

$$
F\left(J_{1}, \sqrt{J_{2}}, k\right)=\left[J_{1}-L(\kappa)\right]^{2}+R^{2} \bar{J}_{2}-[X(k)-L(\kappa)]^{2}=0
$$

where A, B, and C are material constants (Figure 3.5); $\mathrm{R}$ is a parameter which will be defined below; $X(K)$ and $L(K)$ define the intersections of the hardening surface with the $J_{1}$ axis and the failure envelope $f\left(J_{1}, \sqrt{J_{2}}\right)$, respectively; and $k$ is the hardening parameter, which generally is a function of the history of plastic volumetric strain, $\varepsilon_{k k}^{P}$. For most soils, $k$ can be chosen as

$$
\kappa=\varepsilon_{k k}^{P}
$$

Equation 3.5 allows the elliptic hardening surface to expand and contract as well as to translate relative to the origin of the $J_{1}, \sqrt{J}_{2}$ axes. Note that the hardening surface (Figure 3.5) was chosen so that the tangent at its intersection with the failure envelope is horizontal. 
This condition is guaranteed by the following relationships between $k$, $L(\kappa)$, and $x(\kappa): *$

$$
\begin{gathered}
L(K)=\left\{\begin{aligned}
\ell(K) & \text { if } \ell(K)>0 \\
0 & \text { if } \ell(K) \leq 0
\end{aligned}\right. \\
K=\varepsilon_{k k}^{P}=W\{1-\exp [-D X(k) \cdot]\}+W_{1}[X(k)]^{2} \exp \left[-D_{1} X(k)\right] \\
X(K)=\ell(K)+R\{A-C \exp [-B \ell(K)]\}
\end{gathered}
$$

where $D, D_{1}$, and $W_{1}$ are material constants, and $W$ is also a material constant which defines the maximum plastic volumetric compaction that the material can experience under hydrostatic loading (Figure 3.1). The parameter $R$, in Equations 3.4 and 3.8 , is the ratio of the major to the minor axes of the elliptic yield surface (Figure 3.5). The value of $R$ depends on the state of compaction of the material. For a contractive material (i.e., loose sand or normally consolidated clay, curves marked " $2 \rightarrow 3$ " in Figure 2.2), the value of $R$ is greater than $1 / \alpha$ where $\alpha=\mathrm{CB} \exp \left(-\mathrm{BJ}_{1}\right)$ is the slope of the failure envelope (Equation 3.3). For a dilative material (i.e., dense sand or overconsolidated clay, curves marked " $2 \rightarrow 5$ " in Figure 2.2), the value of $R$ is less than $1 / \alpha . R=1 / \alpha$ corresponds to the curves marked " $2 \rightarrow 4$ " in Figure 2.2. These variations in the parameter $\mathrm{R}$ can be accounted for by the following functional relation:

$$
R=\frac{R_{i}}{1+R_{1}}\left\{1+R_{1} \exp \left[-R_{2} L(\kappa)\right]\right\}+R_{3} \exp \left\{-R_{4}\left[L(\kappa)-R_{5}\right]^{2}\right\}
$$

The mathematical form of Equation 3.7 depends on the specific material being modeled. The author believes, however, that the form presented by-Equation 3.7 is suitable for modeling most soils. 
where $R_{i}, R_{1}, R_{2}, R_{3}, R_{4}$, and $R_{5}$ are material constants that can be determined by a trial-and-error process of fitting the model to a variety of laboratory stress-strain data.

\subsection{SUMMARY}

In summary, there are five potential functions (two elastic and three plastic) that describe the complete behavior of the single-phase model. These functions are summarized in Table 3.1. In addition, 21 material constants are used to characterize these functions in the present model. They too are summarized in Table 3.1.

In the next chapter, it is shown how the present single-phase model can be adapted to simulate multiphase soil materials. 
Table 3.1. Summary of the Model Parameters

Elastic Response

Plastic Potential

N
Response Functions Equation Number

$\left\{\begin{array}{l}K\left(J_{1}, \varepsilon_{k k}^{P}\right) \\ G\left(\sqrt{J_{2}}, \varepsilon_{k k}^{P}\right)\end{array}\right.$

$\left\{\begin{array}{l}f\left(J_{1}, \sqrt{J_{2}}\right) \\ F\left(J_{1}, \sqrt{J_{2}}, k\right)\end{array}\right.$

$X(k)=X\left(\varepsilon_{k k}^{P}\right)$
Material Constants

$3.1 \quad \mathrm{~K}_{1}, \mathrm{~K}_{1}$, and $\mathrm{K}_{2}$

$3.2 G_{i}, G_{1}, G_{2}, G_{3}$, and $G_{4}$

3.3 A, B, and C

3.4 and $3.9 \quad R_{i}, R_{1}, R_{2}, R_{3}, R_{4}$, and $R_{5}$

3.7 W, $\mathrm{D}, \mathrm{W}_{1}$, and $\mathrm{D}_{1}$ 


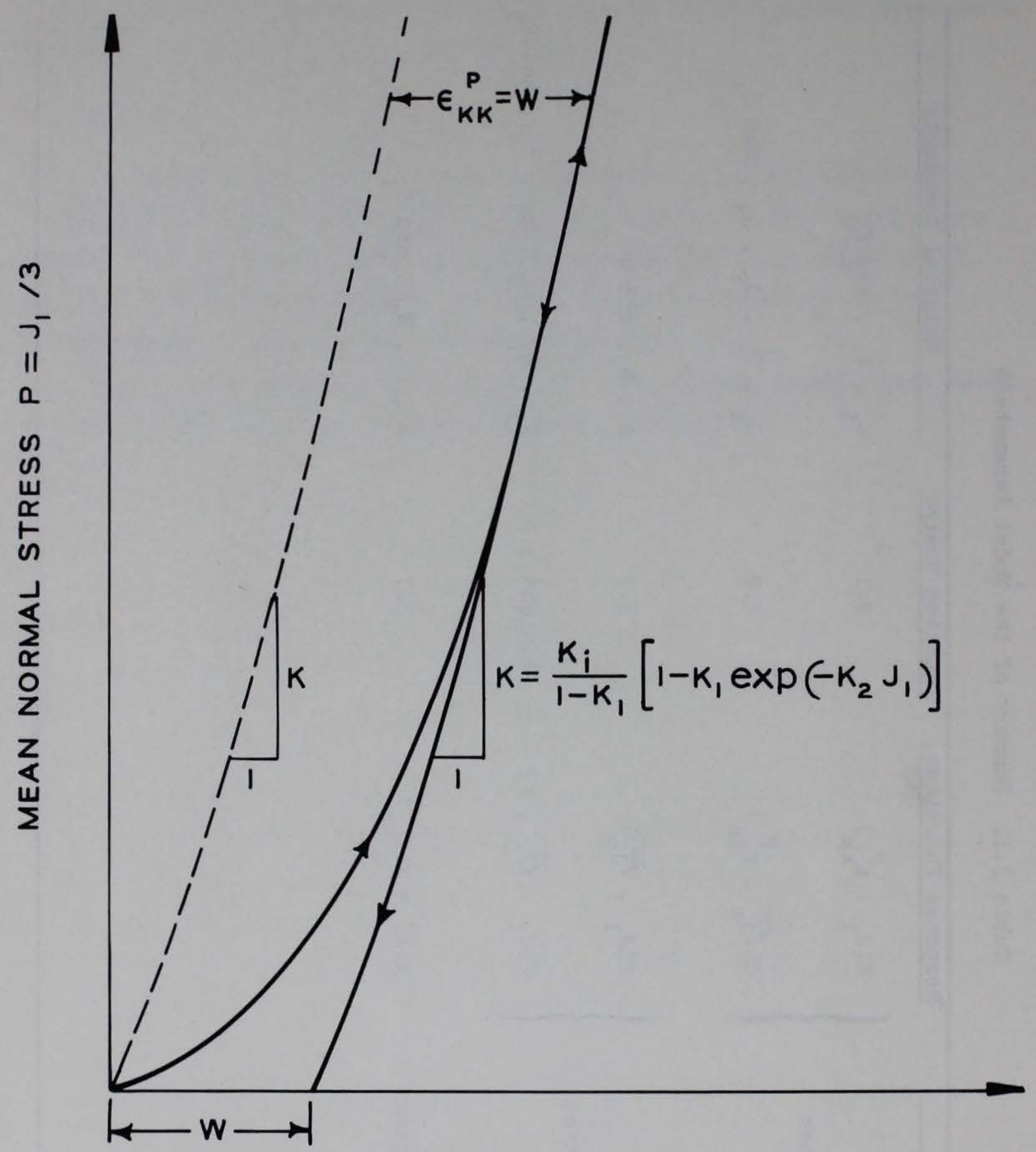

VOLUMETRIC STRAIN $\epsilon_{K K}$

Figure 3.1 Proposed relationship for isotropic compression test, 


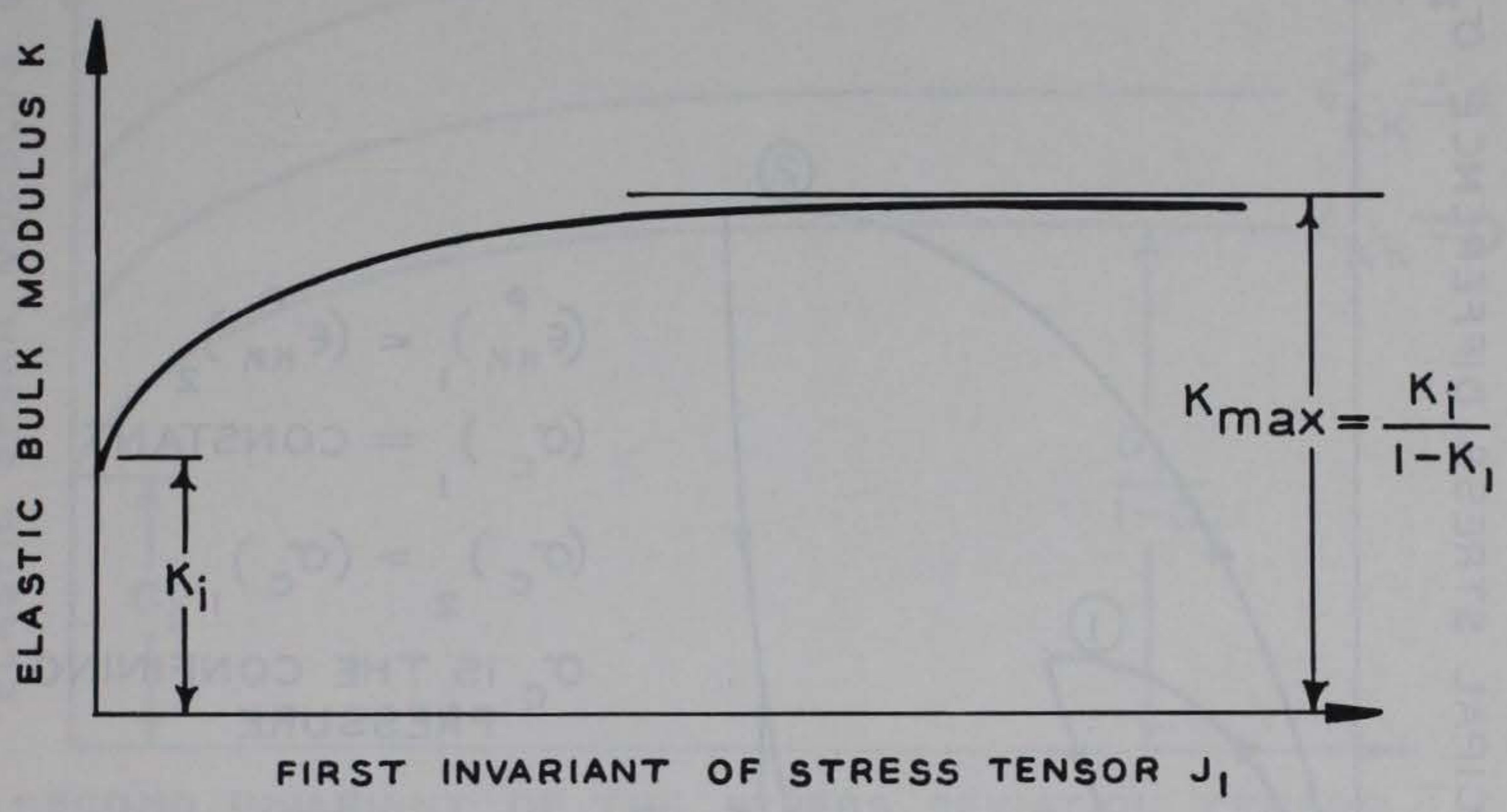

Figure 3.2 Elastic bulk modulus versus first invariant of the stress tensor. 


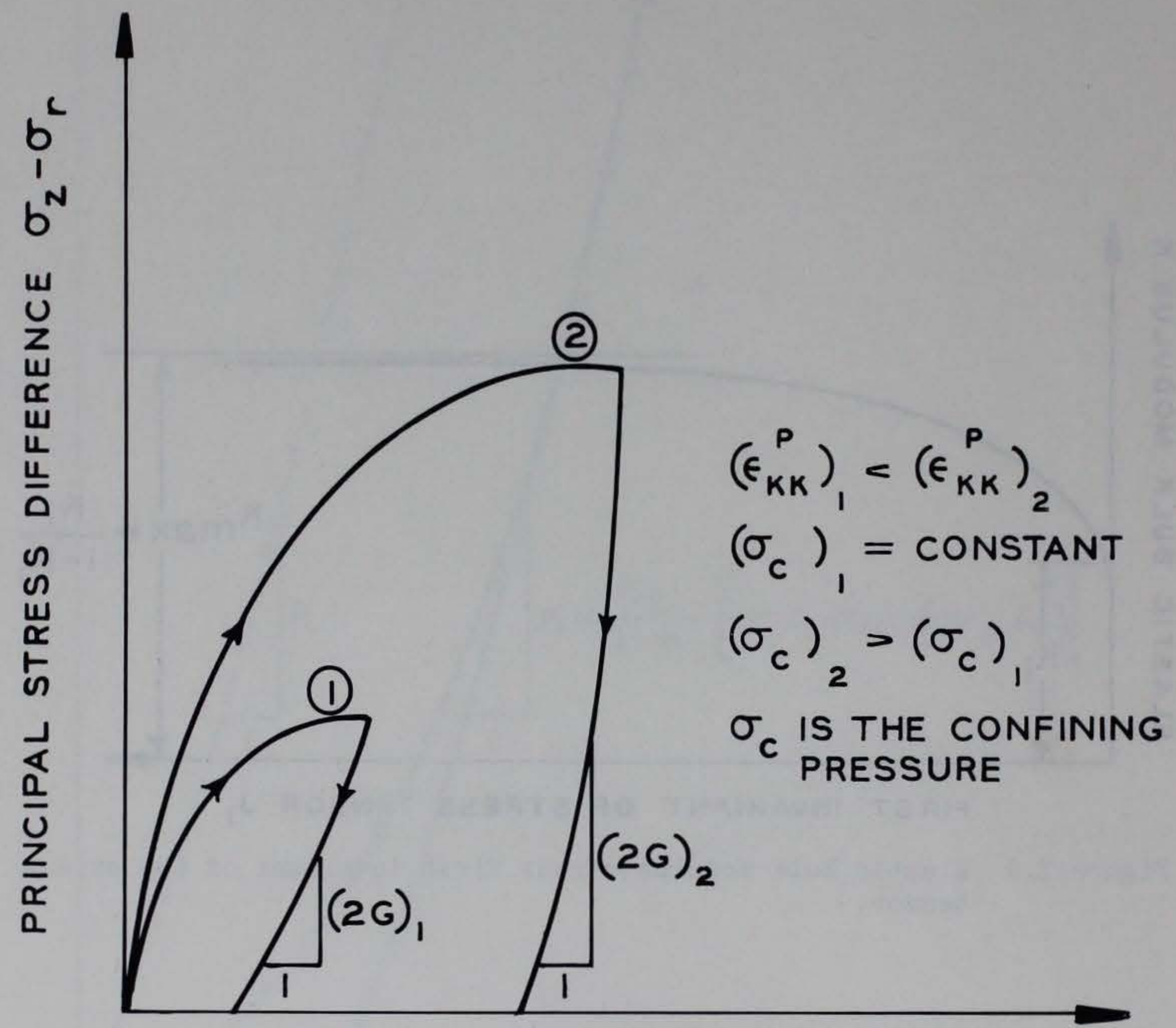

PRINCIPAL STRAIN DIFFERENCE $\epsilon_{z}-\epsilon_{r}$

Figure 3.3 Proposed relationship for triaxial shear test. 


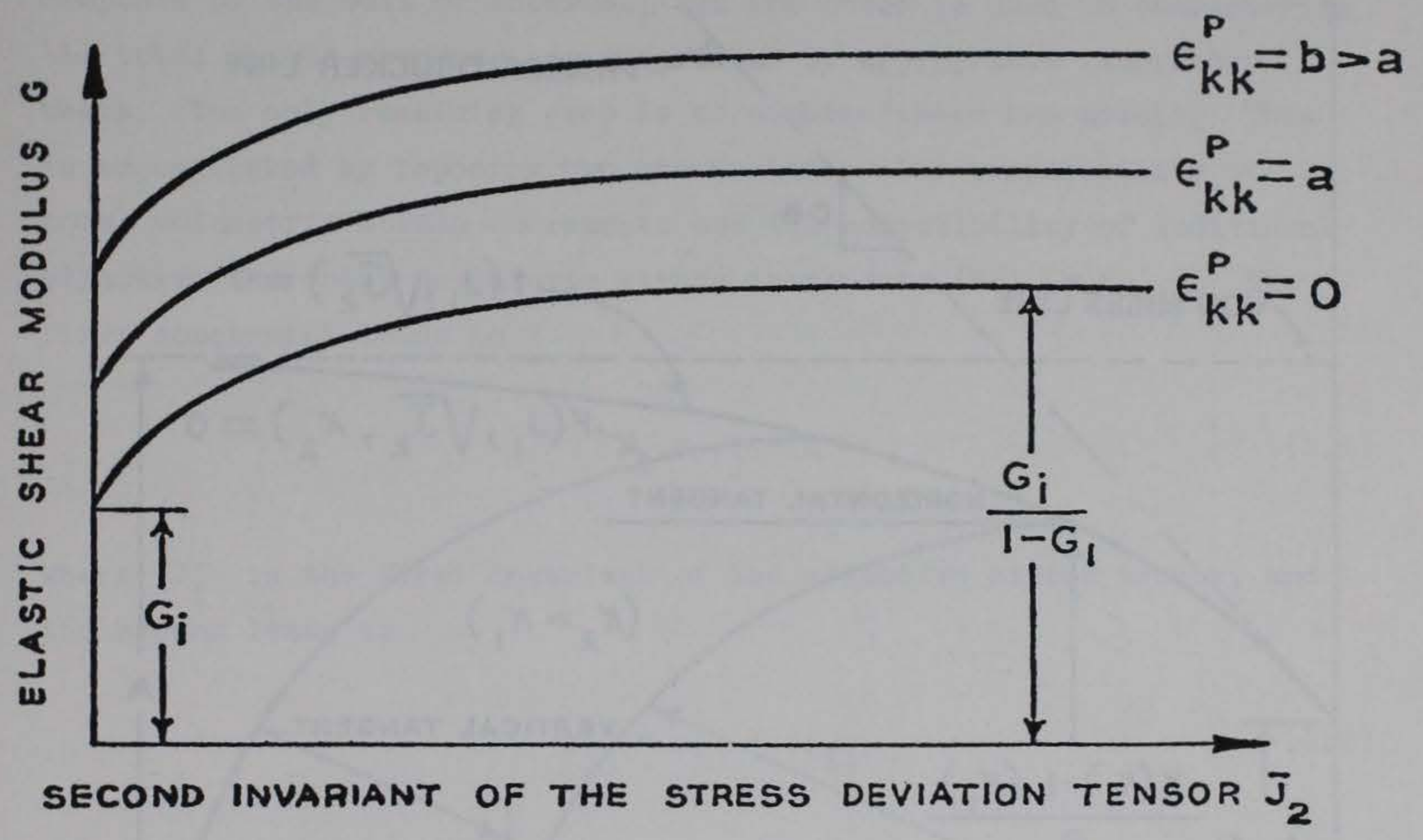

Figure 3.4 Elastic shear modulus versus second invariant of the stress deviation tensor and plastic volumetric strain. 


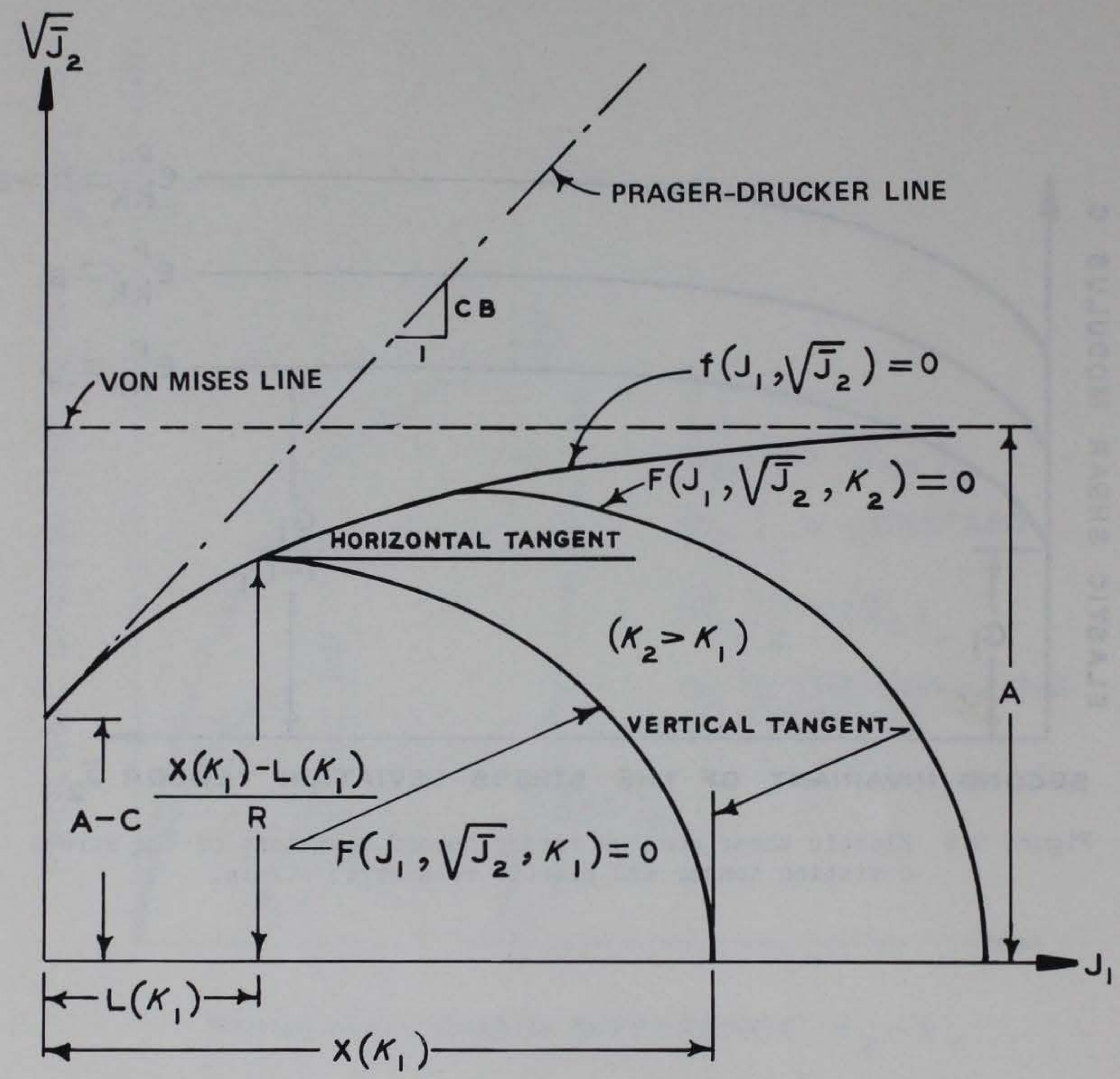

Figure 3.5 Proposed yield surfaces for the elastic-plastic strain-hardening model. 
The three-phase soil model is patterned on the concepts of effective stress presented in Section 2.1 and is really quite simple. First of all, two single-phase models of the type developed in Chapter 3 are required. One of these is used to characterize the effective stress response of the soil of interest, and the other is used to characterize the total stress response, as determined by appropriate laboratory tests. The only remaining step is to combine these two models. This is accomplished by imposing two constraints: (1) compatibility of total volumetric strain increments and (2) compatibility of individual effective and total deviatoric stress increments $\left(d S_{i j}^{\prime}=d S_{i j}\right)$. The first constraint leads to

$$
\mathrm{J}_{1}=\mathrm{J}_{1}^{\prime}+\mathrm{u}
$$

where $J_{i}^{\prime}$ is the first invariant of the effective stress tensor; and the second leads to

$$
\sigma_{i j}=\sigma_{i j}^{\prime}+u \delta_{i j}
$$

which is Equation 2.2. The resulting model is thus able to predict deformations, total and effective stresses, and pore pressures for real three-phase media. The predicted pore pressures, however, are the overall pore pressures, $u$; the model does not distinguish between the pore air pressure $\mathrm{P}_{\mathrm{a}}$ and the pore water pressure $\mathrm{P}_{\mathrm{w}}$ discussed in Chapter 2. ${ }^{1}$ Consequently, it is only a three-phase model in a "phenomenological" sense. Perhaps it should be thought of as a "pseudo" threephase model. Be that as it may, the model does predict observed

The pore air pressure $P_{\mathrm{a}}$ and the pore water pressure $P_{W}$ could be calculated from Equation 2.1 if an appropriate laboratory test is conducted to determine the value of $x$. 
three-phase material response; and it does this quite well, as will be demonstrated in the next chapter.

Technically speaking then, modeling the behavior of multiphase soil systems requires two separate sets of material constants, such as those shown in Table 3.1. The first set must reflect the effective stress properties of the soil (i.e., the properties of the soil skeleton alone) and must be determined by fitting test data obtained for the material under fully drained conditions. The second set must reflect the total stress properties of the soil (i.e., those of the skeletonwater-air mixture), which must be determined by fitting test data obtained for the material under completely undrained conditions. The resulting two sets of model parameters are summarized in Table $4.1 .^{2}$

Combining these two models through volumetric strain compatibility and effective and total deviatoric stress compatibility allows for calculation of the pore pressure and deformation response and the total and effective stress response of a multiphase system subjected to given stress or strain increments. Either one of the following two procedures can be used for this purpose:

1. If stress increments are given,

a. Calculate the undrained volumetric strain using the second set of response functions and material constants listed in Table 4.1, i.e., the undrained model parameters.

b. Impose this volumetric strain on the drained model (i.e., the first set of response functions and material constants listed in Table 4.1) and calculate the resulting stress path and associated material response. This stress path is the effective stress path that the material will experience during this undrained load application. The pore pressure is simply the difference between the total and the effective normal stresses.

This procedure is illustrated in the following diagram:

Note that 42 material constants are required to fully define the general model presented in Table 4.1. Depending on the actual material, however, fewer than 42 constants may be needed. 


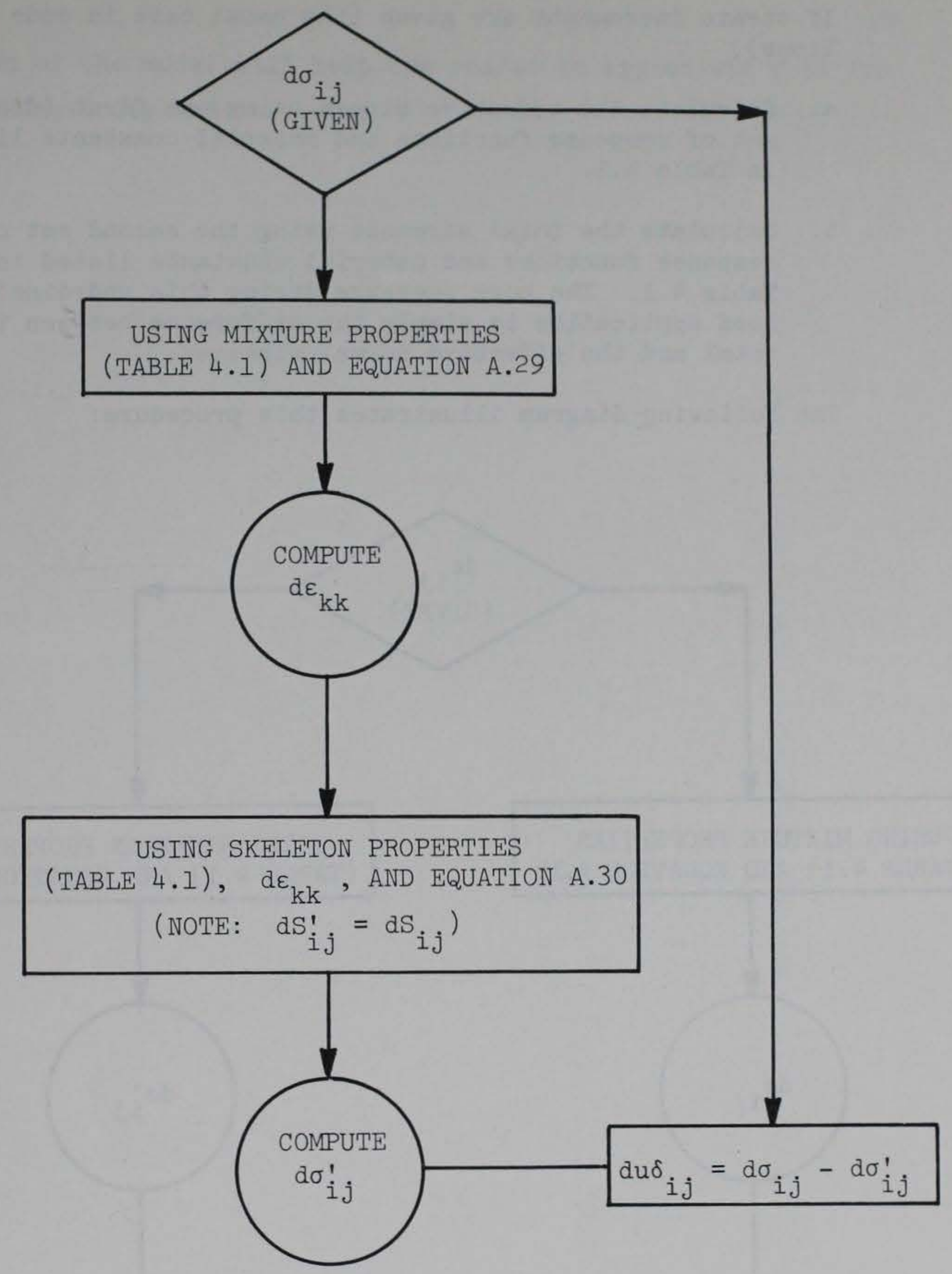

where

$$
\begin{aligned}
& S_{i j}=\sigma_{i j}-\left(J_{1} / 3\right) \delta_{i j}=\text { total stress deviation tensor } \\
& S_{i j}^{\prime}=\sigma_{i j}^{\prime}-\left(J_{1}^{\prime} / 3\right) \delta_{i j}=\text { effective stress deviation tensor }
\end{aligned}
$$


2. If strain increments are given (the usual case in code calculations),

a. Calculate the effective stress using the first (drained) set of response functions and material constants listed in Table 4.1 .

b. Calculate the total stresses using the second set of response functions and material constants listed in Table 4.1. The pore pressure during this undrained load application is simply the difference between the total and the effective normal stresses.

The following diagram illustrates this procedure:

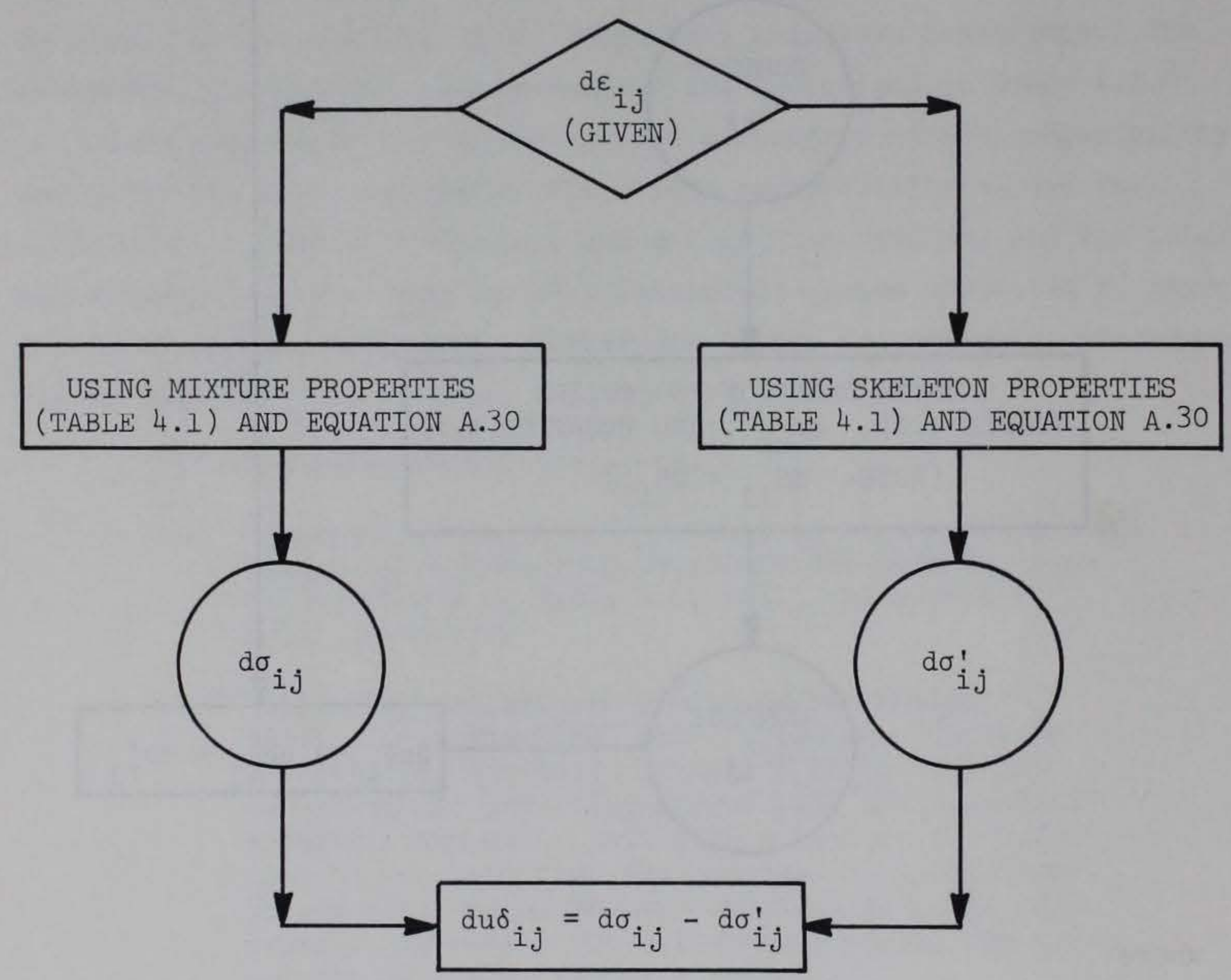

The response of this multiphase material model subjected to undrained standard triaxial test conditions is examined in detail in the next chapter using the first of these procedures. This 
exposition of the model will help the reader to appreciate both its relative simplicity and its power. 
Table 4.1. Summary of the model parameters for a multiphase system.

Set 1

Soil Skeleton

(Drained Condition)

Response Functions Material Constants

Elastic Responsea

$$
\begin{cases}K_{s}\left(J_{1}^{\prime}, \varepsilon_{k k}^{P}\right) & K_{i s}, K_{l s}, \text { and } K_{2 s} \\ G_{s}\left(\sqrt{J_{2}}, \varepsilon_{k k}^{P}\right) & G_{i s}, G_{1 s}, G_{2 s}, \\ & G_{3 s}, \text { and } G_{4 s}\end{cases}
$$

o

$$
\begin{aligned}
& \text { Plastic Potential } \\
& \text { Plastic Hardening }
\end{aligned}
$$

\section{Set 2}

Solid Particles, Water, and Gas Mixture (Undrained Condition)

Response Functions Material Constants

$$
\begin{array}{ll}
K_{m}\left(J_{1}, \varepsilon_{k k}^{P}\right) & K_{i m}, K_{I m}, \text { and } K_{2 m} \\
G_{m}\left(\sqrt{J_{2}}, \varepsilon_{k k}^{P}\right) & \begin{array}{l}
G_{i m}, G_{I m}, G_{2 m}, \\
G_{3 m}, \text { and } G_{4 m}
\end{array}
\end{array}
$$$$
A_{m}, B_{m} \text {, and } C_{m}
$$

$\mathrm{R}_{i \mathrm{~m}}, \mathrm{R}_{1 \mathrm{~m}}, \mathrm{R}_{2 \mathrm{~m}}$,

$R_{3 m}, R_{4 m}$, and $R_{5 m}$

$\mathrm{W}_{\mathrm{m}}, \mathrm{D}_{\mathrm{m}}, \mathrm{W}_{1 \mathrm{~m}}$, and $\mathrm{D}_{\mathrm{Im}}$

a The mathematical forms of these response functions are identical with those indentified in Table 3.1 . 


\section{BEHAVIOR OF THE MULTPHASE CONSTITUTIVE MODEL UNDER TRIAXIAL TEST CONDITIONS}

\subsection{INTRODUCTION}

The ability of the new model to simulate the response of multiphase soil systems can be more clearly understood if the model is examined under familiar laboratory test boundary conditions. Since most of the mechanical testing of soils for engineering purposes is performed with the triaxial test (TX) apparatus, it is appropriate to investigate the model under both drained and undrained TX conditions. Adopting the $\mathrm{z}-$ axis of a cylindrical coordinate system $(z, r$, and $\theta)$ as the axis of symmetry of the test sample, the total and effective stress tensors and the total strain tensor associated with this configuration become, respectively

$$
\begin{aligned}
& \sigma_{i j}=\left[\begin{array}{lll}
\sigma_{z} & 0 & 0 \\
0 & \sigma_{r} & 0 \\
0 & 0 & \sigma_{r}
\end{array}\right] \\
& \sigma_{i j}^{\prime}=\left[\begin{array}{ccc}
\sigma_{z}^{\prime} & 0 & 0 \\
0 & \sigma_{r}^{\prime} & 0 \\
0 & 0 & \sigma_{r}^{\prime}
\end{array}\right] \\
& \varepsilon_{i j}=\left[\begin{array}{lll}
\varepsilon_{z} & 0 & 0 \\
0 & \varepsilon_{r} & 0 \\
0 & 0 & \varepsilon_{r}
\end{array}\right]
\end{aligned}
$$

where $\varepsilon_{z}$ and $\varepsilon_{r}$ are the total vertical and radial strains, respectively. Equations 5.1 and 5.2 imply homogeneity of stress $\left(\sigma_{\theta}=\sigma_{r}\right)$, 
and Equation 5.3 implies homogeneity of deformation (total tangential strain $\varepsilon_{\theta}=\varepsilon_{r}$ ). The variables $P^{\prime}=J_{l}^{\prime} / 3$ (effective mean normal stress), $P=J_{1} / 3$ (total mean normal stress), $\bar{J}_{2}^{\prime}$ (the second invariant of the effective stress deviation tensor), $\bar{J}_{2}$ (the second invariant of the total stress deviation tensor), and $\varepsilon_{k k} / 3$ (mean volumetric strain) associated with the above stress and strain tensors take the following forms

$$
\begin{gathered}
P^{\prime}=J_{1}^{\prime} / 3=\frac{\sigma_{z}^{\prime}+2 \sigma_{r}^{\prime}}{3} \\
P=J_{1} / 3=\frac{\sigma_{z}+2 \sigma_{r}}{3} \\
\bar{J}_{2}^{\prime}=\bar{J}_{2}=\frac{\left(\sigma_{z}^{\prime}-\sigma_{r}^{\prime}\right)^{2}}{3}=\frac{\left(\sigma_{z}-\sigma_{r}\right)^{2}}{3} \\
\frac{1}{3} \frac{\Delta V}{V_{0}}=\frac{\varepsilon_{k k}}{3}=\frac{\varepsilon_{z}+2 \varepsilon_{r}}{3}
\end{gathered}
$$

where $\Delta \mathrm{V} / \mathrm{V}_{0}$ is the volumetric strain. The TX test is generally conducted in two phases: the hydrostatic phase and the shear phase. Both phases can be conducted either drained or undrained. They are discussed below.

\subsection{HYDROSTATIC PHASE}

\subsubsection{Drained Condition}

During the drained hydrostatic phase of a TX test, the pore pressure is always zero, and the behavior of the soil skeleton alone (i.e., the effective stress behavior) is examined. The following conditions are obtained:

$$
\begin{gathered}
\sigma_{\mathrm{z}}^{\prime}=\sigma_{r}^{\prime}=\sigma_{\theta}^{\prime} \\
\varepsilon_{\mathrm{z}}=\varepsilon_{r}=\varepsilon_{\theta}=\frac{\varepsilon_{\mathrm{kk}}}{3}
\end{gathered}
$$


The relation between the increment of the first invariant of effective stress and the elastic volumetric strain increment is given as (see Equation A.13 and Set 1 of Table 4.1)

$$
d J_{i}^{\prime}=3 K_{s} d \varepsilon_{k k}^{E}
$$

where the response function $K_{S}$ is given by Equation 3.1. Equation 3.1 is substituted into Equation 5.10, and the resulting expression is integrated to provide the following relation between the elastic volumetric strain $\varepsilon_{\mathrm{kk}}^{\mathrm{E}}$ and $\mathrm{J}_{1}^{\prime}$

$$
\varepsilon_{\mathrm{kk}}^{\mathrm{E}}=\frac{1-\mathrm{K}_{1 \mathrm{~s}}}{3 \mathrm{~K}_{2 \mathrm{~s}} \mathrm{~K}_{\mathrm{is}}} \ln \left[\frac{\exp \left(\mathrm{K}_{2 \mathrm{~s}} \mathrm{~J}_{1}^{\prime}\right)-\mathrm{K}_{1 \mathrm{~s}}}{1-\mathrm{K}_{1 \mathrm{~s}}}\right]
$$

The relation between the plastic volumetric strain, $\varepsilon_{k k}^{P}$ and $J_{1}^{\prime}$ is given by Equation 3.7, where $k$ for this phase of the test is $\varepsilon_{k k}^{P}$ and $X(k)$ is $J_{i}^{\prime}$, thus:

$$
\varepsilon_{k k}^{P}=W_{s}\left[1-\exp \left(-D_{s} J_{l}^{\prime}\right)\right]+W_{1 s}\left(J_{l}^{\prime}\right)^{2} \exp \left(-D_{1 s} J_{I}^{\prime}\right)
$$

In view of Equations 5.11 and 5.12, the total volumetric strain takes the following form

$$
\begin{aligned}
& \varepsilon_{k k}=\frac{1-K_{1 s}}{3 K_{2 s} K_{i s}} \ln \left[\frac{\exp \left(K_{2 s} J_{1}^{\prime}\right)-K_{1 s}}{1-K_{1 s}}\right] \\
& +W_{s}\left[1-\exp \left(-D_{s} J_{I}^{\prime}\right)\right]+W_{1 s}\left(J_{I}^{\prime}\right)^{2} \exp \left(-D_{1 s_{1}} J_{1}^{\prime}\right)
\end{aligned}
$$

Equations 5.9 and 5.11 through 5.13 provide a complete specification for the deformation response of the soil skeleton subjected to a drained hydrostatic test (i.e., isotropic consolidation). 
The qualitative behavior of the model during a drained hydrostatic test is shown in Figure 5.1. The slope of the $J_{i}^{\prime}-\varepsilon_{k k}$ curve during virgin loading can be obtained from Equation 5.13 with the help of Equations 5.12 and 3.1 :

$$
\frac{d J_{1}^{\prime}}{d \varepsilon_{k k}}=\frac{3 K_{s}}{1+K D 1+K D 2}=3 \tilde{K}_{s}
$$

where

$$
\begin{aligned}
& K D I=3 K_{S} D_{S}\left(W_{S}-\varepsilon_{k k}^{P}\right)
\end{aligned}
$$

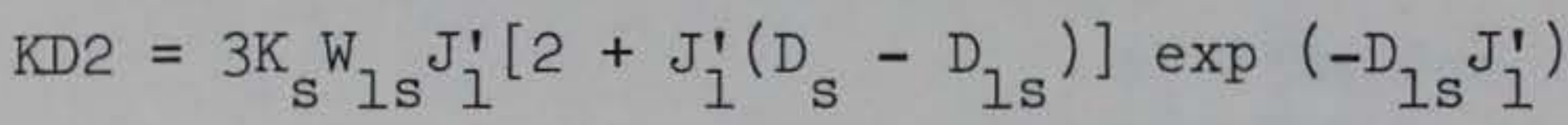

and $K_{S}$ and $\tilde{K}_{S}$ are, respectively, the elastic (Equation 3.1 and Table 4.1) and the apparent bulk moduli of the soil skeleton under drained hydrostatic loading. The second and third terms in the denominator of Equation 5.14 produce a softening of the apparent bulk modulus due to plastic volumetric compaction. At high pressures, the softening term goes to zero, i.e., as $\varepsilon_{k k}^{P} \rightarrow W_{s}$ and $\exp \left(-D_{1 s} J_{l}^{\prime}\right) \rightarrow 0$, the apparent modulus $\tilde{\mathrm{K}}_{\mathrm{S}}$ approaches the elastic bulk modulus, $\mathrm{K}_{\mathrm{S}}$.

Note that if a sample is first isotropically consolidated (from point 1 to point 2 in Figure 5.1), then unloaded (point 2 to point 3 ), and then reloaded (point 3 to point 2), the model dictates that the unloading-reloading behavior is purely elastic.

\subsubsection{Undrained Condition}

During an undrained hydrostatic loading, the effective stresses and the pore pressure are generally not zero. The stress-strain relations for this drainage condition can be obtained in a manner similar to that used to derive Equations 5.11 through 5.13, except that these new expressions will involve the total stresses (Equations 5.5 and 5.6) instead of the effective stresses; i.e., the model coefficients will have the subscript $m$ (mixture) instead of the subscript $s$ (skeleton) (Table 4.1); thus: 


$$
\begin{gathered}
\varepsilon_{k k}^{E}=\frac{1-K_{1 m}}{3 K_{2 m} K_{i m}} \ln \left[\frac{\exp \left(K_{2 m} J_{1}\right)-K_{1 m}}{1-K_{1 m}}\right] \\
\varepsilon_{k k}^{P}=W_{m}\left[1-\exp \left(-D_{m} J_{1}\right)\right]+W_{1 m}\left(J_{l}\right)^{2} \exp \left(-D_{1 m} J_{1}\right)
\end{gathered}
$$

and

$$
\begin{aligned}
\varepsilon_{k k} & =\frac{1-K_{1 m}}{3 K_{2 m} K_{i m}} \ln \left[\frac{\exp \left(K_{2 m} J_{l}\right)-K_{l m}}{1-K_{l m}}\right]+W_{m}\left[1-\exp \left(-D_{m} J_{l}\right)\right] \\
& +W_{l m}\left(J_{l}\right)^{2} \exp \left(-D_{l m} J_{l}\right)
\end{aligned}
$$

\subsubsection{Computation of Effective Stress and Pore Pressure}

The effective stresses and the pore pressures generated during undrained hydrostatic loading tests (in which the applied total stresses are known) can be computed using the assumption that the volumetric strains from Equations 5.13 and 5.17 are equal (Procedure 1 of Chapter 4); thus:

$$
\begin{aligned}
& \frac{1-K_{1 s}}{3 K_{2 s} K_{i s}} \ln \left[\frac{\exp \left(K_{2 s} J_{1}^{\prime}\right)-K_{1 s}}{1-K_{1 s}}\right] \\
& +W_{s}\left[1-\exp \left(-D_{s} J_{l}^{\prime}\right)\right]+W_{1 s}\left(J_{l}^{\prime}\right)^{2} \exp \left(-D_{1 s} J_{l}^{\prime}\right) \\
& =\frac{1-K_{1 m}}{3 K_{2 m} K_{i m}} \ln \left[\frac{\exp \left(K_{2 m} J_{1}\right)-K_{1 m}}{1-K_{1 m}}\right] \\
& +\mathrm{W}_{\mathrm{m}}\left[1-\exp \left(-\mathrm{D}_{\mathrm{m}} \mathrm{J}_{1}\right)\right]+\mathrm{W}_{1 \mathrm{~m}}\left(\mathrm{~J}_{1}\right)^{2} \exp \left(-\mathrm{D}_{1 \mathrm{~m}} \mathrm{~J}_{1}\right)
\end{aligned}
$$


from which $J_{1}^{\prime}$ can be obtained as a function of $J_{1}$ using a bit of algebra. The effective stresses and the pore pressure $u$ then become (see Equation 2.4)

$$
\begin{aligned}
& \sigma_{z}^{\prime}=\sigma_{r}^{\prime}=\frac{J_{1}^{\prime}}{3} \\
& u=\frac{\left(J_{1}-J_{1}^{\prime}\right)}{3}
\end{aligned}
$$

Note that when the material is fully saturated (i.e., a two-phase system) and the water is assumed to be incompressible, the right side of Equation 5.17 or 5.18 becomes zero (i.e., $J_{1}^{\prime}$ is independent of $J_{1}$ ), and Equation 5.18 can be satisfied if and only if $J_{1}^{\prime}$ is equal to zero. This means that all of the applied load is carried by the water.

\subsection{SHEAR PHASE}

During the shear phase of a conventional TX test, the cell pressure is held constant while the axial stress is changed; i.e.,

$$
\sigma_{r}=\text { constant }=P_{c}
$$

and

$$
d \sigma_{r}=0
$$

where $P_{c}$ is the total confining pressure at the end of the hydrostatic compression phase. If the hydrostatic compression phase preceding shear was drained, the confining pressure $P_{c}$ is also the effective confining pressure $\mathrm{P}_{\mathrm{c}}^{\prime}$.

\subsubsection{Drained Condition}

During a drained shear test, the effective and total stresses are equal (i.e., the effective stress path is known and is identical with the total stress path). 
The response of the soil skeleton is modeled using Equation A.29 of Appendix $A$ and the response functions and material parameters listed under Set 1 of Table 4.1 (for the drained condition). Thus:

$$
d \varepsilon_{i j}=\frac{d J_{i}^{\prime}}{9 K_{s}} \delta_{i j}+\frac{d S_{i j}^{\prime}}{2 G_{s}}+d \lambda_{s}\left[\frac{\partial \sigma_{s}}{\partial J_{1}^{\prime}} \delta_{i j}+\frac{1}{2 \sqrt{J_{2}^{\prime}}} \frac{\partial \sigma_{s}}{\partial \sqrt{J_{2}^{\prime}}} S_{i j}^{\prime}\right]
$$

where

$$
\begin{aligned}
& d \varepsilon_{i j}=\text { component of the total strain increment tensor } \\
& \sqrt{\bar{J}_{2}^{\prime}}=\sqrt{\bar{J}_{2}} \\
& \sigma_{s}= \begin{cases}F_{s}\left(J_{1}^{\prime}, \sqrt{J_{2}^{\prime}}, \kappa_{s}\right) \text { on the hardening surface } \\
f_{s}\left(J_{1}^{\prime}, \sqrt{J_{2}^{\prime}}\right) \text { on the failure envelope }\end{cases}
\end{aligned}
$$

Equation A.28 of Appendix A defines $d \lambda_{S}$ using the material parameters for the drained condition (Table 4.1).

In view of Equations A.13 and A.22 of Appendix A, the deviatoric components of the total strain increment tensor are

$$
d e_{i j}=d e_{i j}^{E}+d e_{i j}^{P}=\frac{d S_{i, j}^{\prime}}{2 G_{s}}+\frac{d \lambda_{s}}{2 \sqrt{J_{2}^{\prime}}} \frac{\partial f_{S}}{\partial \sqrt{J_{2}^{\prime}}} S_{i j}^{\prime}
$$

According to Equations $A .22$ and 3.3 or 3.4 , the value of $d \lambda_{S}$ can be written as

$$
d \lambda_{s}=\frac{2\left(\sqrt{d I_{2}^{P}}\right)_{s}}{\frac{\partial f_{s}}{\partial \sqrt{J_{2}^{\prime}}}}
$$


where

$$
d I_{2}^{P}=\frac{1}{2} d e_{i j}^{P} d e_{i j}^{P}=\begin{aligned}
& \text { second invariant of the plastic strain } \\
& \text { increment deviation tensor }
\end{aligned}
$$

Substitution of Equation 5.25 into Equation 5.24 leads to

$$
d S_{i j}^{\prime}=2 G_{S}\left[d e_{i j}-\left(\sqrt{d I_{2}^{P}}\right)_{S} \frac{S_{i j}^{\prime}}{\sqrt{\bar{J}_{2}^{\prime}}}\right]
$$

For TX test conditions, Equation 5.26 can be written as

$$
d\left(\sigma_{z}^{\prime}-\sigma_{r}^{\prime}\right)=2 G_{S} d\left(\varepsilon_{z_{1}}-\varepsilon_{r}\right)-2 \sqrt{3} G_{S}\left(\sqrt{d I_{2}^{P}}\right)_{S}
$$

and

$$
\frac{d\left(\sigma_{z}^{\prime}-\sigma_{r}^{\prime}\right)}{d\left(\varepsilon_{z}-\varepsilon_{r}\right)}=2 G_{S}-\frac{2 \sqrt{3} G_{S}\left(\sqrt{d T_{2}^{P}}\right)}{d\left(\varepsilon_{z}-\varepsilon_{r}\right)}=2 \tilde{G}_{S}
$$

where $\tilde{G}_{S}$ is the apparent shear modulus of the material under drained triaxial loading conditions. The second term on the right side of Equation 5.28 produces a softening of the apparent loading shear modulus due to plastic flow.

Within the yield surface, the plastic strain increments are zero and the apparent shear modulus equals the elastic shear modulus $G_{S}$.

The volumetric strain increment can be obtained by multiplying both sides of Equation 5.23 by the Kronecker delta, $\delta_{i j}$, and then using Equation 5.25; thus:

$$
d \varepsilon_{k k}=\frac{d J_{1}^{\prime}}{3 K_{s}}+6\left(\sqrt{d I_{2}^{P}}\right) s\left(\frac{\frac{\partial \sigma_{s}}{\partial J_{1}^{\prime}}}{\frac{\partial \sigma_{s}}{\partial \sqrt{J_{2}}}}\right)
$$


Typical (qualitative) results predicted by the new model for two types of drained TX shear tests are shown in Figure 5.2.

\subsubsection{Undrained Conditions}

During an undrained shear test (following isotropic consolidation), 1 only the total stress path and, consequently, the total stresses are known for the skeleton-water-air mixture. The material response for this test can be modeled using the mixture model from Table 4.1, and equations similar to Equations 5.23 through 5.29 can be developed except that they will involve the total stresses (Equations 5.5 and 5.6) instead of the effective stresses. These model coefficients will have the subscript $m$ (mixture) instead of, the subscript $s$ (skeleton). The resulting total strain increments are

$$
d \varepsilon_{i j}=\frac{d J_{1}}{9 K_{m}} \delta_{i j}+\frac{d S_{i, j}}{2 G_{m}}+\frac{2\left(\sqrt{d I_{2}^{P}}\right)_{m}}{\frac{\partial \sigma_{m}}{\partial \sqrt{J_{2}}}}\left[\frac{\partial \sigma_{m}}{\partial J_{1}} \delta_{i j}+\left(\frac{1}{2 \sqrt{J_{2}}}\right)\left(\frac{\partial \sigma_{m}}{\partial \sqrt{J_{2}}}\right) S_{i j}\right]
$$

and the deviatoric and volumetric strain ${ }_{1}$ increments are

$$
\begin{gathered}
d e_{i j}=\frac{d S_{i j}}{2 G_{m}}+\left(\sqrt{d I_{2}^{P}}\right)_{m}\left(\frac{s_{i j}}{\sqrt{J_{2}}}\right) \\
d \varepsilon_{k k}=\frac{d J_{1}}{3 K_{m}}+6\left(\sqrt{d I_{2}^{P}}\right)_{m}\left(\frac{\frac{\partial \sigma_{m}}{\partial J_{I}}}{\frac{\partial \sigma_{m}}{\partial \sqrt{J_{2}}}}\right)
\end{gathered}
$$

where

$$
\sigma_{m}=\left\{\begin{array}{l}
F_{m}\left(J_{1}, \sqrt{\bar{J}_{2}}, k_{m}\right) \text { on the hardening surface } \\
f_{m}\left(J_{1}, \sqrt{\bar{J}_{2}}\right) \text { on the failure envelope }
\end{array}\right.
$$

1 The isotropic compression phase preceding shear could either be drained or undrained. In this example, however, it was chosen to be drained. 
Equation A.28 of Appendix A defines $d \lambda_{m}$, and consequently $\left(\sqrt{\mathrm{dI}_{2}^{\mathrm{P}}}\right)_{\mathrm{m}}$, using the material parameters for the undrained condition (Table 4.1).

Equation 5.31 can be written in a form similar to that of Equation 5.28 :

$$
\frac{d\left(\sigma_{z}-\sigma_{r}\right)}{d\left(\varepsilon_{z}-\varepsilon_{r}\right)}=2 G_{m}-\frac{2 \sqrt{3} G_{m}\left(\sqrt{a I_{2}^{P}}\right)_{m}}{d\left(\varepsilon_{z}-\varepsilon_{r}\right)}=2 \tilde{G}_{m}
$$

If it is assumed that strain difference increments are the same under both drained and undrained conditions and hence that the effective stress paths for both conditions are identical, then Equations 5.28 and 5.33 lead to

$$
\frac{G_{s}}{G_{m}}=\frac{1-\frac{\sqrt{3}\left(\sqrt{d I_{2}^{P}}\right)_{m}}{d\left(\varepsilon_{z}-\varepsilon_{r}\right)}}{1-\frac{\sqrt{3}\left(\sqrt{d I_{2}^{P}}\right)_{s}}{d\left(\varepsilon_{z}-\varepsilon_{r}\right)}}
$$

Equation 5.34 dictates that the elastic moduli of the material under both drained and undrained shear test conditions will be the same if the material undergoes the same plastic flow under both conditions; i.e., if $\left(\sqrt{a I_{2}^{P}}\right)_{s}=\left(\sqrt{a I_{2}^{P}}\right)_{m}$, then $G_{s}=G_{m}$.

\subsubsection{Effective Stress and Pore Pressure Computations}

During the undrained shear test, the effective stresses and the pore pressure at the end of each applied total stress loading increment can be computed through the assumption that the total volumetric strain increments obtained from Equations 5.29 and 5.32 are equal (i.e., Procedure 1 of Chapter 4). This assumption entails the added assumption that the pore fluid has no effect on the shear behavior of the material. The strain compatibility constraint gives 


$$
\frac{d J_{1}^{\prime}}{3 K_{s}}+6\left(\sqrt{d I_{2}^{P}}\right) s\left(\frac{\frac{\partial \sigma_{s}}{\partial J_{1}^{\prime}}}{\frac{\partial \sigma_{s}}{\partial \sqrt{\bar{J}_{2}}}}\right)=\frac{d J_{1}}{3 K_{m}}+6\left(\sqrt{d I_{2}^{P}}\right) m\left(\frac{\frac{\partial f_{m}}{\partial J_{1}}}{\frac{\partial f_{m}}{\partial \sqrt{\bar{J}_{2}}}}\right)
$$

from which $J_{i}^{\prime}$ can be obtained as a function of $J_{1}$. The pore pressure and the effective stresses then become (see Equation 2.4)

$$
\begin{gathered}
u=\frac{J_{I}-J_{I}^{\prime}}{3} \\
\sigma_{z}^{\prime}=\sigma_{z}-u \\
\sigma_{r}^{\prime}=\sigma_{r}-u
\end{gathered}
$$

Typical (qualitative) results predicted by the new model for undrained TX shear tests are shown in Figure 5.3. Figure 5.3 also depicts qualitatively the effects of the parameter $R$ on the stress-strain and pore pressure responses during a conventional undrained shear test.

When the material is fully saturated (i.e., a two-phase system) and the water is assumed to be incompressible, the right-hand side of Equation 5.35 becomes zero; i.e., $J_{1}^{\prime}$ is independent of $J_{1}$. This means that the effective stress path is independent of the total stress path applied to the material. This behavior is predicted by the model reported in Reference 15. 


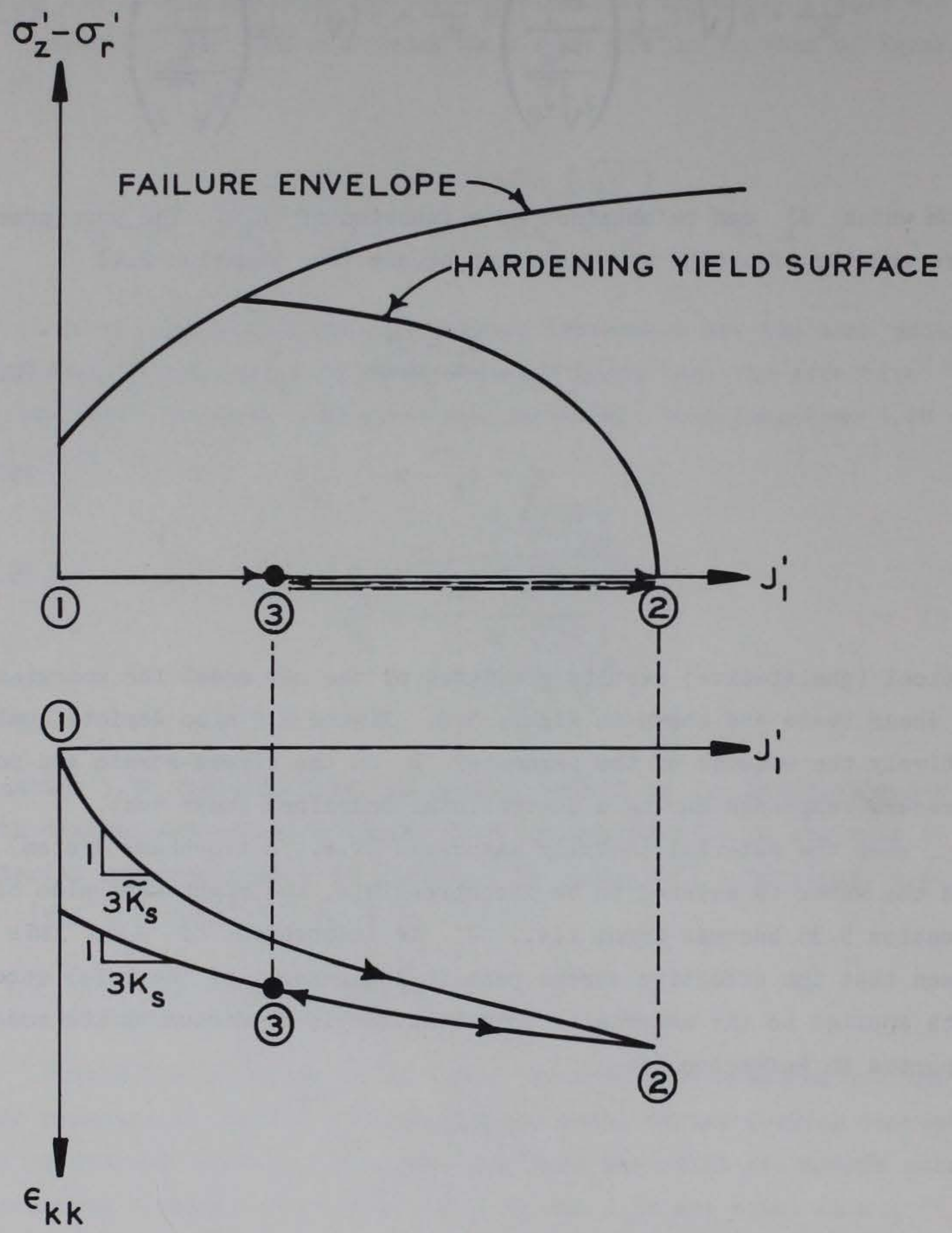

Figure 5.1 Behavior of the model under drained hydrostatic compression (isotropic consolidation). 

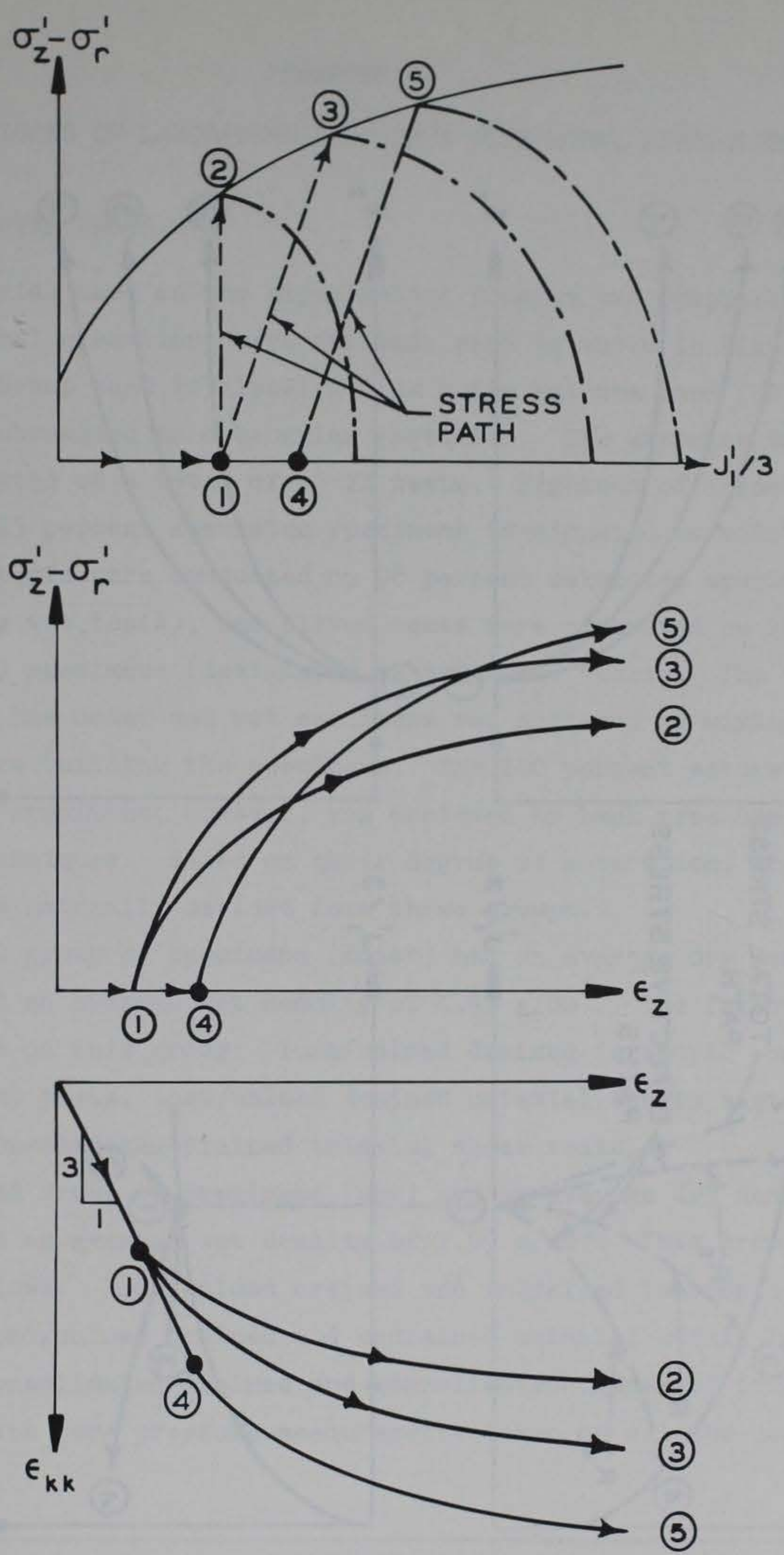

Figure 5.2 Drained shear behavior predicted by the model for a conventional triaxial test and a constant mean normal stress test. 


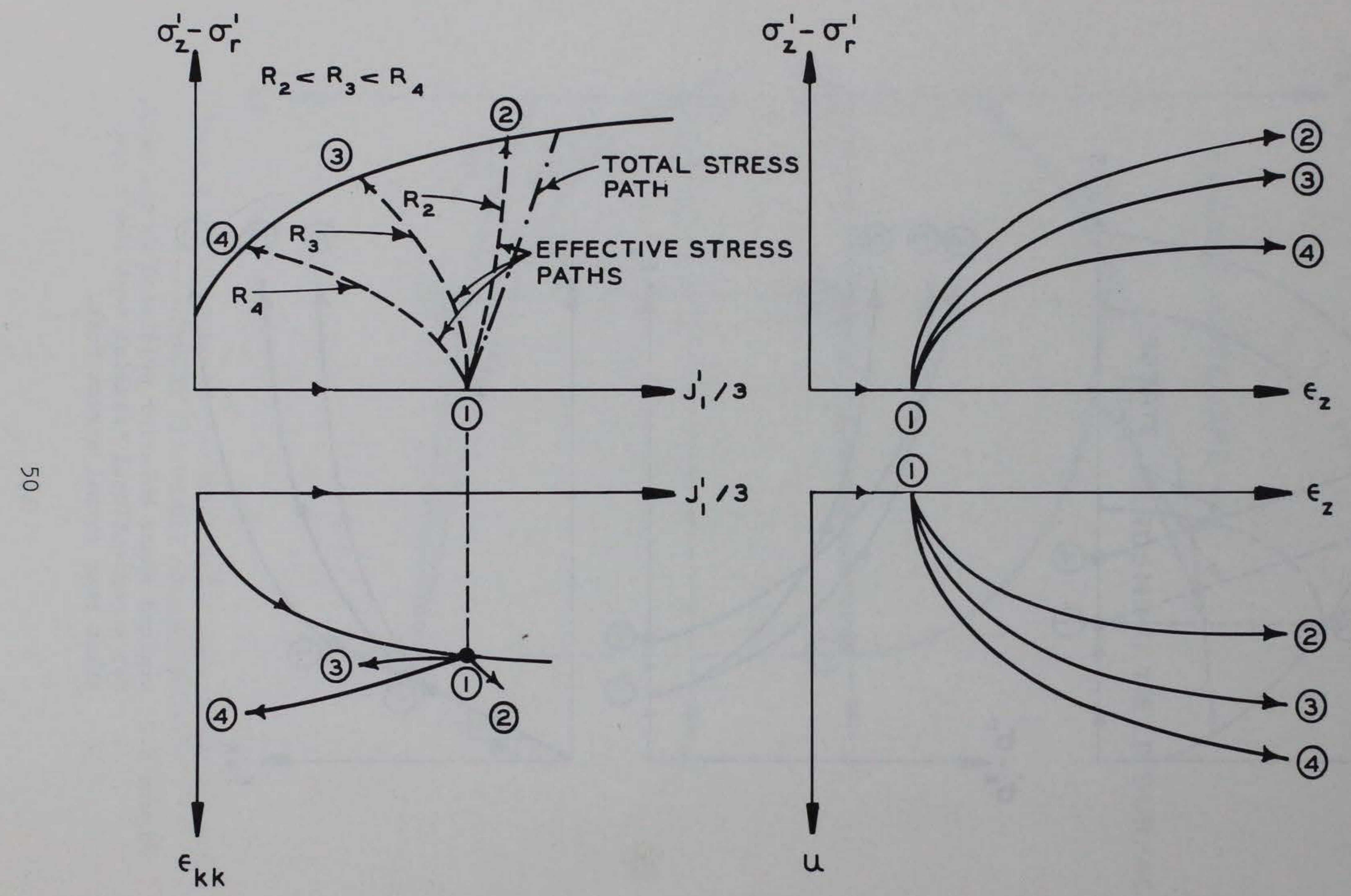

Figure 5.3 Undrained shear behavior predicted by the model, showing the influence of the parameter $\mathrm{R}$ on the effective stress path in a conventional undrained TX test. 


\subsection{EXPERIMENTAL PROGRAM}

The material used in the experimental program was Campbell Swamp sand. A typical gradation curve for this sand is shown in Figure 6.1. The Campbell Swamp sand is classified as a tan uniform sand (SP) and consists of subrounded to subangular particles. The experimental program consisted of a total of 52 TX tests. Eighteen of these were conducted on 15 percent saturated specimens (designated as moist tests), twenty-three tests were conducted on 98 percent saturated specimens (designated as wet tests), and eleven tests were conducted on 100 percent saturated specimens (designated as saturated tests). The degree of saturation in the moist and wet specimens was achieved by mixing water and sand before building the specimens. The 100 percent saturation of the saturated specimens, however, was achieved by back-pressure saturation (BPS) techniques. Based on their degree of saturation, the 52 test specimens were naturally divided into three groups.

The first group of specimens (moist) had an average dry density ${ }^{l}$ of $1.43 \mathrm{~g} / \mathrm{cm}^{3}$ and an average wet density of $1.49 \mathrm{~g} / \mathrm{cm}^{3}$. The following tests were conducted on this group: load/unload drained isotropic compression (consolidation) tests, load/unload drained uniaxial strain tests, and load/unload consolidated-drained triaxial shear tests.

The second group of specimens (wet) had an average dry density of $1.62 \mathrm{~g} / \mathrm{cm}^{3}$ and an average wet density of $1.99 \mathrm{~g} / \mathrm{cm}^{3}$. This group was tested as follows: load/unload drained and undrained isotropic compression tests, load/unload drained and undrained uniaxial strain tests, and load/unload consolidated-drained and consolidated-undrained triaxial shear tests with pore pressure measurements taken on all the undrained tests.

1 A table of factors for converting metric (SI) units of measurement to U. S. customary units and U. S. customary units to metric (SI) units is found on page 7 . 
The third group of specimens (saturated) had an average dry density of $1.62 \mathrm{~g} / \mathrm{cm}^{3}$ and an average wet density of $2.01 \mathrm{~g} / \mathrm{cm}^{3}$. This group was tested as follows: load/unload drained isotropic compression tests and load/unload consolidated-drained, consolidated-undrained, and unconsolidated-undrained triaxial shear tests, with pore pressure measurements taken on the undrained tests.

The complete experimental program is summarized in the following tabulation:

\begin{tabular}{|c|c|c|c|}
\hline Experimental Program & $\begin{array}{l}\text { Group I } \\
\text { (Moist) } \\
\end{array}$ & $\begin{array}{l}\text { Group } 2 \\
\text { (Net) }\end{array}$ & $\begin{array}{c}\text { Group } 3 \\
\text { (Saturated) } \\
\end{array}$ \\
\hline Dry density, $\mathrm{g} / \mathrm{cm}^{3}$ & 1.43 & 1.62 & 1.62 \\
\hline Wet density, $\mathrm{g} / \mathrm{cm}^{3}$ & 1.49 & 1.99 & 2.01 \\
\hline Degree of saturation, \% & 15.0 & 98.0 & 100.0 \\
\hline Number of tests conducted & 18 & 23 & 11 \\
\hline \multirow{6}{*}{ Type of tests conducted ${ }^{a}$} & IC & IC & IC \\
\hline & DUX & UIC & CDTX \\
\hline & CDTX & DUX & CUTX \\
\hline & & UUX & UUTX \\
\hline & & CDTX & \\
\hline & & CUTX & \\
\hline
\end{tabular}

a CDTX - Consolidated-drained triaxial shear test

CUTX - Consolidated-undrained triaxial shear test

DUX - Drained uniaxial strain test

IC - Isotropic compression (consolidation) test; drained

UIC - Undrained isotropic compression test

UUTX - Unconsolidated-undrained triaxial shear test

UUX - Undrained uniaxial strain test

\subsection{MATERIAL CONSTANTS}

As indicated in Chapter 4, a maximum of 42 material constants are associated with the proposed multiphase constitutive model (see Table 4.1), which must be determined experimentally by fitting the model to laboratory test results. Twenty-one of the material constants are 
associated with the drained behavior, and twenty-one are associated with the undrained behavior. The actual number of constants needed to simulate the behavior of a given material, however, depends on its degree of saturation. If the material is partially saturated (i.e., the wet group of Campbell Swamp sand tests), all 42 constants are generally needed. If the material is fully saturated, fewer constants are needed. For example, for the Group 3 Campbell Swamp sand, only 24 material constants were needed (Tables 6.1 and 6.2); 21 of these are associated with the drained behavior (subscript $s$, Table 4.1), while 3 are associated with the undrained isotropic compression behavior (subscript $\mathrm{m}$ ). Finally, if the material is nearly dry (i.e., the water content is negligible, such as occurs in the moist group of Campbell Swamp sand tests), the pore air pressures should be small; hence, only 21 material constants are needed. These are the material constants listed in Table 4.1 with the subscript $s$.

The numerical values of the material constants for the moist (Group 1), the wet (Group 2), and the saturated (Group 3) Campbell Swamp sand tests are given in Table 6.1 for the drained behavior (subscript s) and Table 6.2 for the undrained behavior (subscript $m$ ). The derivation of the numerical values of these constants is not discussed herein. The purpose of this chapter is simply to elucidate the capabilities of the new model.

\subsection{COMPARISON OF TEST RESULTS WITH MODEL BEHAVIOR}

Figures 6.2 through 6.4 compare actual test results with the model fits for the moist (Group 1) material. ${ }^{1}$ Figure 6.2 compares effective mean normal stress versus volumetric strain for the isotropic compression test. Effective stress paths for uniaxial strain and the effective failure envelope are compared in Figure 6.3. Figure 6.4 compares

1 Because the initial degree of saturation of this group of tests was only 15 percent, no undrained tests were conducted on this material. However, it is anticipated that the undrained behavior of these tests could also be represented by Figures 6.2 through 6.4 . 
consolidated drained triaxial shear test response for various confining pressure levels.

Test results are compared with model behavior for the wet (Group 2) material in Figures 6.5 through 6.8. Figure $6.5^{2}$ compares effective and total mean normal stress versus volumetric strain. Effective and total stress paths in drained and undrained states of uniaxial strain are comared in Figure 6.6.2 Figure 6.7 compares consolidated drained triaxial shear test response. The results of consolidated undrained triaxial shear tests are compared with the model's behavior in Figure 6.8 .

Figures 6.9 through 6.13 compare test results versus model behavior for the saturated (Group 3) material. ${ }^{3}$ The comparison plots for isotropic consolidation are shown in Figure 6.9. Figure 6.10 compares consolidated drained triaxial shear response. Figures 6.11 and $6.12 \mathrm{com-}$ pare consolidated undrained triaxial shear response. Principal stress difference versus axial strain and pore pressure versus axial strain for unconsolidated undrained triaxial shear are compared in Figure 6.13.

Figures 6.2 through 6.13 clearly show that the proposed constitutive model qualitatively simulates the various stress-strain and pore pressure responses of Campbell Swamp sand for the moist (Group I), the wet (Group 2), and the saturated (Group 3) conditions. It should be pointed out that pore pressure measurements are not needed for fitting the new model; they are useful, however, for verifying the resultant model fits.

2 The drained and undrained tests conducted on the wet (Group 2) sand produced identical results; i.e., no pore pressures were measured in the undrained tests. It is anticipated that at stress levels above those employed in the current experimental program ( 20 bars) the wet sand would approach and eventually reach full saturation during undrained tests and consequently the undrained test results would

3 diverge from the drained test results. The bulk modulus of this material under undrained isotropic compression was assumed to be constant and equal to $45 \mathrm{kbars}$ (see Table 6.2). This value was calculated from mixture theory; no undrained isotropic compression test was actually conducted on this particular material. 
Table 6.1. Numerical values of material constants for drained behavior of Campbell Swamp sand.

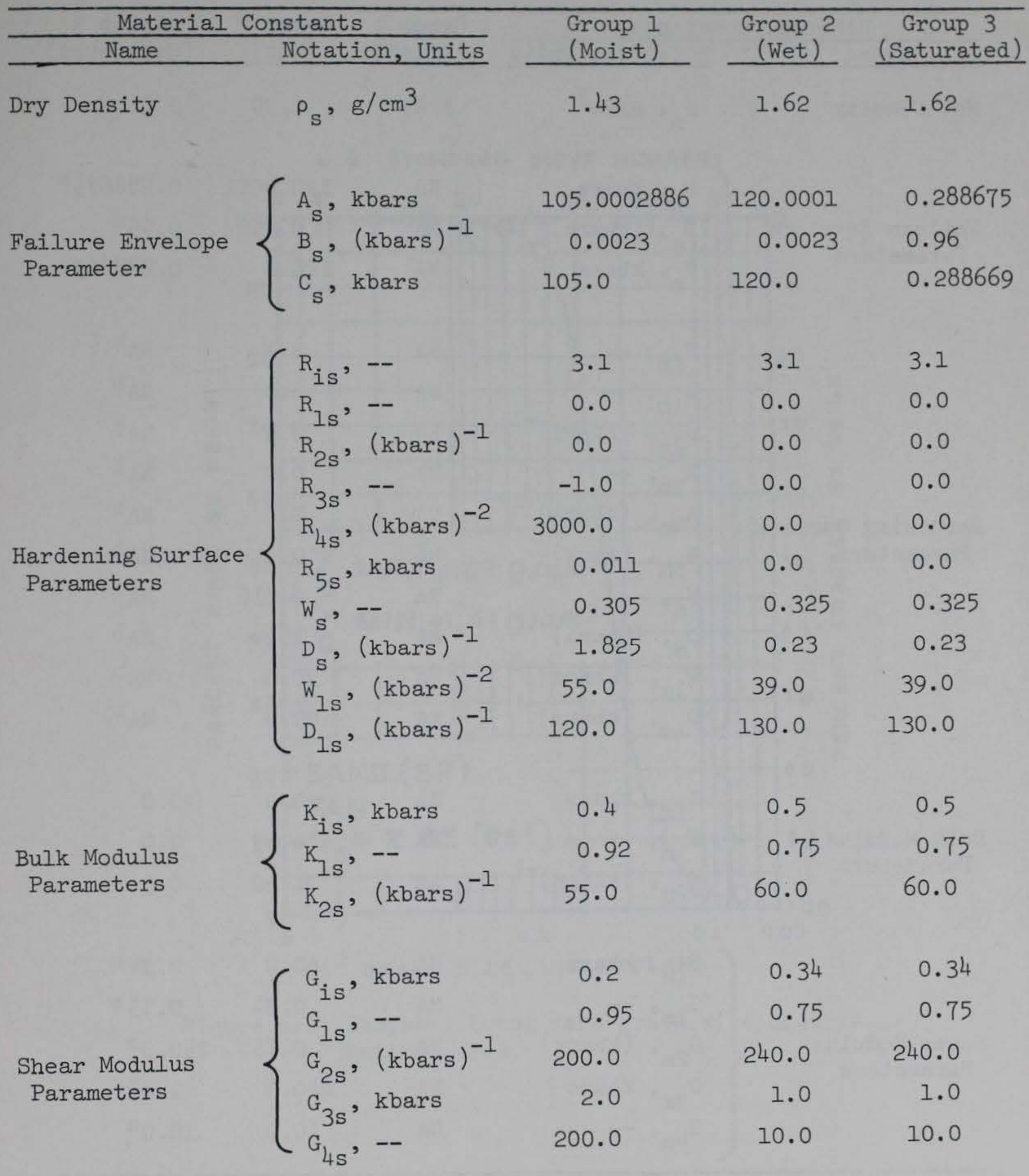


Table 6.2. Numerical values of material constants for undrained behavior of Campbell Swamp sand.

\begin{tabular}{|c|c|c|c|c|}
\hline \multicolumn{2}{|c|}{ Material Constants } & \multirow{2}{*}{$\begin{array}{l}\text { Group } 1 \\
\text { (Moist) }\end{array}$} & \multirow{2}{*}{$\begin{array}{l}\text { Group } 2 \\
\text { (Wet) }\end{array}$} & \multirow{2}{*}{$\begin{array}{c}\text { Group } 3 \\
\text { (Saturated) } \\
\end{array}$} \\
\hline Name & Notation, Units & & & \\
\hline Wet Density & $\rho_{m}, \mathrm{~g} / \mathrm{cm}^{3}$ & 1.49 & 1.99 & 2.01 \\
\hline \multirow{3}{*}{$\begin{array}{l}\text { Failure Envelope } \\
\text { Parameters }\end{array}$} & $A_{m}, k b a r s$ & NA & 120.0001 & $0.288675^{a}$ \\
\hline & $B_{m},(k b a r s)^{-1}$ & NA & 0.0023 & $0.96^{a}$ \\
\hline & $\mathrm{C}_{\mathrm{m}}$, kbars & NA & 120.0 & $0.288669^{a}$ \\
\hline \multirow{10}{*}{$\begin{array}{l}\text { Hardening Surface } \\
\text { Parameters }\end{array}$} & m, -- & NA & 3.1 & $\mathrm{NA}^{\mathrm{b}}$ \\
\hline & $R_{I m},--$ & NA & 0.0 & $\mathrm{NA}^{\mathrm{b}}$ \\
\hline & $R_{2 m},(k b a r s)^{-1}$ & NA & 0.0 & $N A^{b}$ \\
\hline & $R_{3 m},--$ & NA & 0.0 & $N A^{b}$ \\
\hline & $\mathrm{R}_{4 \mathrm{~m}},(\mathrm{kbars})^{-2}$ & NA & 0.0 & $N A^{b}$ \\
\hline & $\mathrm{R}_{5 \mathrm{~m}}$, kbars & NA & 0.0 & $\mathrm{NA}^{\mathrm{b}}$ \\
\hline & $W_{m},--$ & NA & 0.016 & $N A^{b}$ \\
\hline & $\mathrm{D}_{\mathrm{m}},(\mathrm{kbars})^{-1}$ & NA & 1.0 & $N A^{b}$ \\
\hline & $\mathrm{W}_{1 \mathrm{~m}},(\mathrm{kbars})^{-2}$ & NA & 30.0 & $\mathrm{NA}^{\mathrm{b}}$ \\
\hline & $\mathrm{D}_{1 \mathrm{~m}},(\mathrm{kbars})^{-1}$ & NA & 95.0 & $\mathrm{NA}^{\mathrm{b}}$ \\
\hline \multirow{3}{*}{$\begin{array}{l}\text { Bulk Modulus } \\
\text { Parameters }\end{array}$} & $\mathrm{K}_{\mathrm{im}}$, kbars & NA & 0.5 & 45.0 \\
\hline & $\mathrm{K}_{1 \mathrm{~m}},--$ & NA & 0.99 & 0.0 \\
\hline & $\mathrm{K}_{2 \mathrm{~m}},(\mathrm{kbars})^{-1}$ & NA & 1.30 & 0.0 \\
\hline \multirow{5}{*}{$\begin{array}{l}\text { Shear Modulus } \\
\text { Parameters }\end{array}$} & $\mathrm{G}_{\text {im }}$, kbars & NA & 60.0 & $0.34 a$ \\
\hline & $\mathrm{G}_{1 \mathrm{~m}},--$ & NA & 0.34 & $0.75^{\mathrm{a}}$ \\
\hline & $\mathrm{G}_{2 \mathrm{~m}},(\mathrm{kbars})^{-1}$ & NA & 0.75 & $240.0^{a}$ \\
\hline & $\mathrm{G}_{3 \mathrm{~m}}$, kbars & NA & 240.0 & $1.0^{\mathrm{a}}$ \\
\hline & $\mathrm{G}_{4 \mathrm{~m}},--$ & NA & 10.0 & $10.0^{\mathrm{a}}$ \\
\hline
\end{tabular}

The failure envelope parameters and the shear modulus parameters for

this material are the same as those in Table 6.1.

For this group the hardening surface was not utilized in the calculations. 


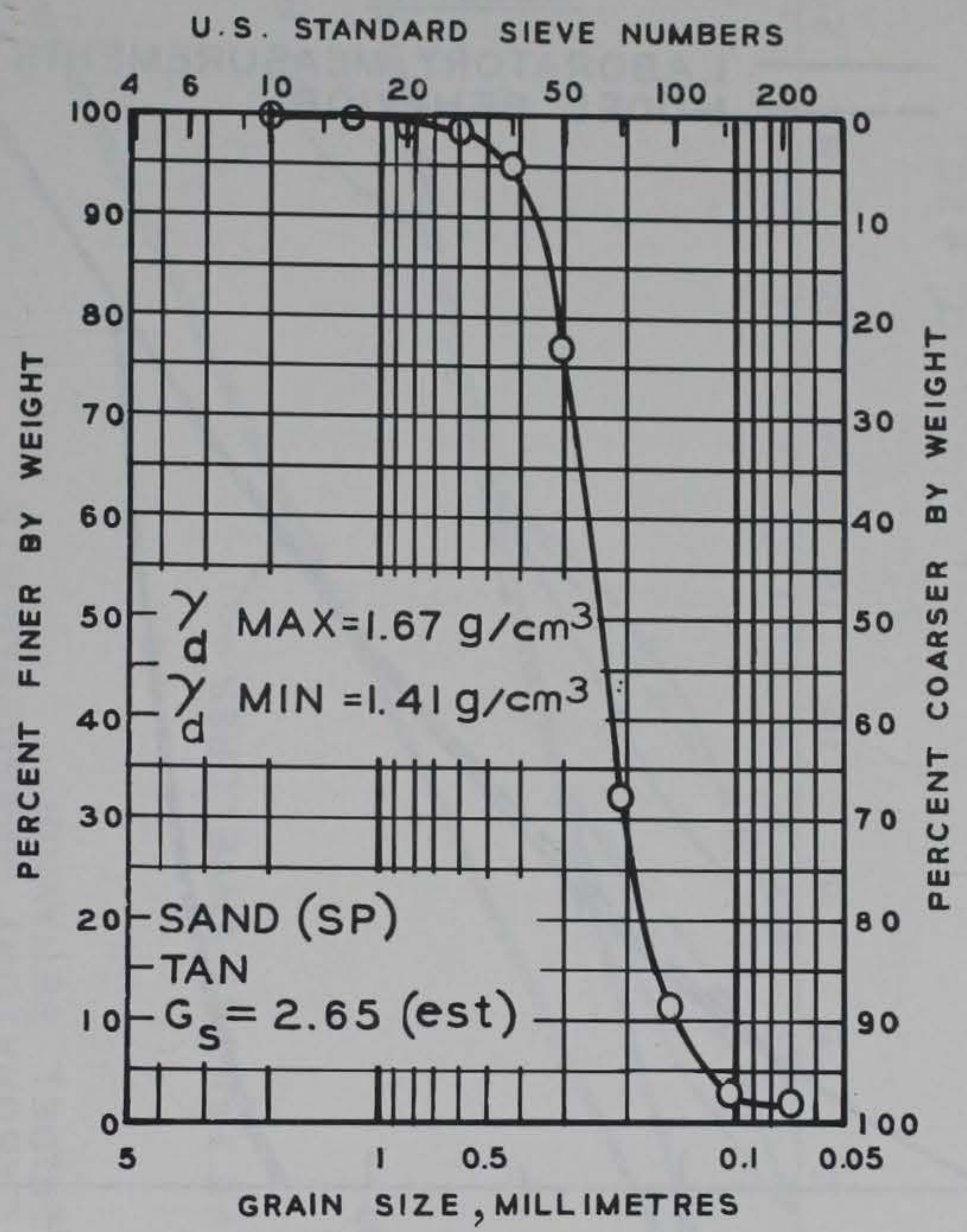

Figure 6.1 Campbell Swamp sand grain size distribution curve. 


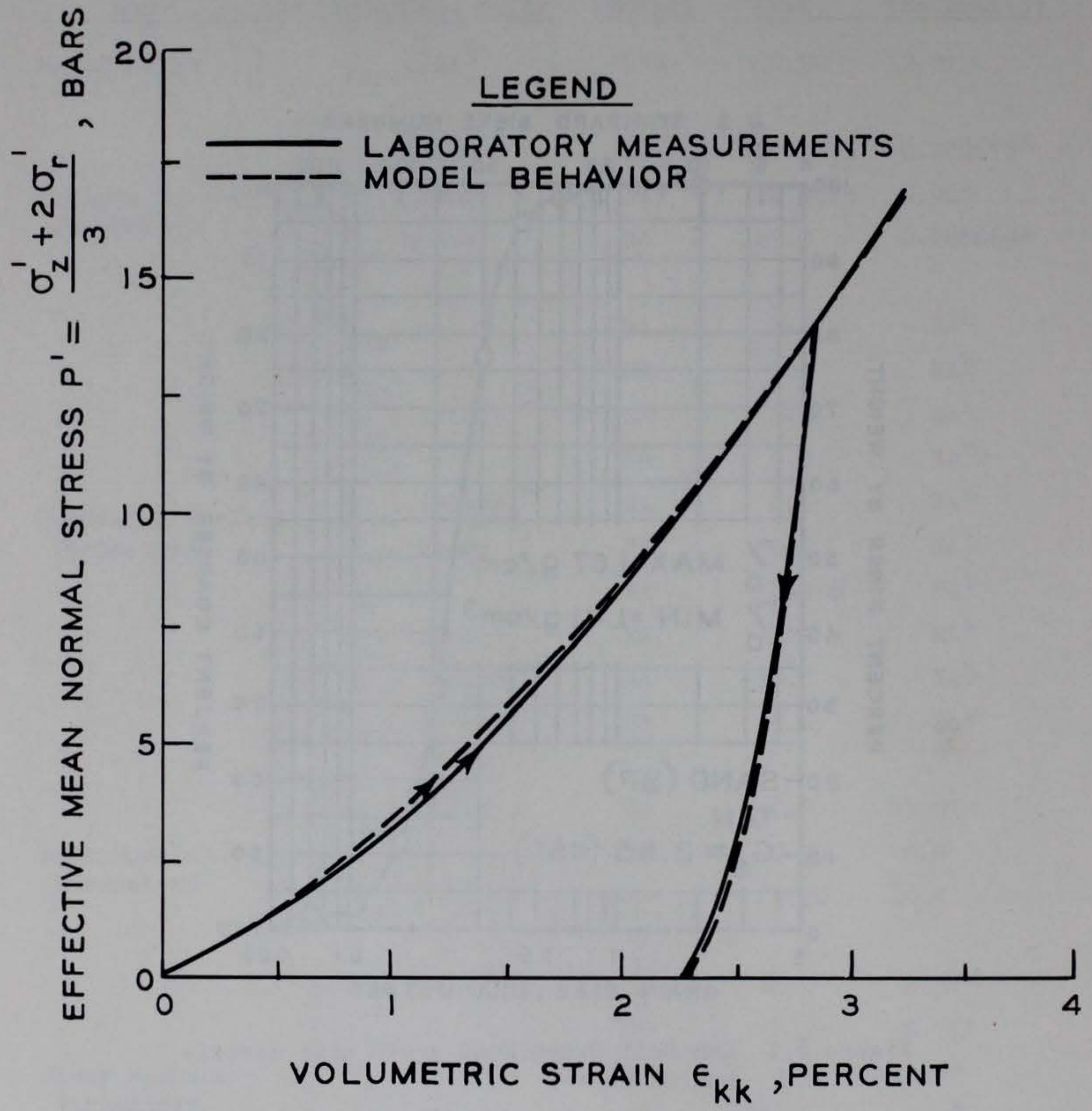

Figure 6.2 Drained isotropic compression response, laboratory measurements versus model behavior, Group 1 . 


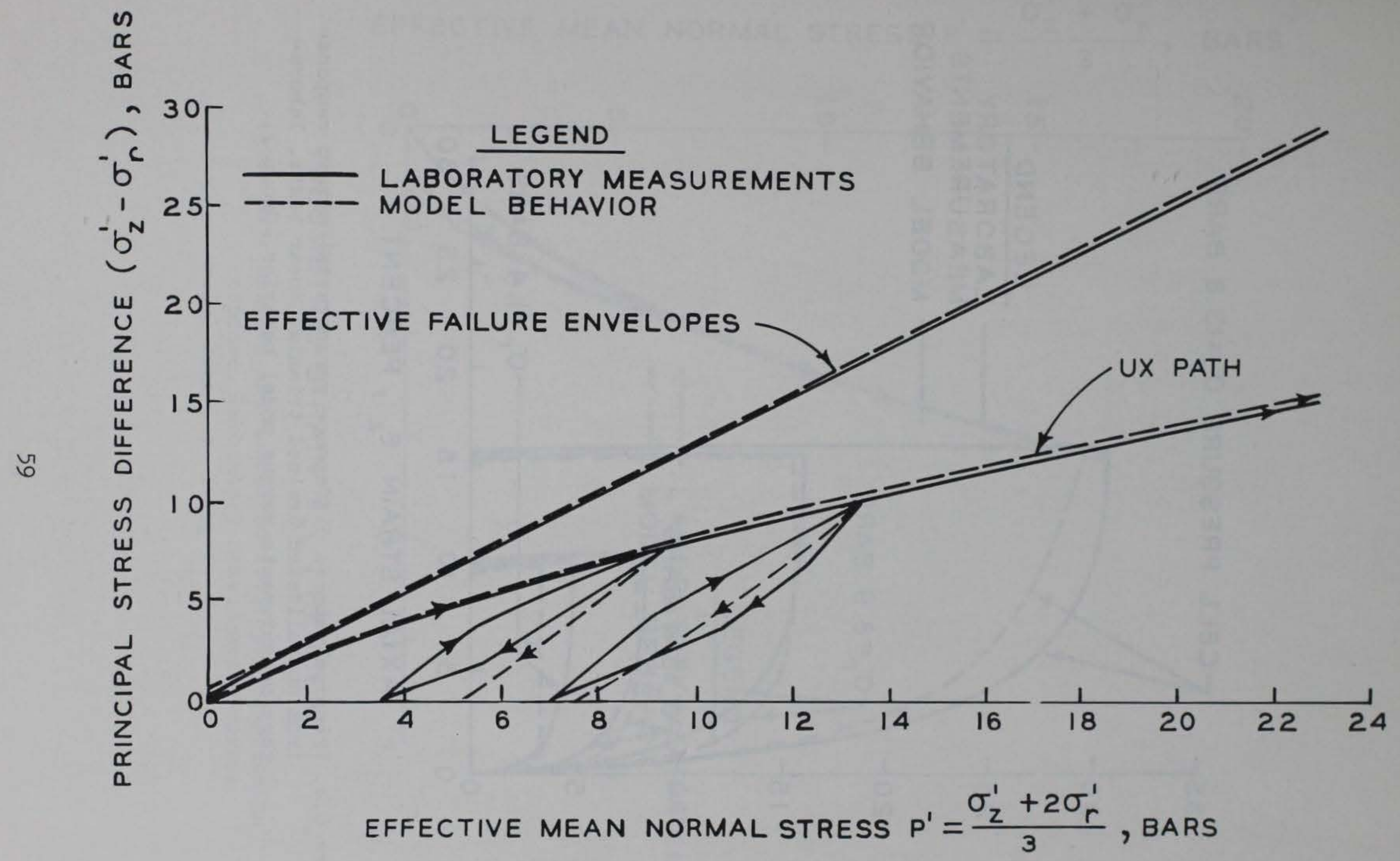

Figure 6.3 Drained stress path for uniaxial (UX) strain and effective stress failure envelope, laboratory measurements versus model behavior, Group 1 . 


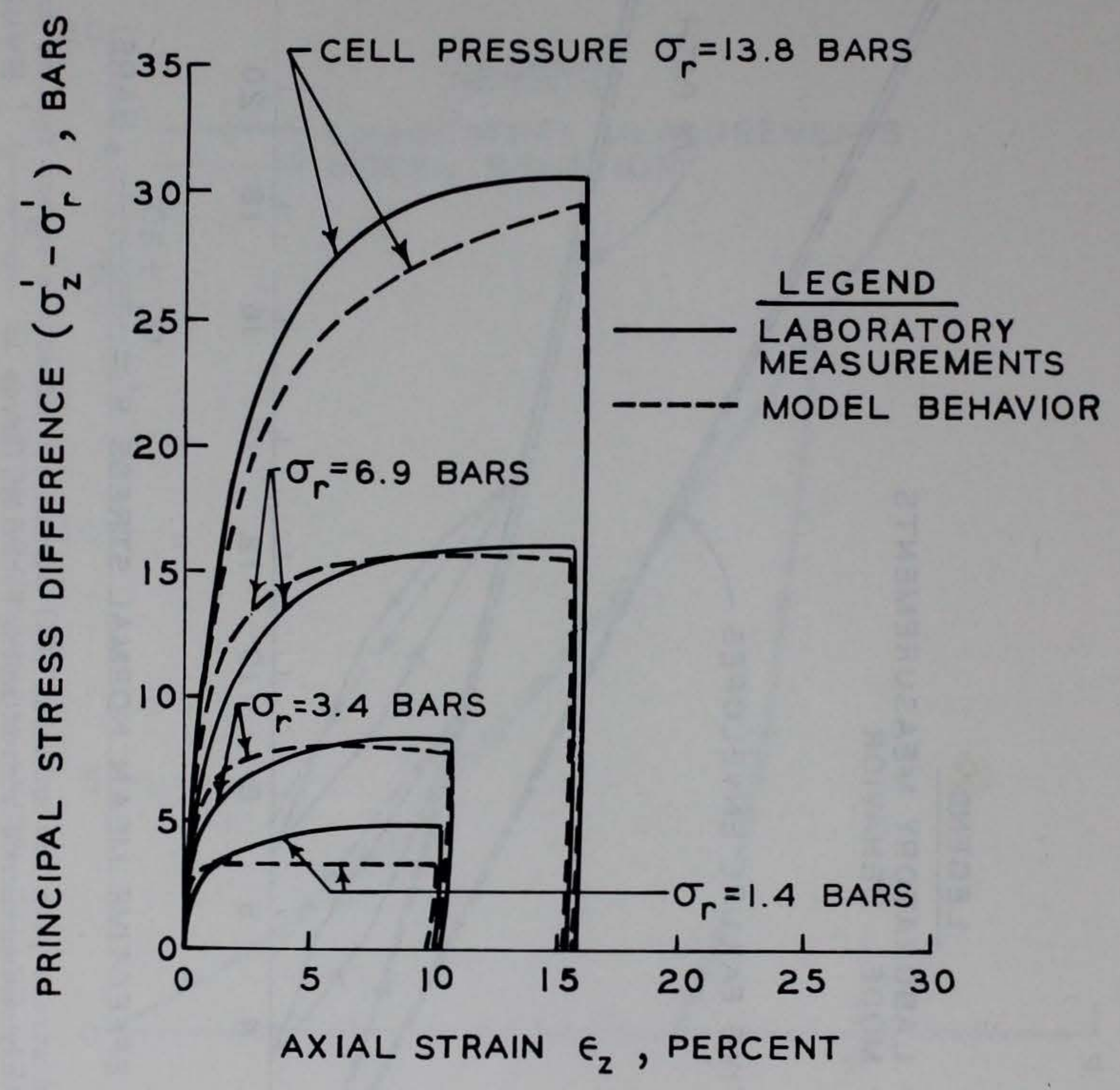

Figure 6.4 Principal stress difference versus axial strain response from consolidated drained triaxial shear tests, laboratory measurements versus model behavior, Group 1 . 


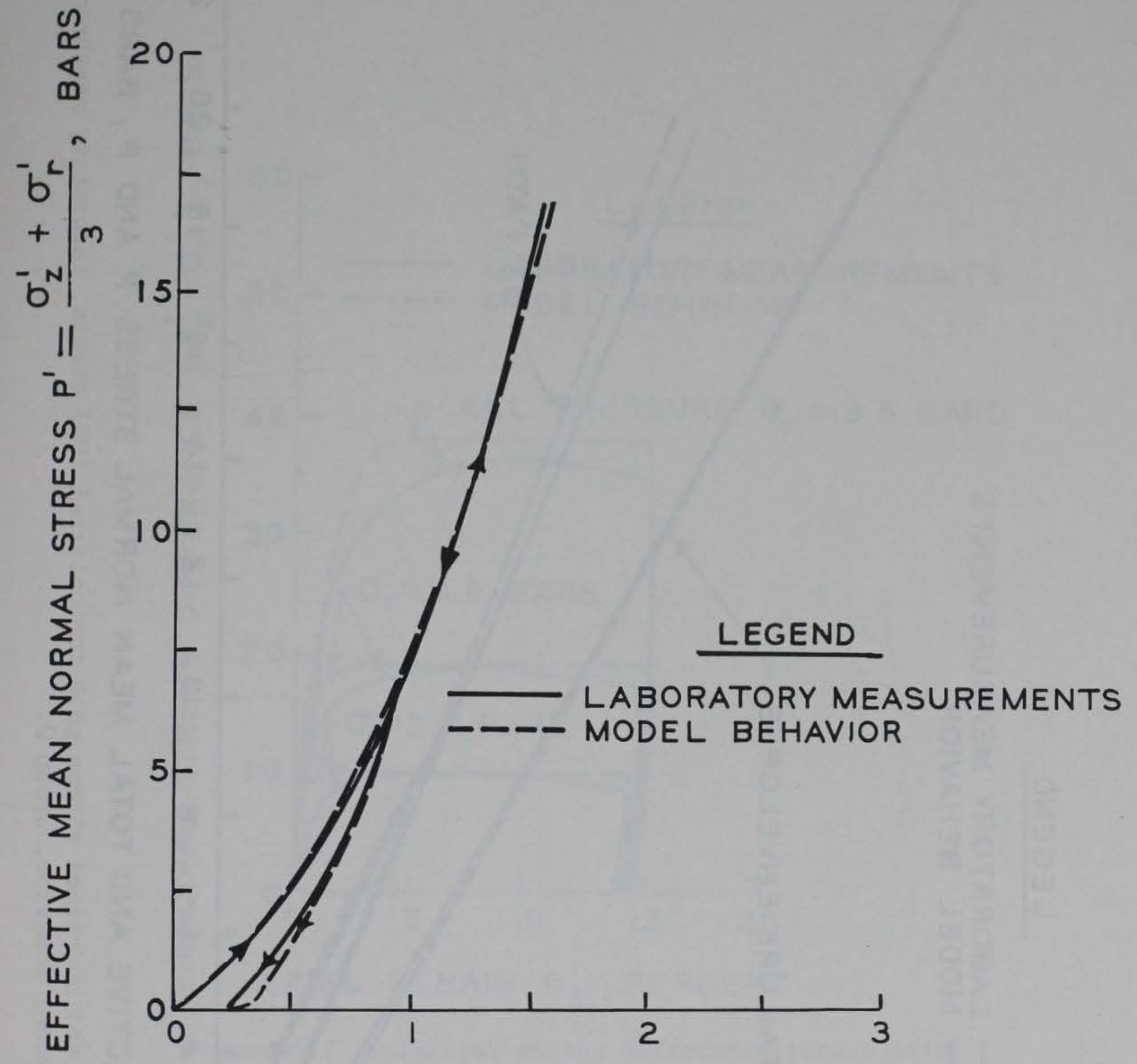

VOLUMETRIC STRAIN $\epsilon_{k k}$, PERCENT

Figure 6.5 Drained and undrained isotropic compression response, laboratory measurements versus model behavior, Group 2. 


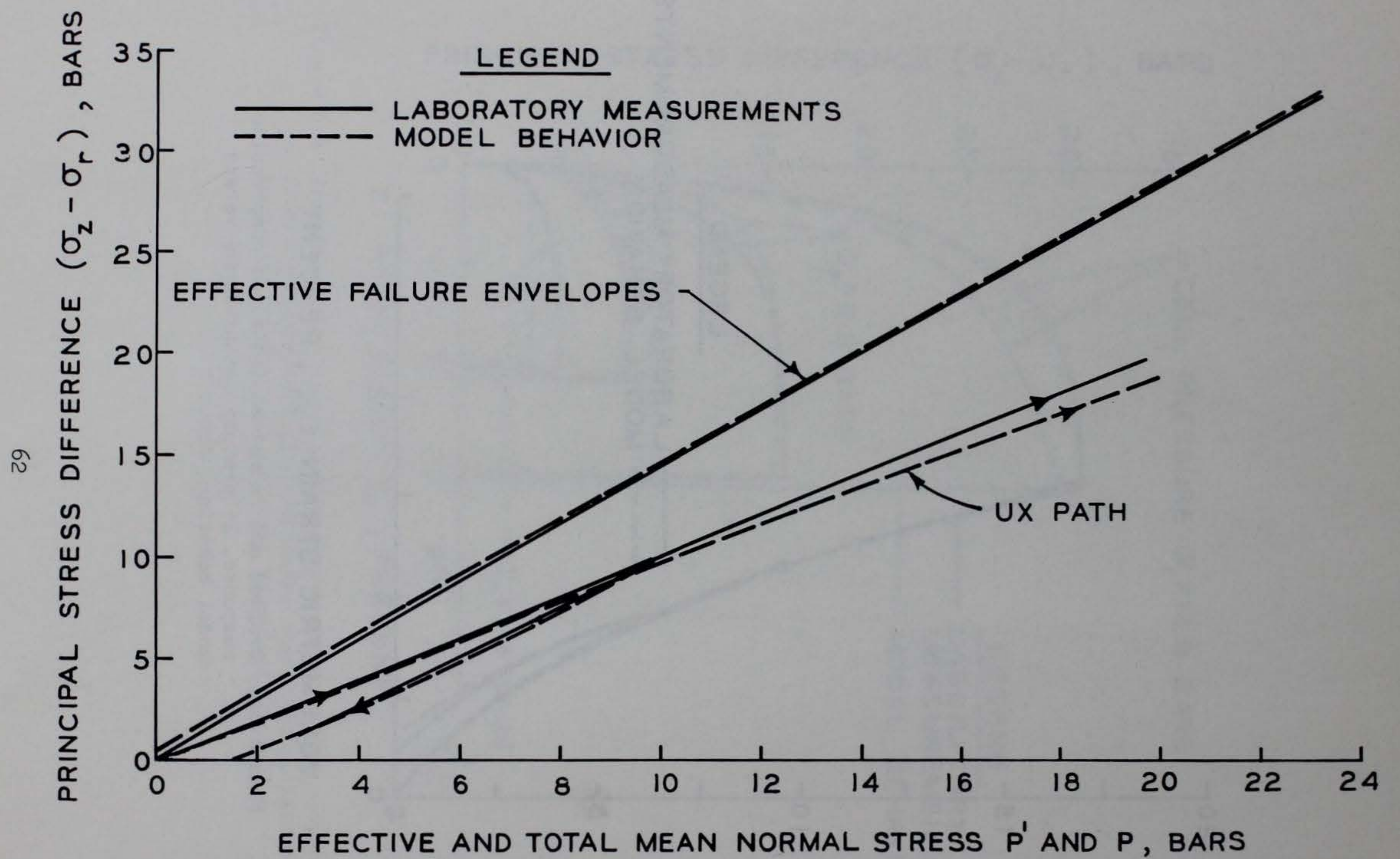

Figure 6.6 Drained and undrained stress path for uniaxial (UX) strain, laboratory measurements versus model behavior, Group 2. 


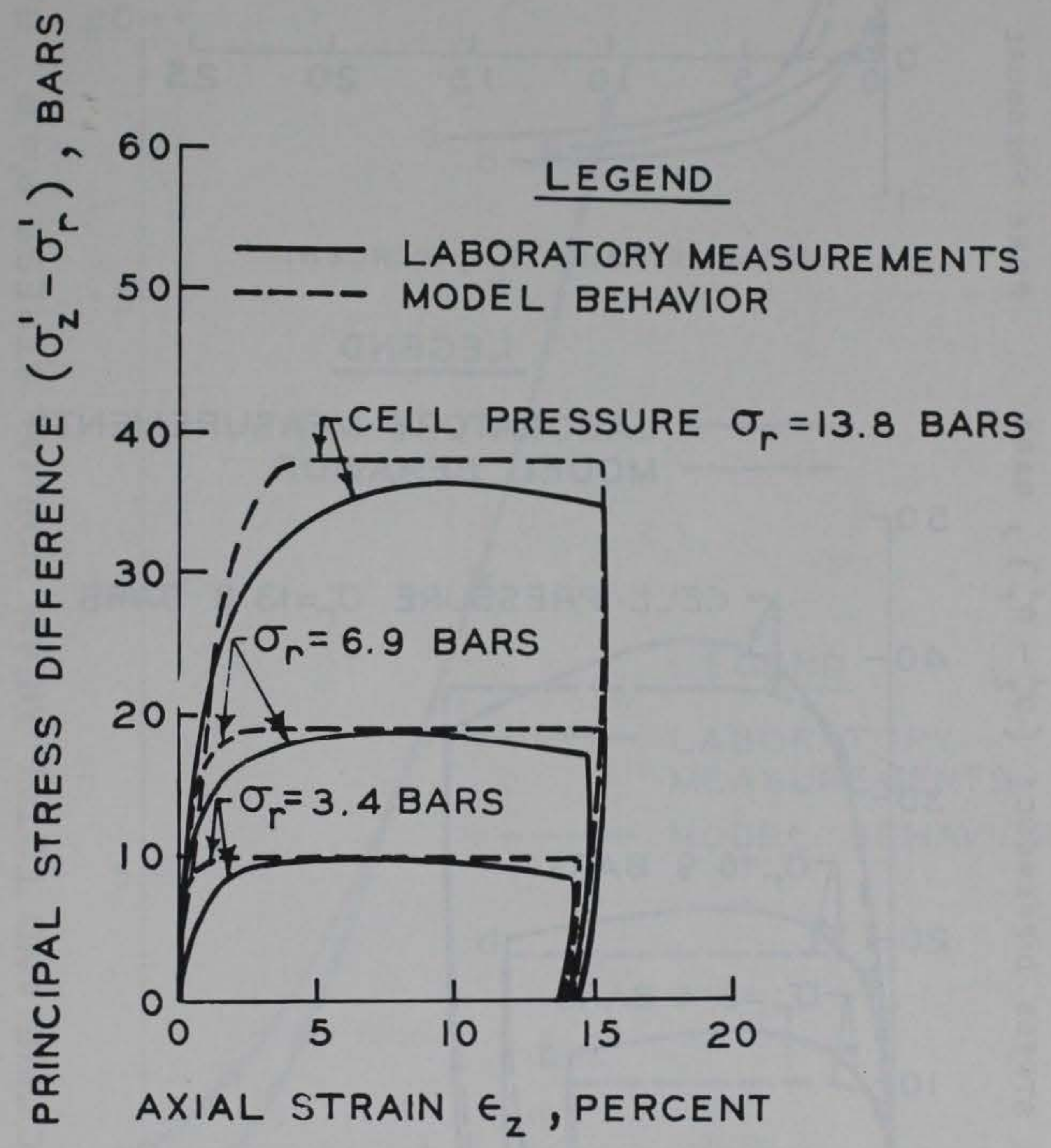

Figure 6.7 Principal stress difference versus axial strain response from consolidated drained triaxial shear tests, laboratory measurements versus model behavior, Group 2 . 


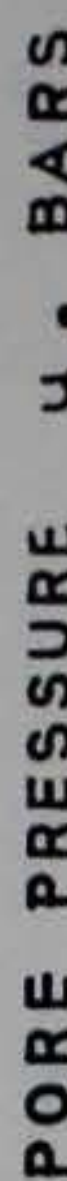

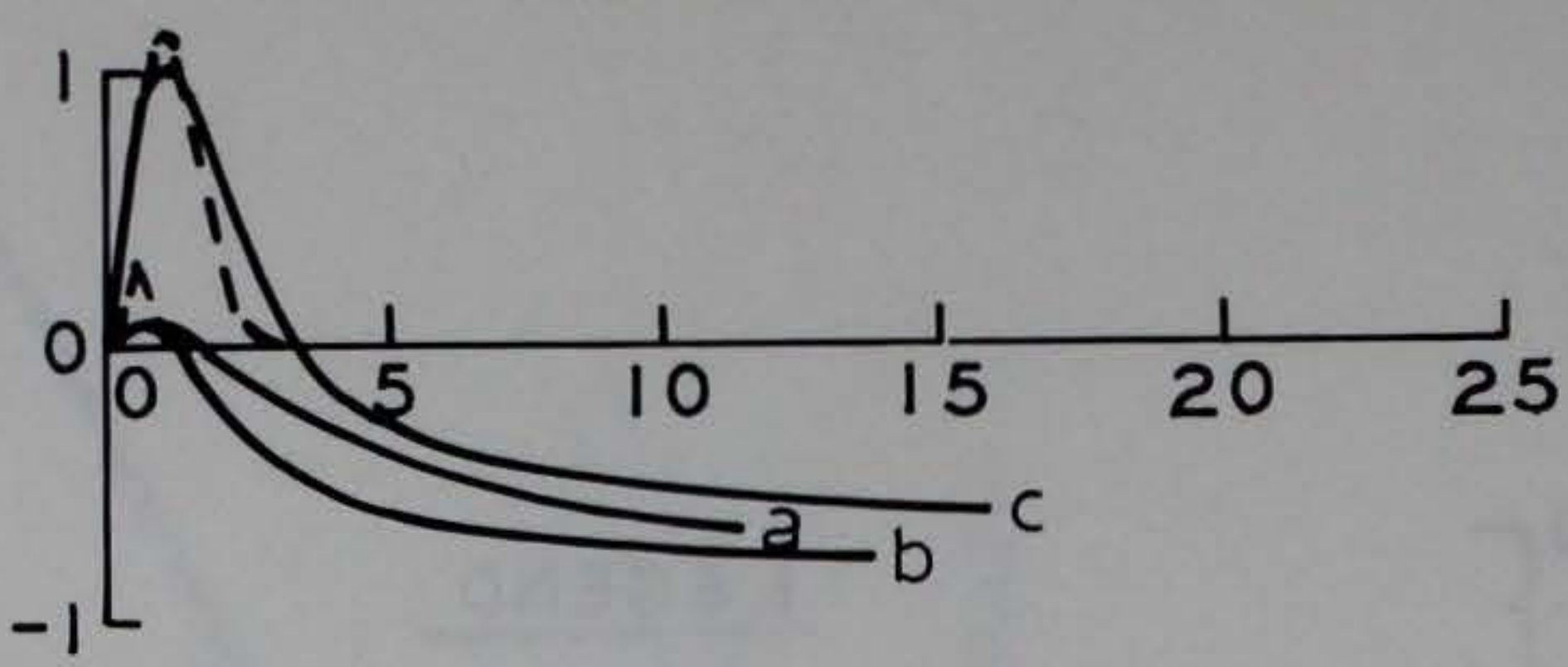

AXIAL STRAIN $\epsilon_{Z}$, PERCENT

LEGEND

(1)

LABORATORY MEASUREMENTS -- - MODEL BEHAVIOR

$\frac{2}{b^{c}}$

$u$
$u$
$u$
$u$
$u$
$u$
$u$
$\frac{u}{0}$
$u$
$u$
$u$
$\alpha$
$v$
$v$

50

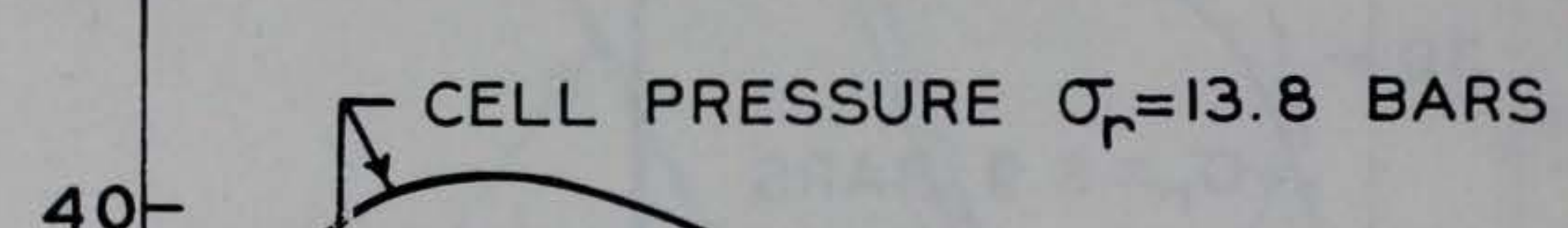

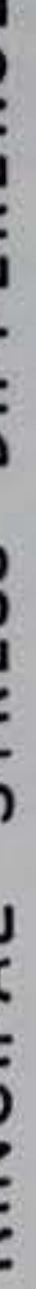

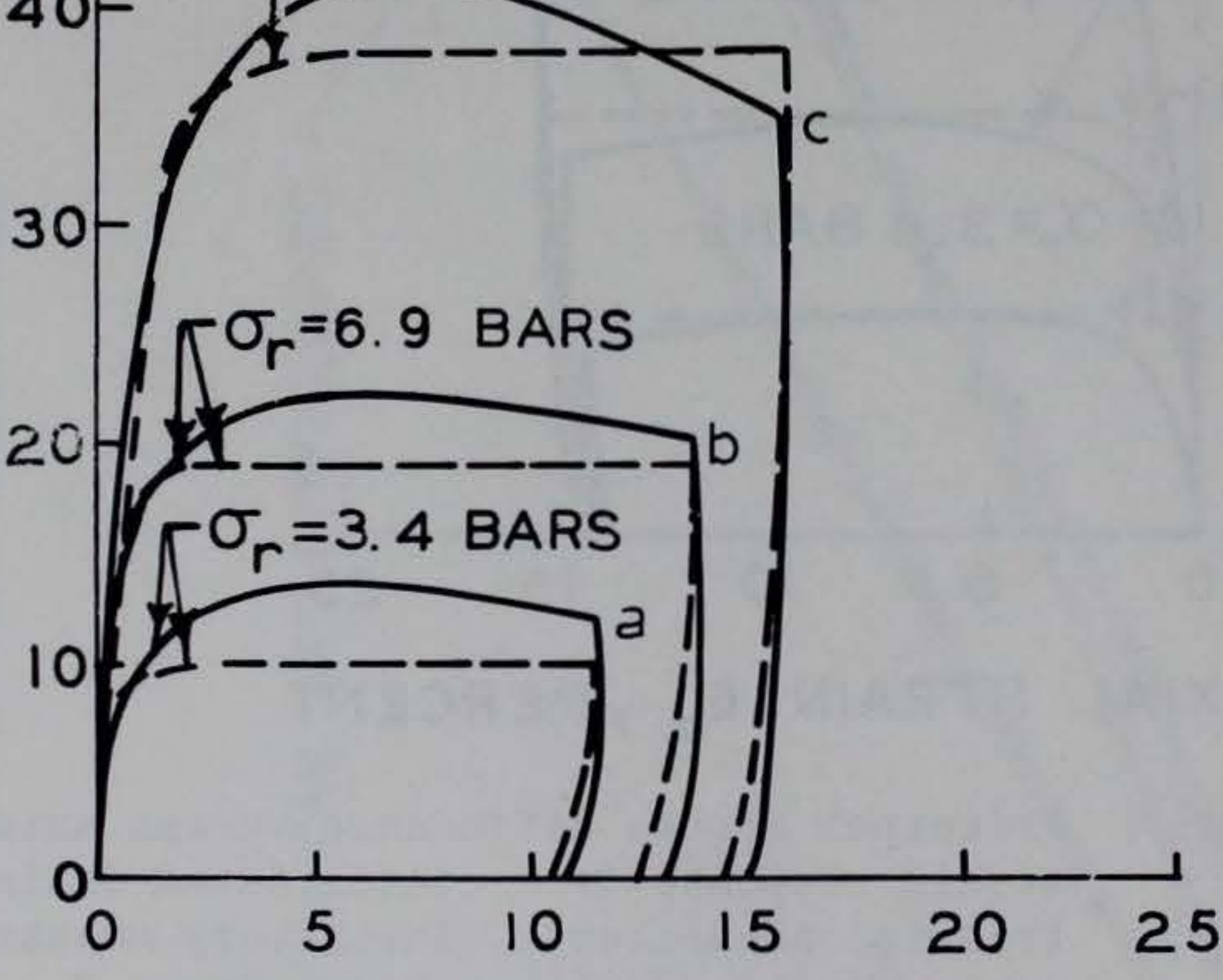

AXIAL STRAIN $E_{Z}$, PERCENT

Figure 6.8 Principal stress difference and excess pore pressure versus axial strain response from consolidated undrained triaxial shear tests, laboratory measurements versus model behavior, Group 2. 


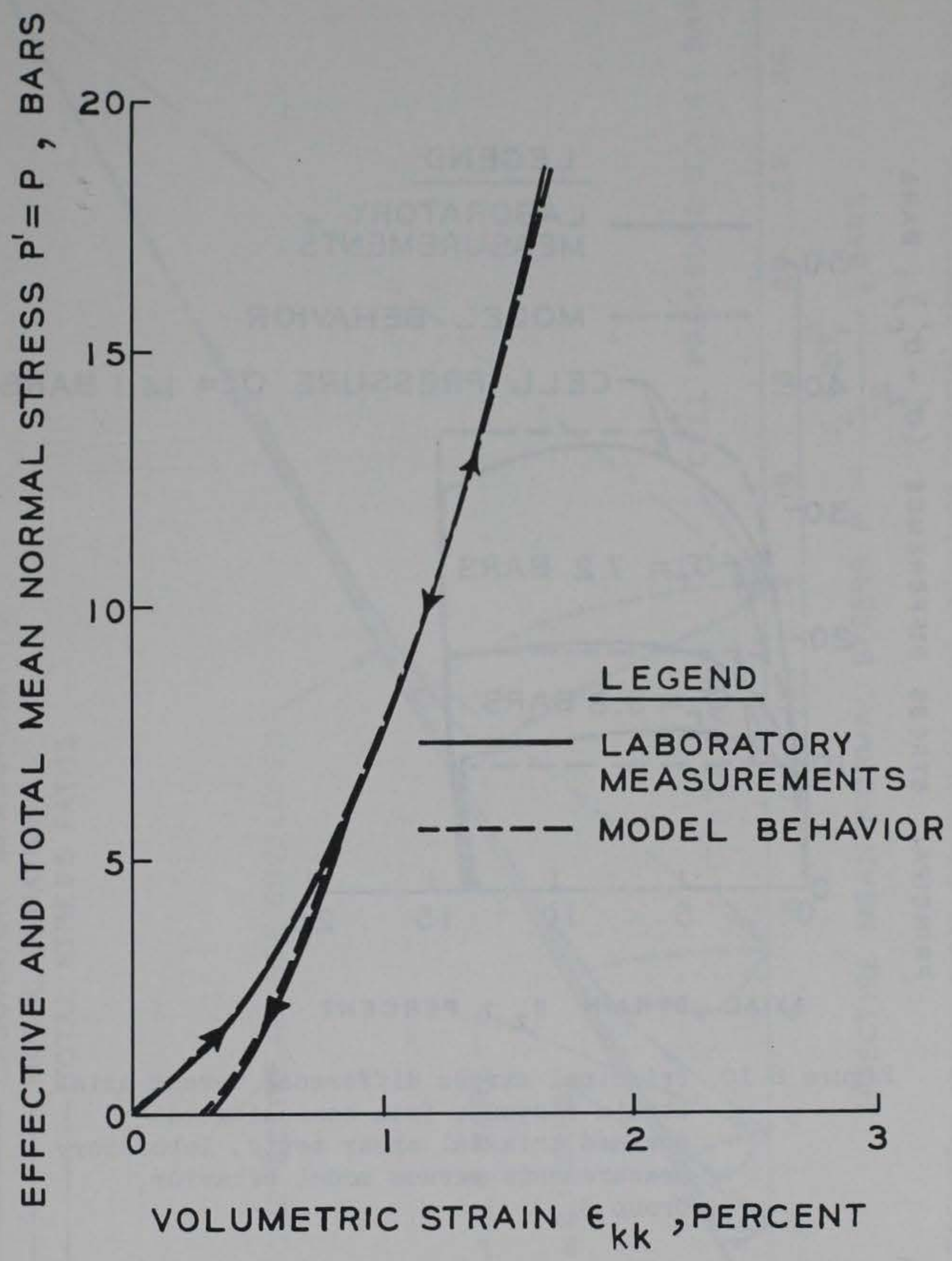

Figure 6.9 Drained isotropic compression response, laboratory measurements versus model behavior, Group 3 . 


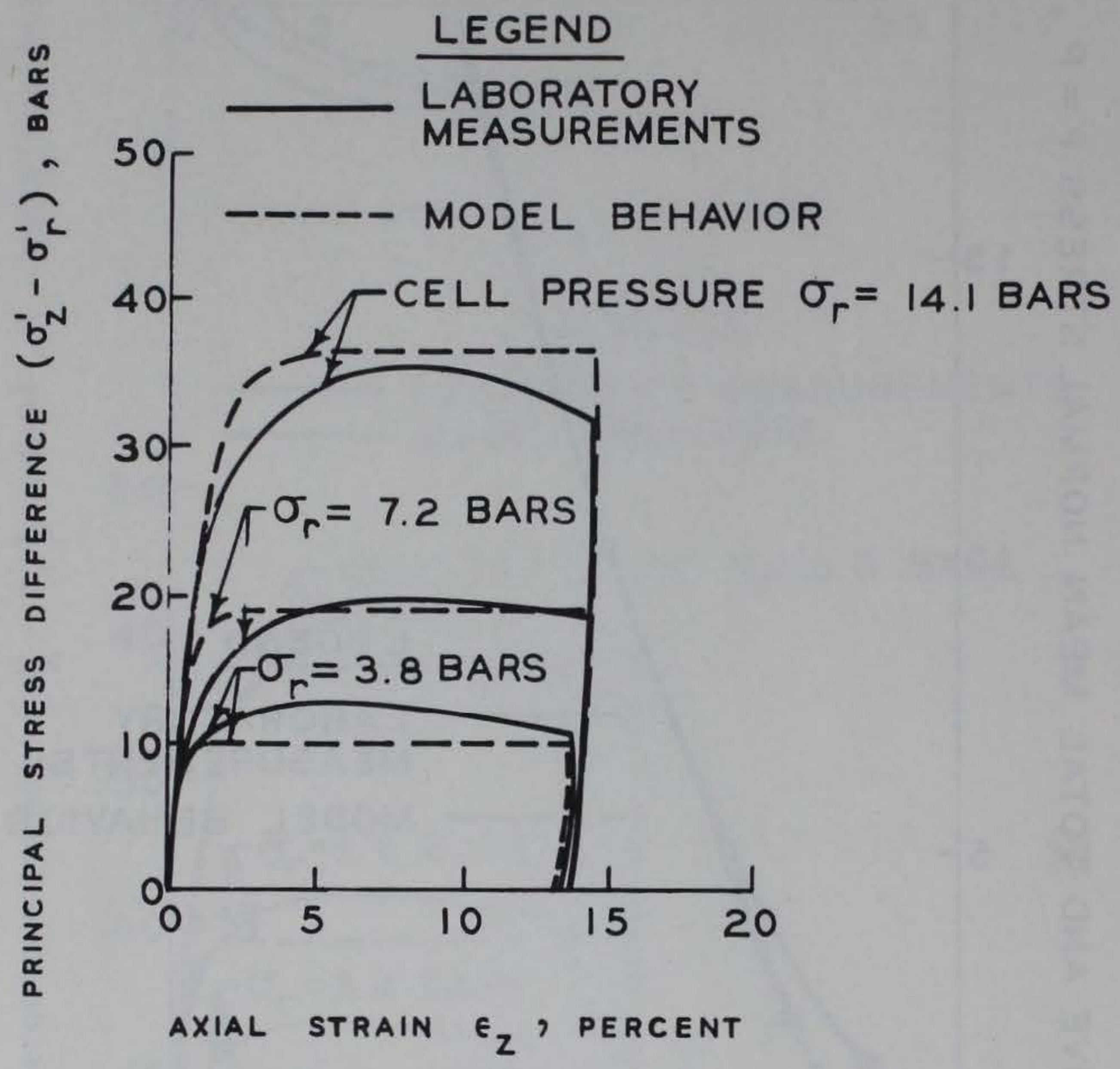

Figure 6.10 Principal stress difference versus axial strain response from consolidated drained triaxial shear tests, laboratory measurements versus model behavior, Group 3. 


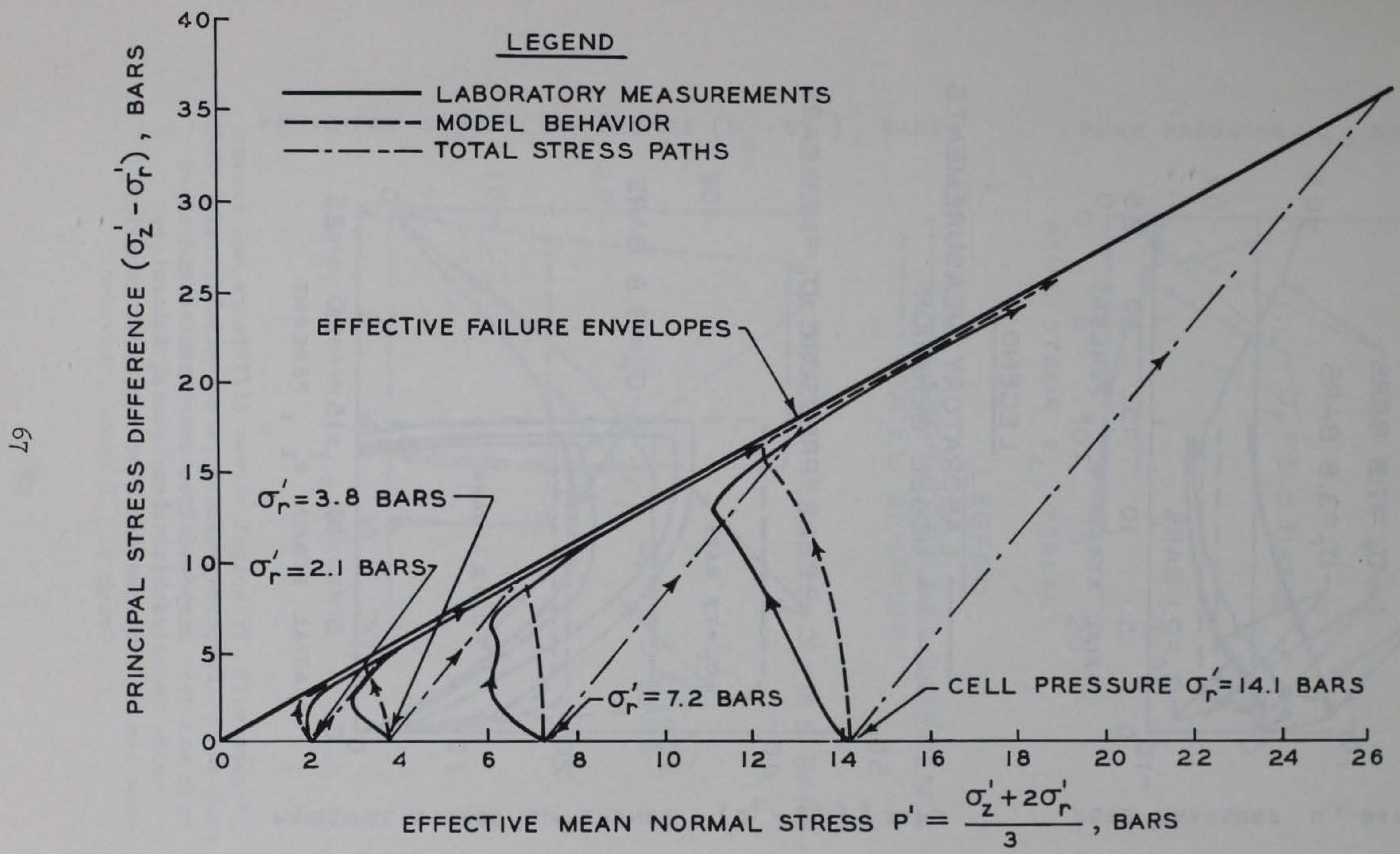

Figure 6.11 Effective stress paths for consolidated undrained triaxial shear tests, laboratory measurements versus model behavior, Group 3 . 

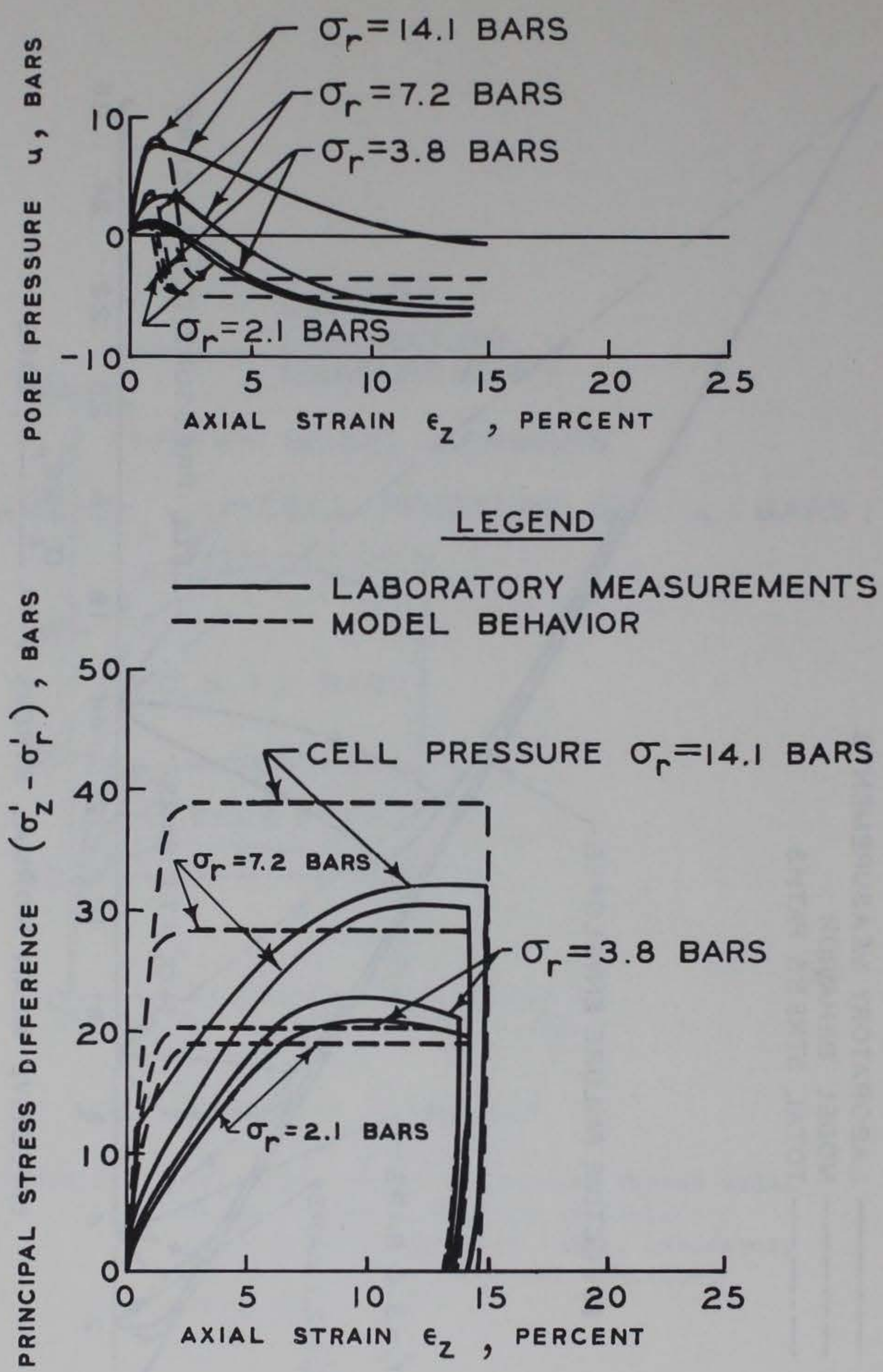

Figure 6.12 Principal stress difference and excess pore pressure versus axial strain response from consolidated undrained triaxial shear tests, laboratory measurements versus model behavior, Group 3. 

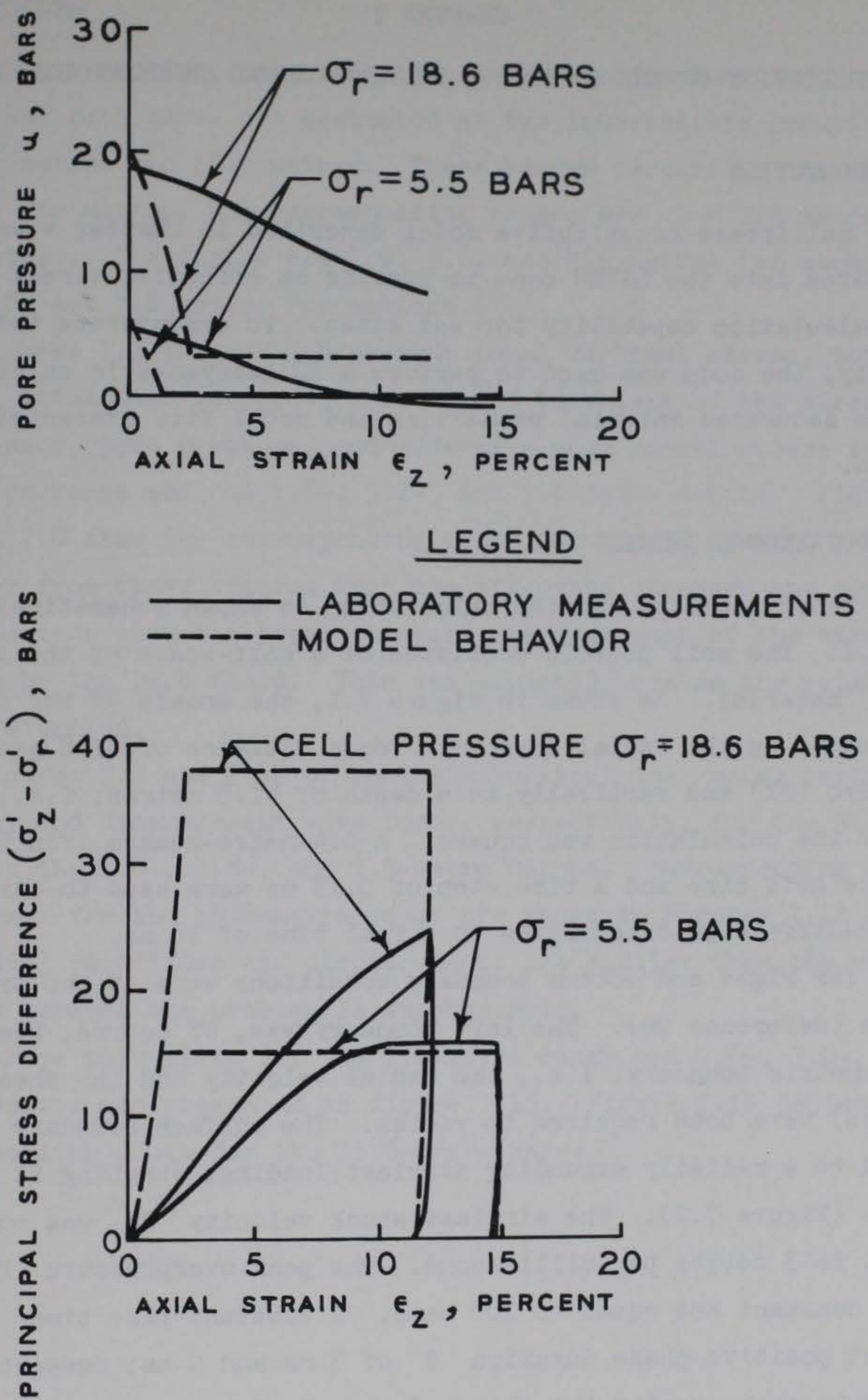

Figure 6.13 Principal stress difference and excess pore pressure versus axial strain response from unconsolidated undrained triaxial shear tests, laboratory measurements versus model behavior, Group 3. 
CHAPTER 7

APPLICATION OF THE MODEL FOR SOLVING GROUND SHOCK PROBLEMS

\subsection{INTRODUCTION}

The multiphase constitutive model described in Chapter 4 was incorporated into the LAYER code to provide an effective stress ground motion calculation capability for wet sites. To demonstrate this capability, the code was used to perform a 2D axisymmetric calculation using the saturated material properties and model fits presented in Chapter 6.

\subsection{COMPUTATIONAL DETAILS}

The basic geometry for the calculation is shown schematically in Figure 7.1. The soil profile consisted of a half-space of the saturated (Group 3) material. As shown in Figure 7.1, the domain of the calculation extended in the radial direction for a distance of 41.8 metres from ground zero (GZ) and vertically to a depth of 41.8 metres; i.e., the region of the calculation was square. A 0.4 -metre-square, finitedifference grid size and a time step of $0.15 \mathrm{~ms}$ were used to carry the 2D finite-difference calculation to a real time of $18 \mathrm{~ms}$.

The far right and bottom boundary conditions were of the transmitting type (Reference 20). The left boundary was, of course, treated as an axisymmetric boundary; i.e., the radial velocity and the shear strain (or stress) were both required to vanish. The surface boundary was subjected to a radially expanding airblast loading, starting at GZ at zero time (Figure 7.2). The airblast shock velocity VS was constant and equal to 3 metres per millisecond. The peak overpressure $P_{\max }$ was also constant and equal to 100 bars. A constant rise time $t_{r}$ and a constant positive phase duration d of $3 \mathrm{~ms}$ and $9 \mathrm{~ms}$, respectively, were used to characterize the shape of the airslap pulse.

The far right and bottom transmitting boundary conditions were applied at velocity points while the left and surface boundary conditions were applied at stress points. 


\subsection{RESULTS}

In this section, selected code stress- and motion-time histories and stress path plots are presented at two intermediate ground ranges: $\mathrm{R}=3.6$ metres and 15.6 metres. These ranges pertain to the stress output; for motion, the corresponding ranges are $R=3.8$ metres and 15.8 metres. The depths are $1.6,3.6$, and 7.6 metres for stresses and $1.8,3.8$, and 7.8 metres for motions.

Figures 7.3 through 7.5 present total vertical stress, total radial stress, total mean normal stress, second invariant of the stress deviation tensor, pore pressure, and effective mean normal stress for the 3.6 -metre range and the $1.6-, 3.6$, and 7.6-metre depths. Figures 7.6 through 7.8 show the corresponding plots for the 15.6-metre range. It is clear from these figures that the effective stresses are very small in comparison with the total stresses and that most of the stress is carried by the pore fluid. This was expected because the material is fully saturated.

Figures 7.9 and 7.10 present the vertical and radial particle velocity and displacement wave forms, respectively, for the 3.8-metre range at the 1.8-, 3.8-, and 7.8-metre depths. Corresponding motion wave forms for the 15.8-metre range are shown in Figures 7.11 and 7.12. The radial velocities and displacements are smaller than the vertical motions because the problem is superseismic.

Stress path plots for the 3.6-metre range and 1.6-, 3.6-, and 7.6metre depths are presented in Figure 7.13. Figure 7.14 depicts the corresponding plots for the 15.6-metre range. 


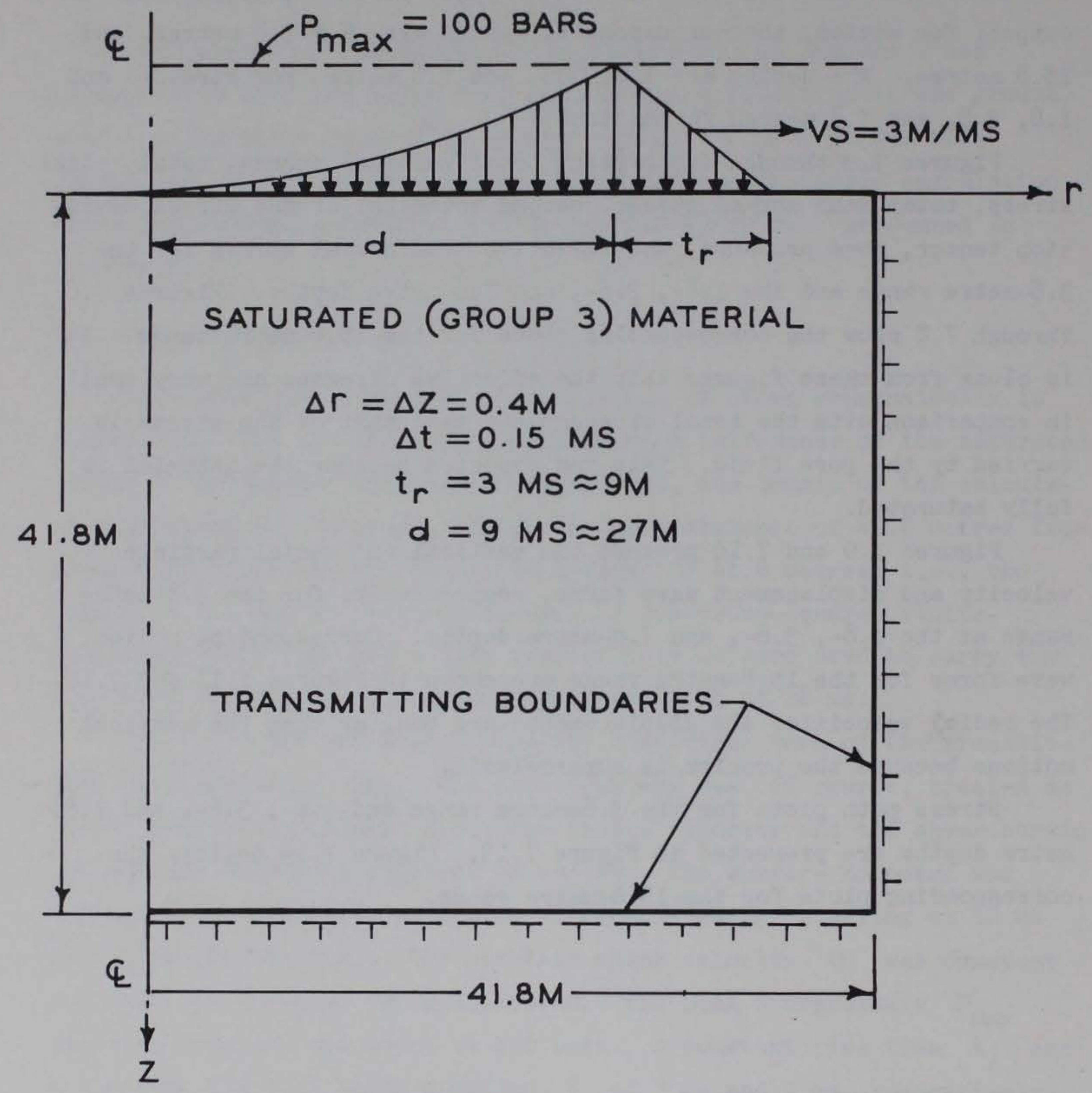

Figure 7.1 Axisymmetric problem geometry. 


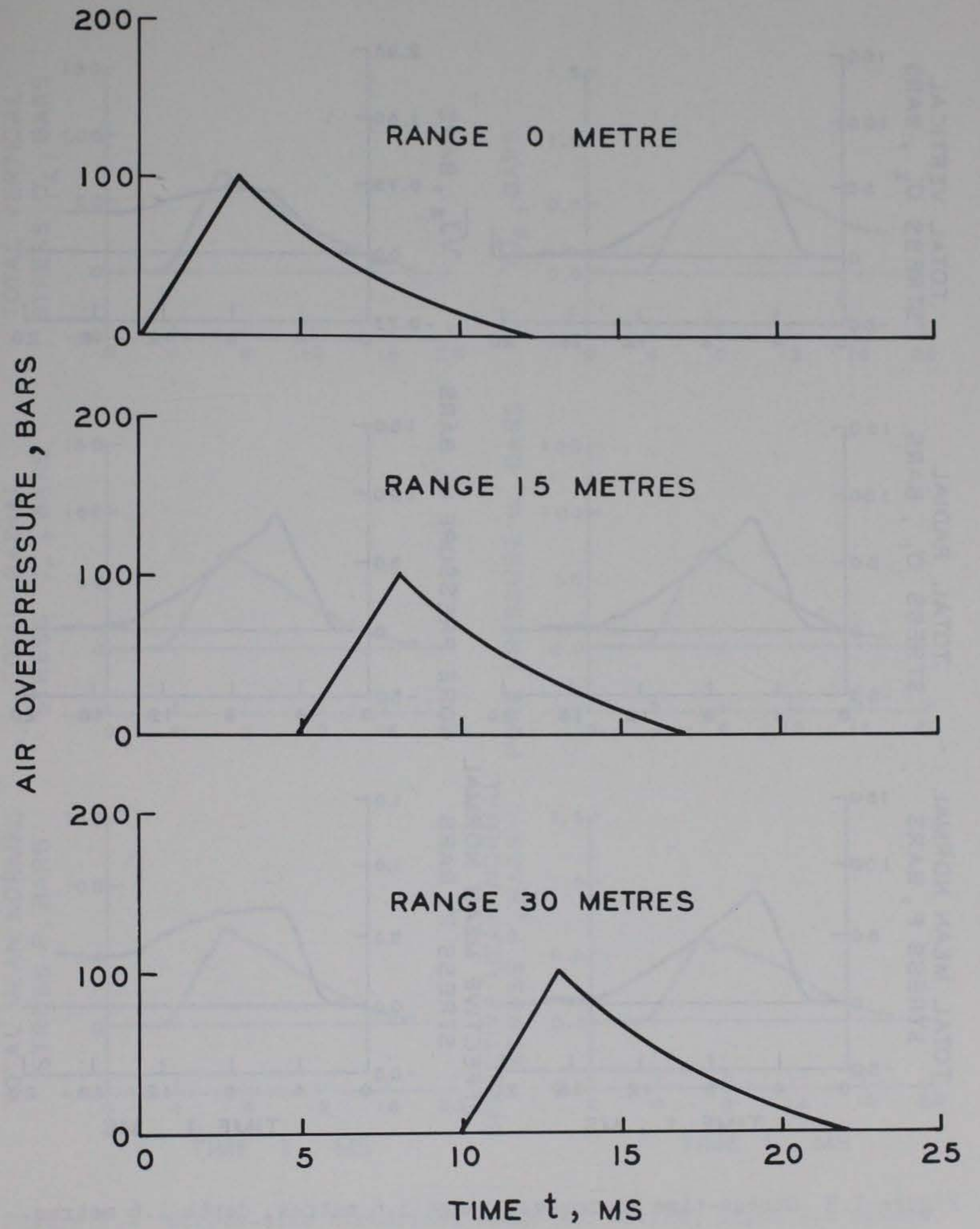

Figure 7.2 Air overpressure versus time. 

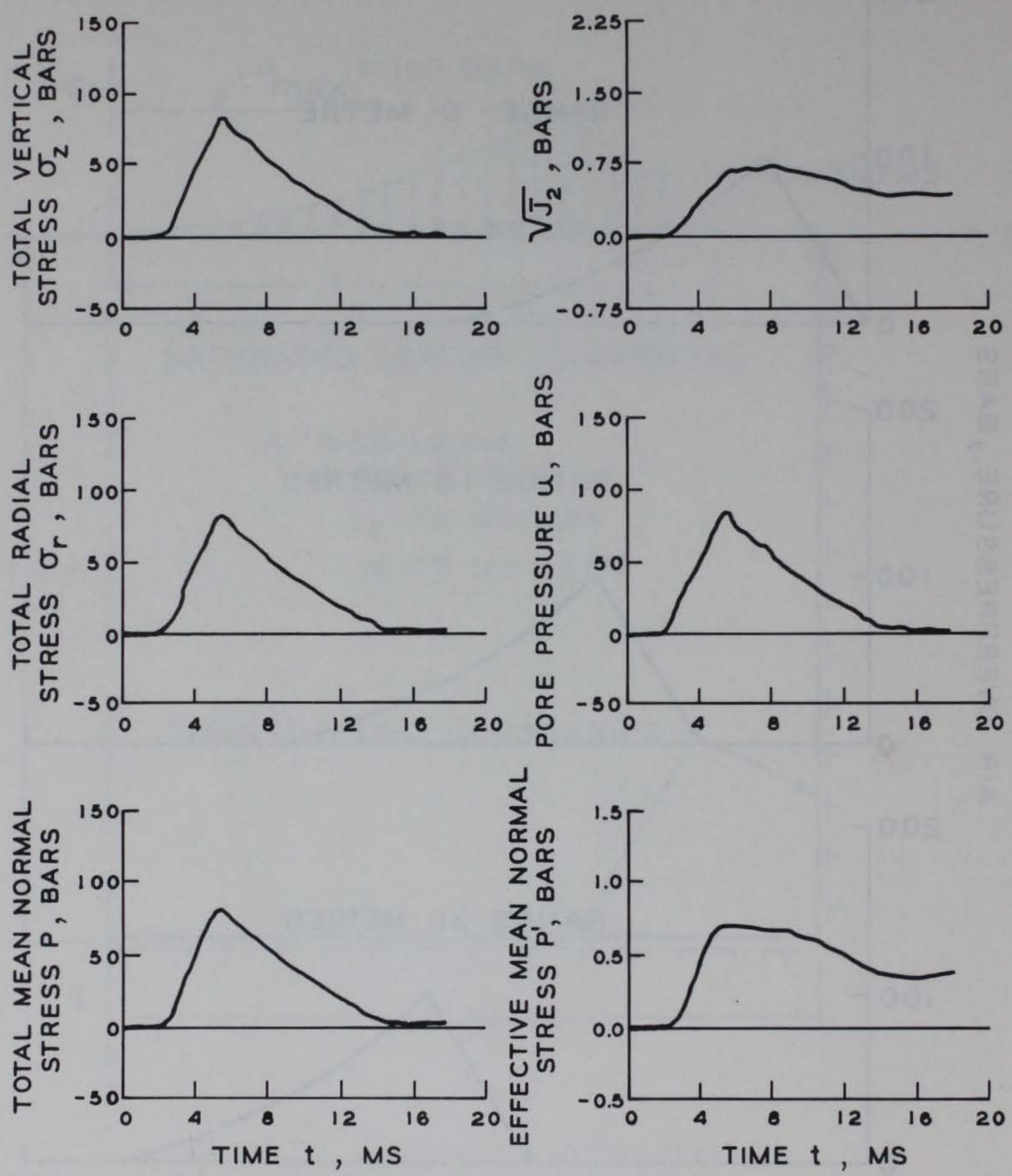

Figure 7.3 Stress-time histories; range 3.6 metres, depth 1.6 metres. 

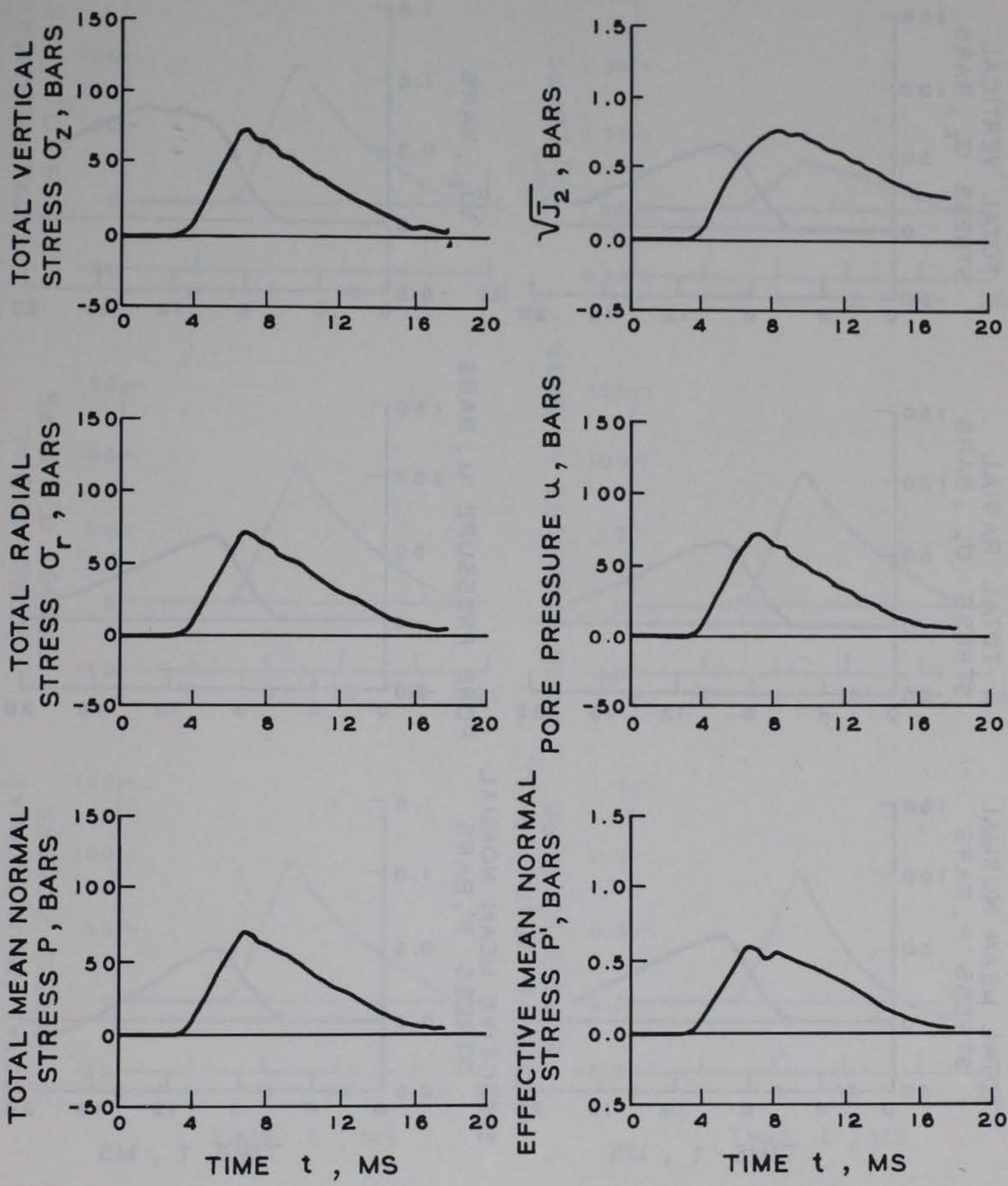

Figure 7.4 Stress-time histories; range 3.6 metres, depth 3.6 metres. 

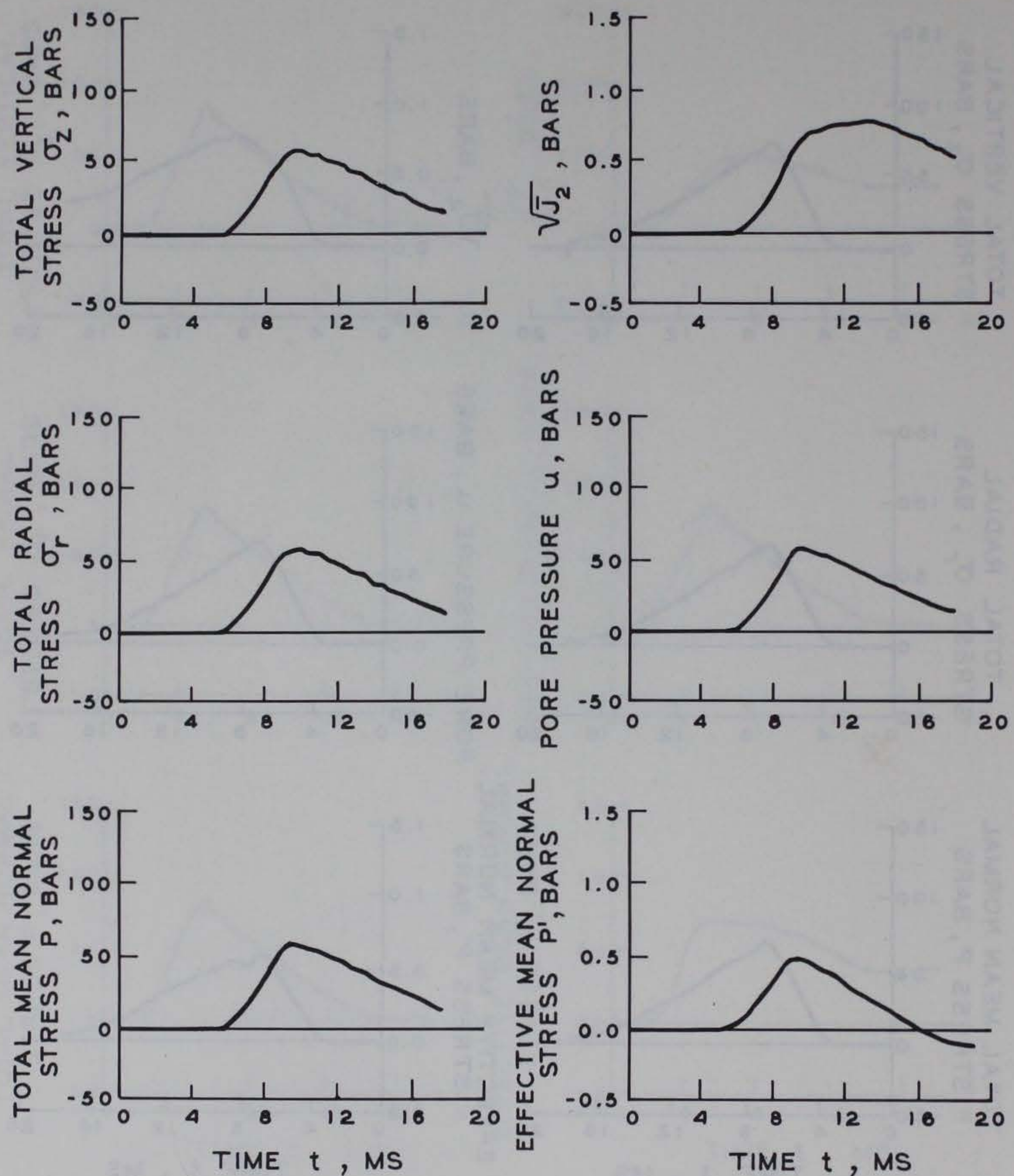

Figure 7.5 Stress-time histories; range 3.6 metres, depth 7.6 metres. 

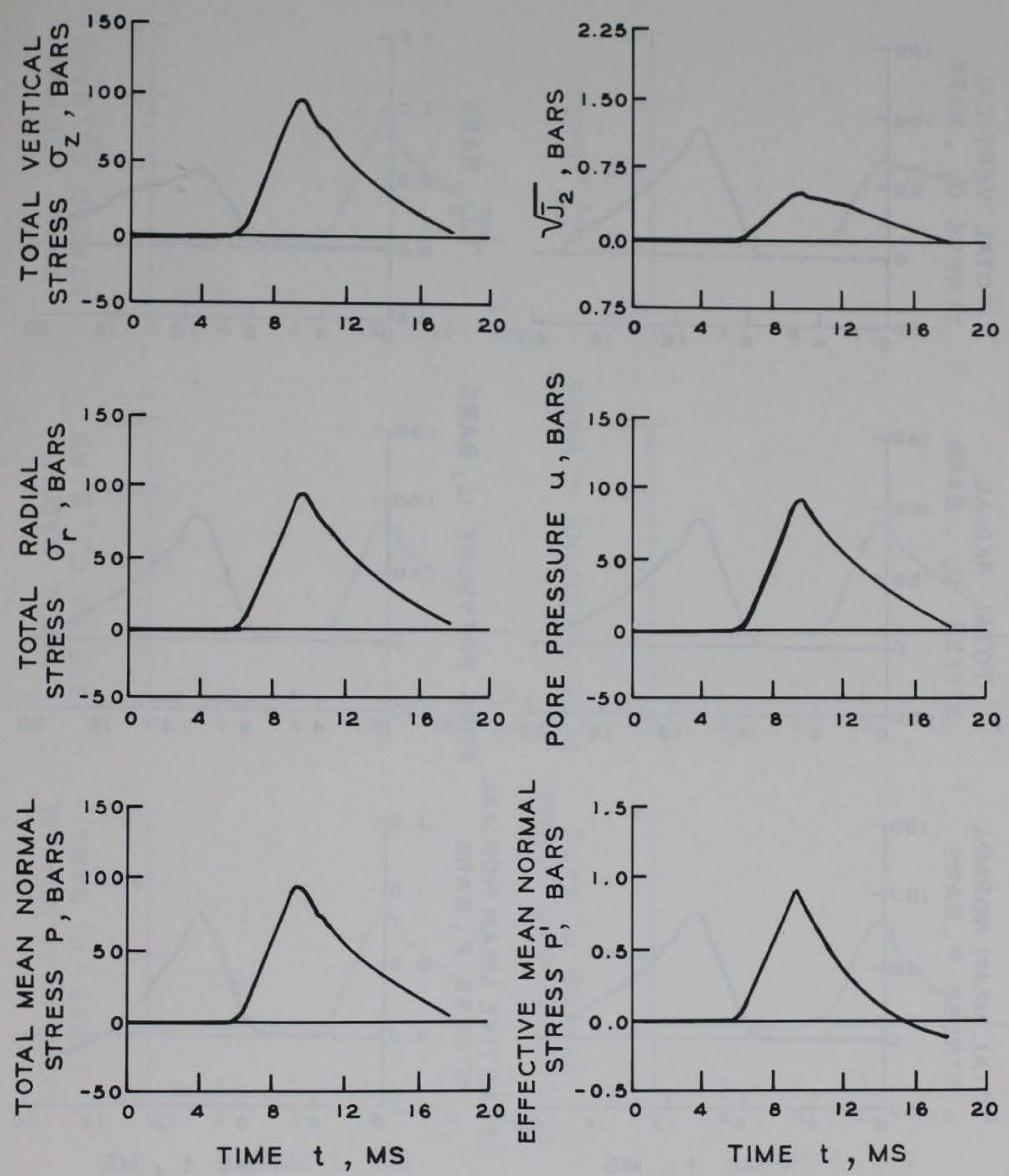

Figure 7.6 Stress-time histories; range 15.6 metres, depth 1.6 metres. 

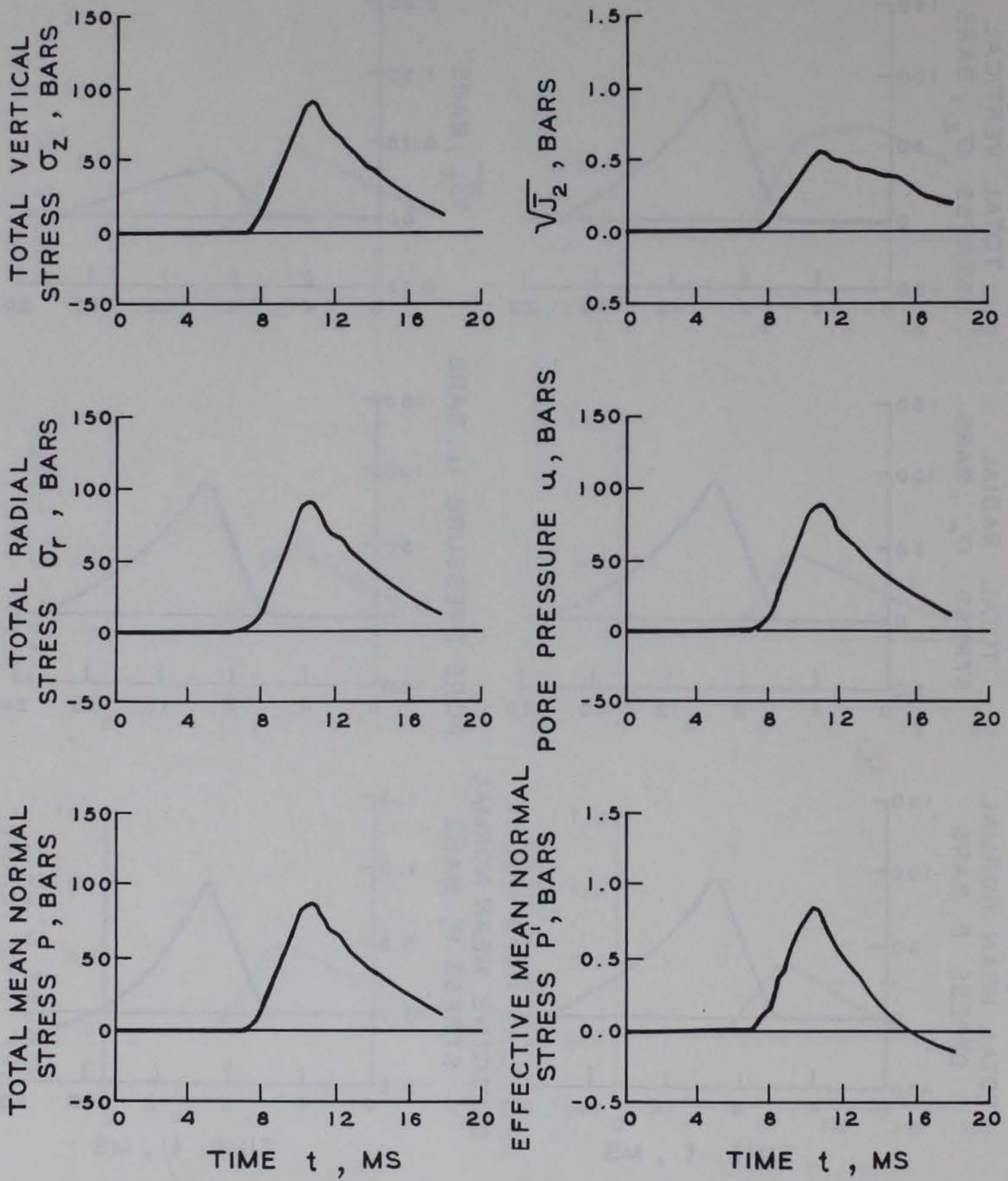

Figure 7.7 Stress-time histories; range 15.6 metres, depth 3.6 metres. 

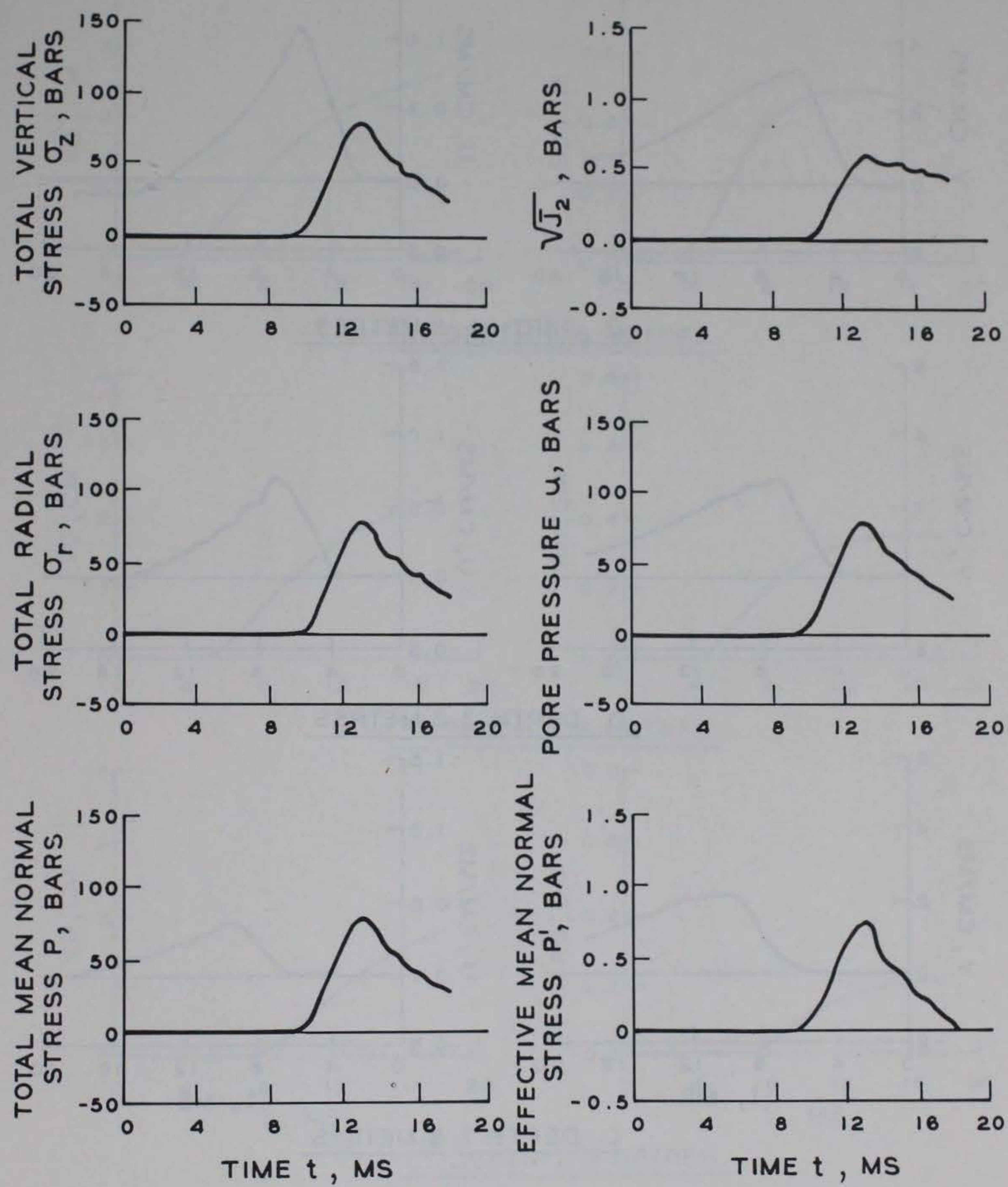

Figure 7.8 Stress-time histories; range 15.6 metres, depth 7.6 metres. 

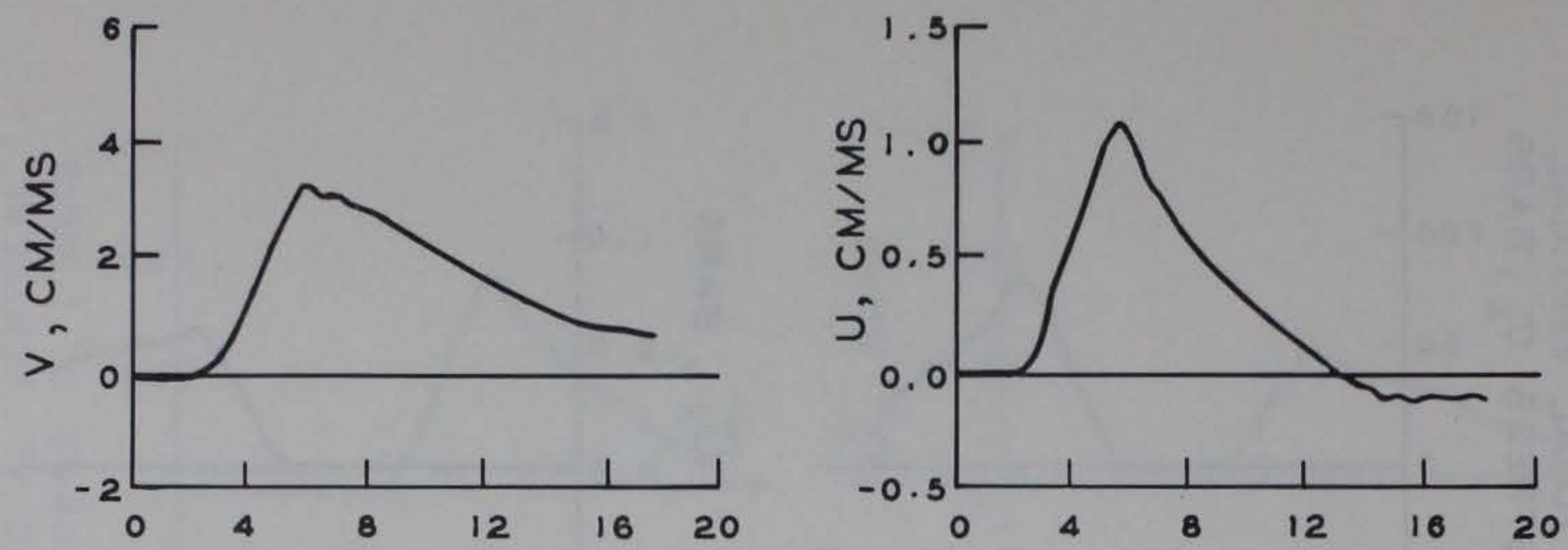

a. DEPTH I . 8 METRES
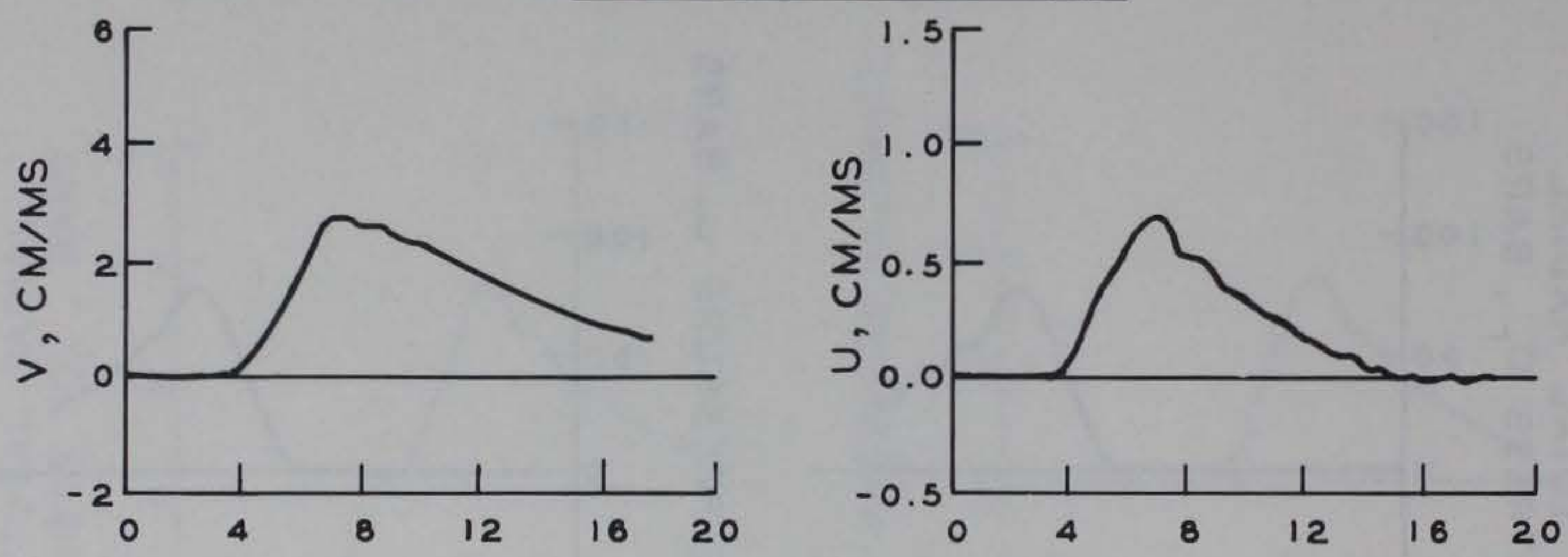

b. DEPTH 3.8 METRES
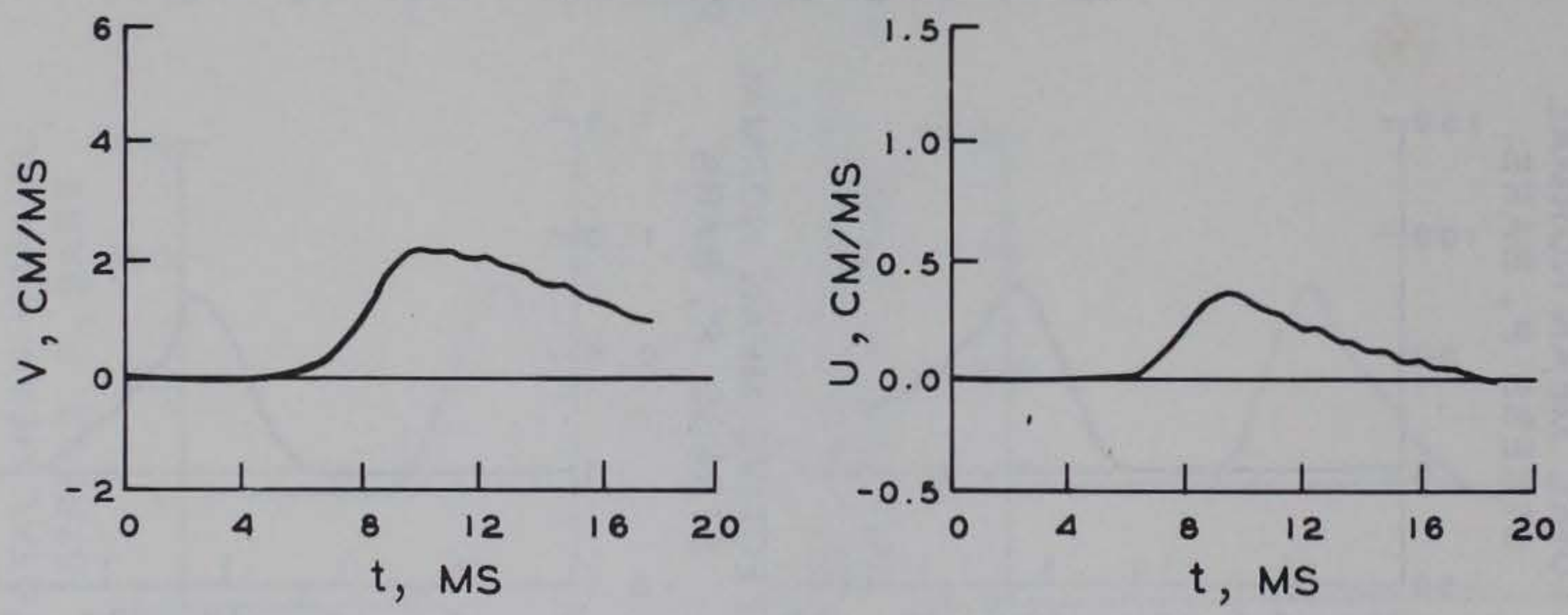

C. DEPTH 7.8 METRES

Figure 7.9 Vertical (V) and radial (U) particle velocity-time histories; range 3.8 metres. 

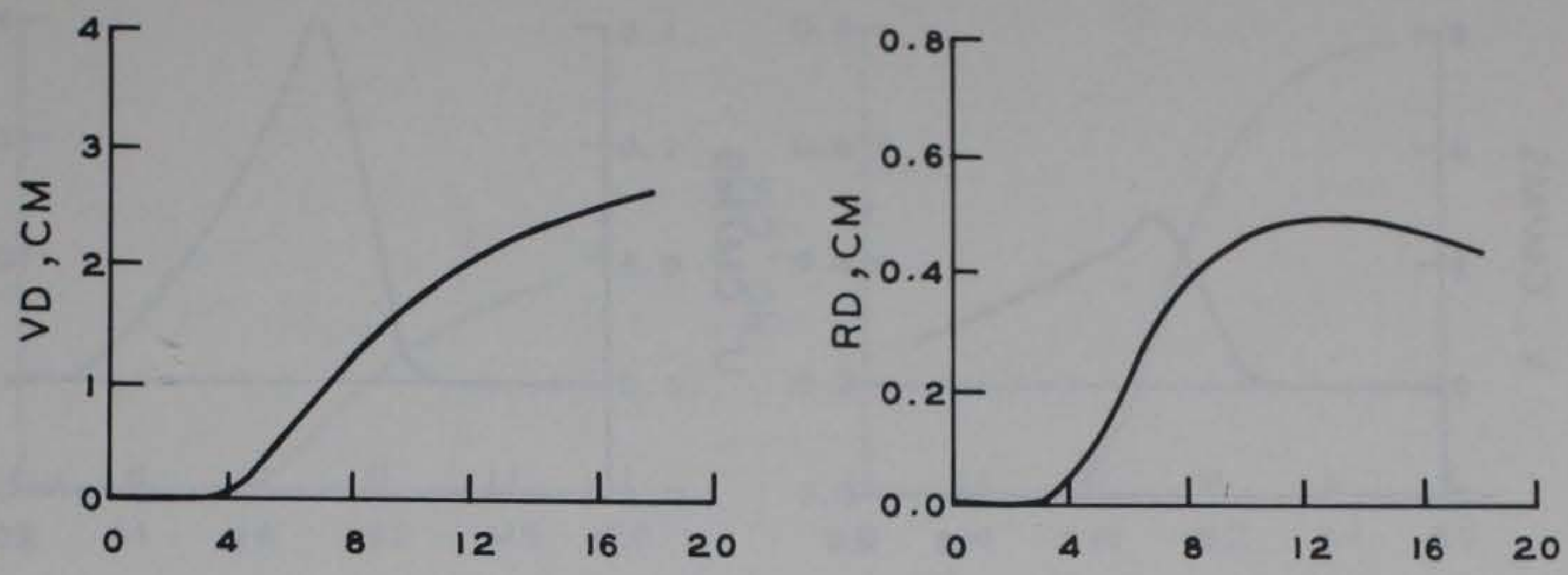

a. DEPTH I.8 METRES
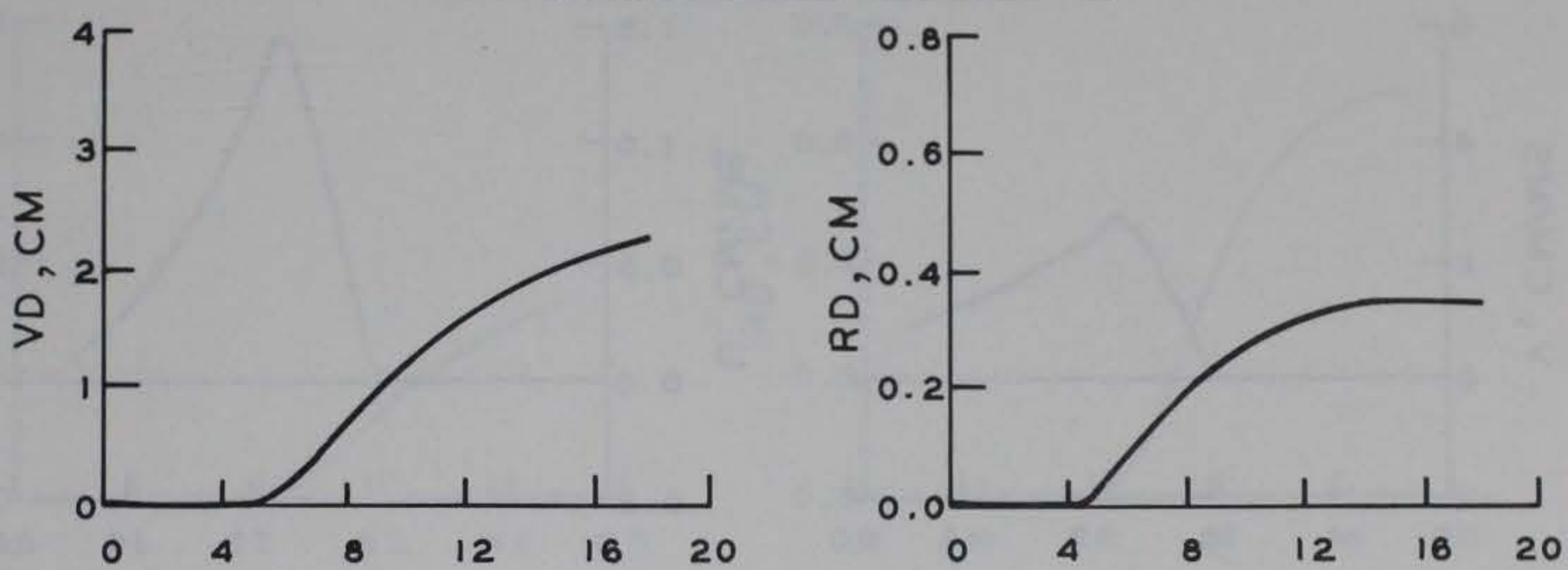

b. DEPTH 3.8 METRES
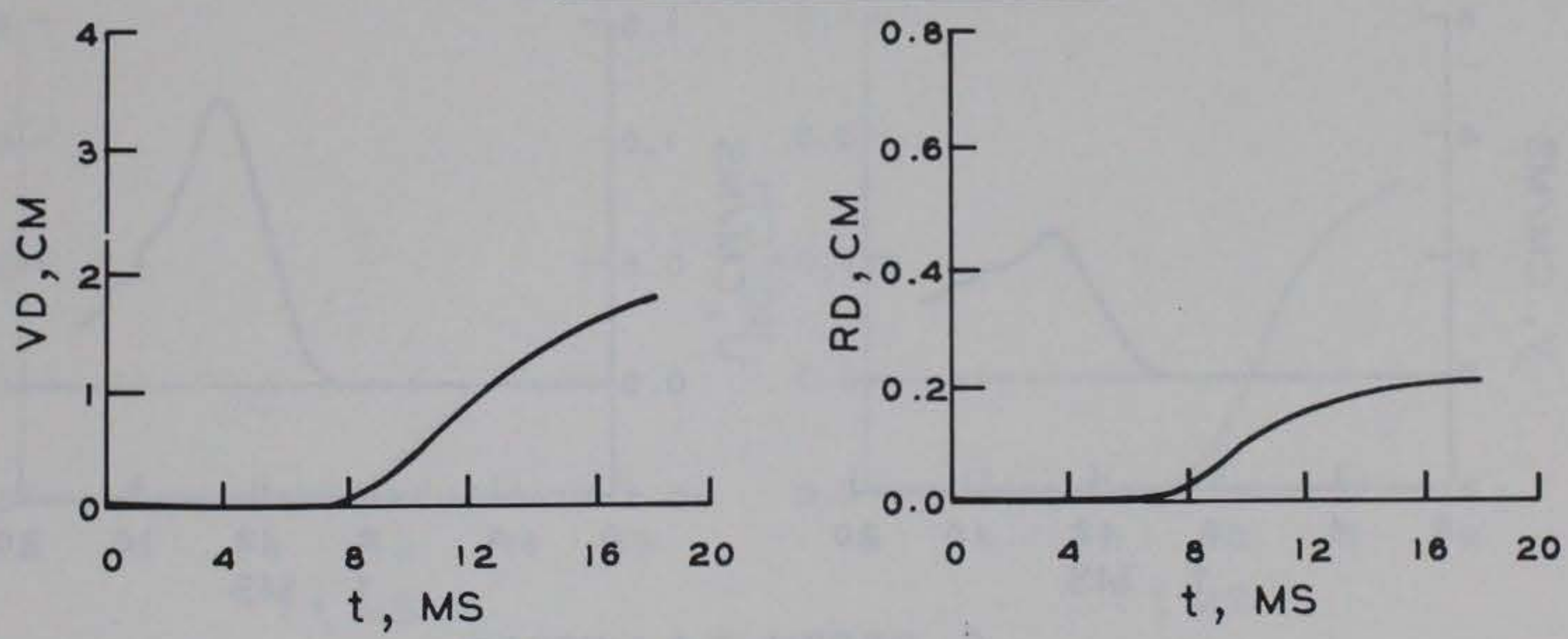

C. DEPTH 7.8 METRES

Figure 7.10 Vertical (VD) and radial (RD) displacement-time histories; range 3.8 metres. 

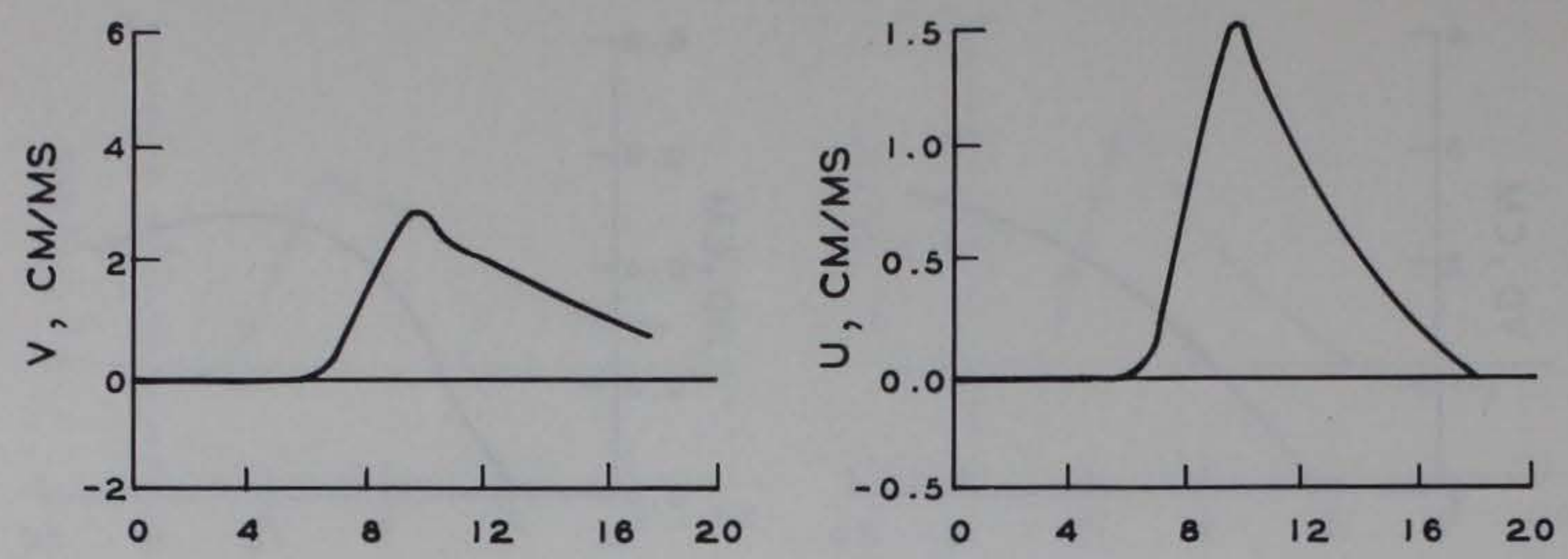

a. DEPTH 1.8 METRES
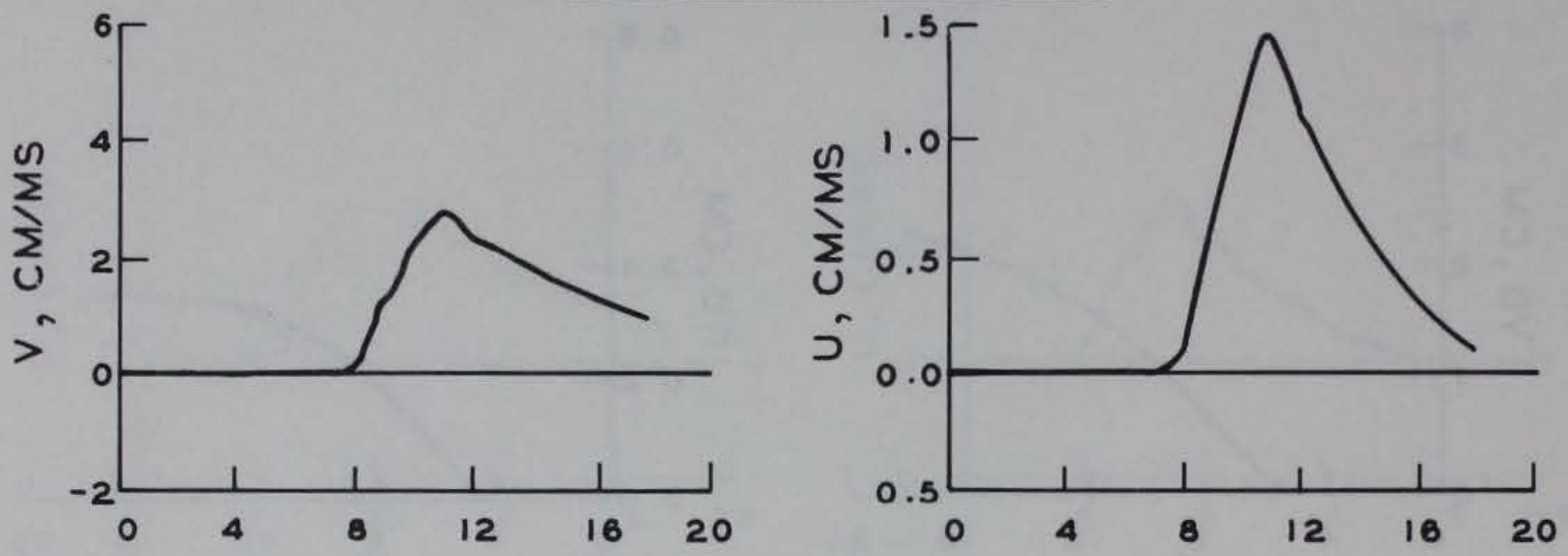

b. DEPTH 3.8 METRES
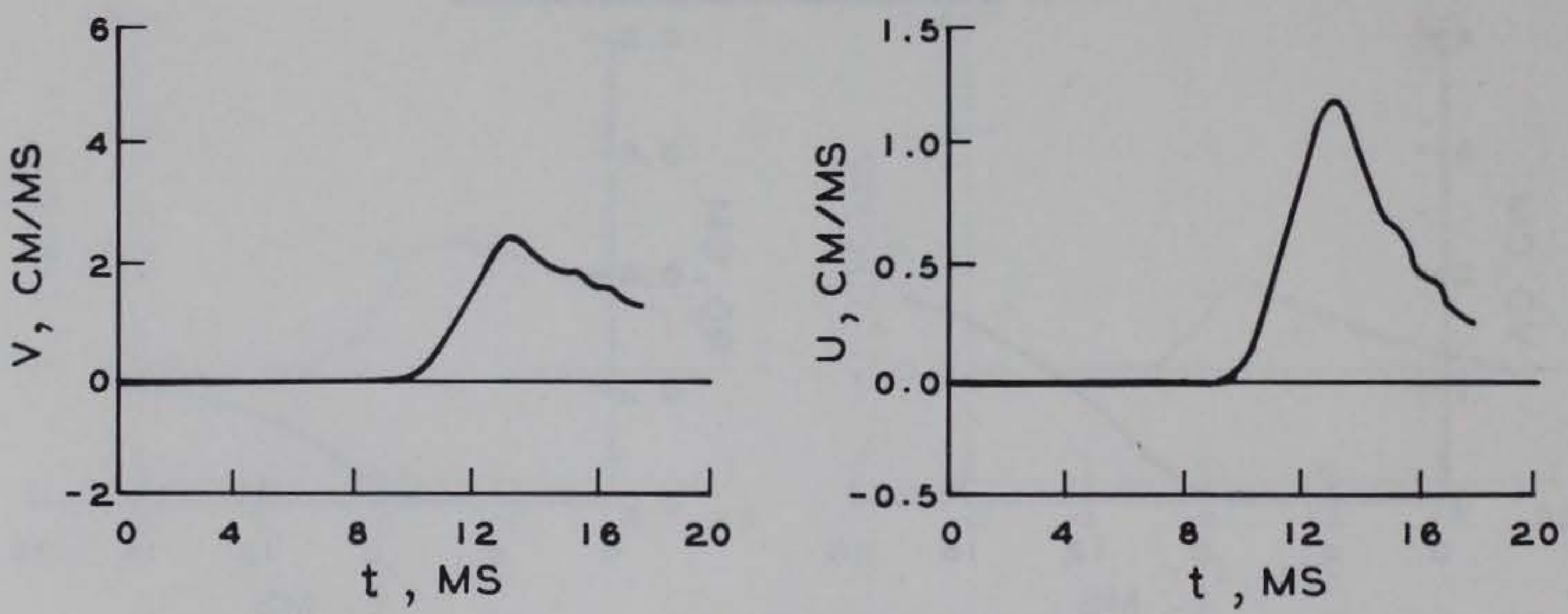

C. DEPTH 7.8 METRES

Figure 7.11 Vertical (V) and radial (U) particle velocity-time histories; range 15.8 metres. 

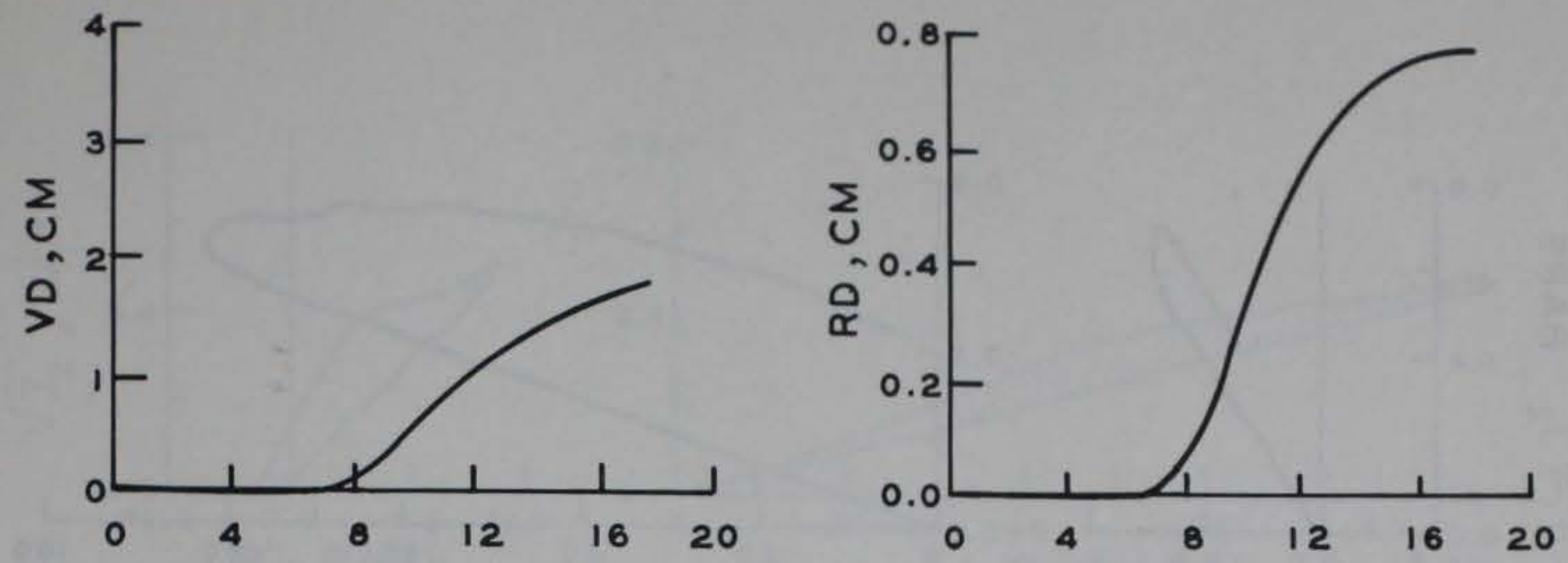

a. DEPTH I.8 METRES
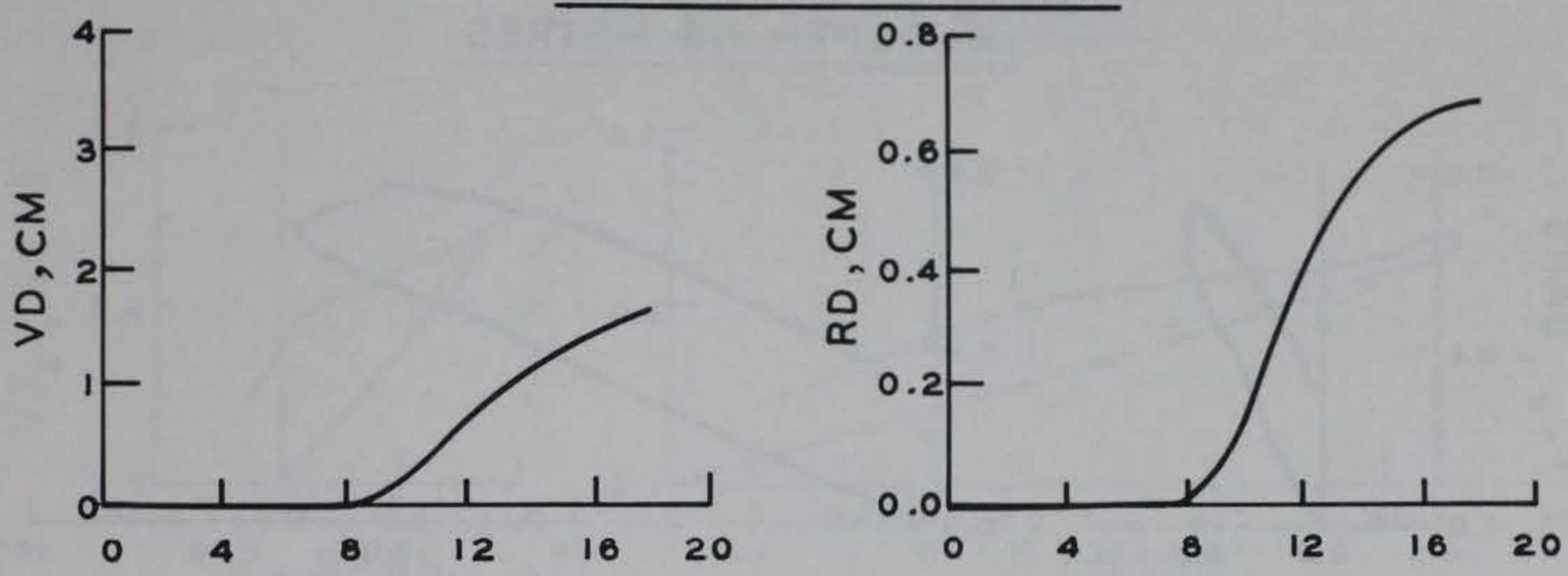

b. DEPTH 3.8 METRES
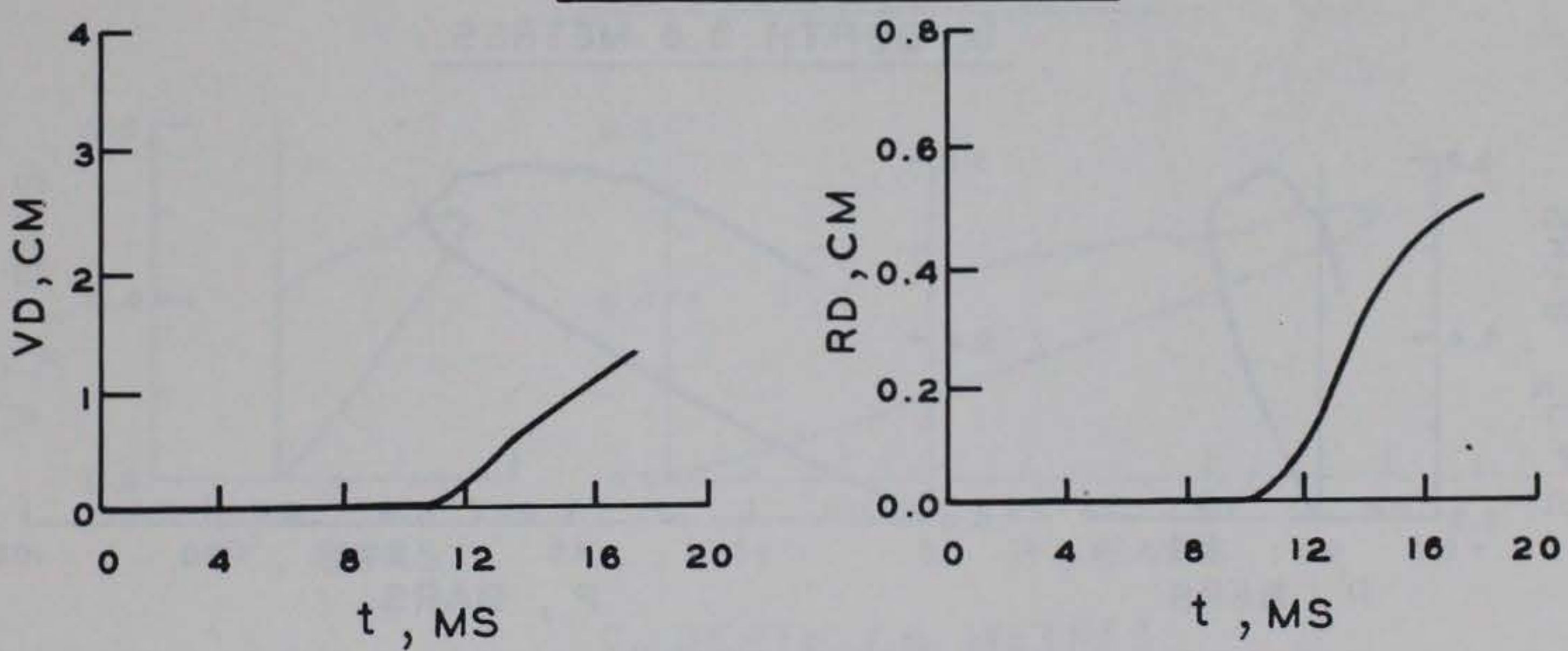

C. DEPTH 7.8 METRES

Figure 7.12 Vertical (VD) and radial (RD) displacement-time histories; range 15.8 metres. 

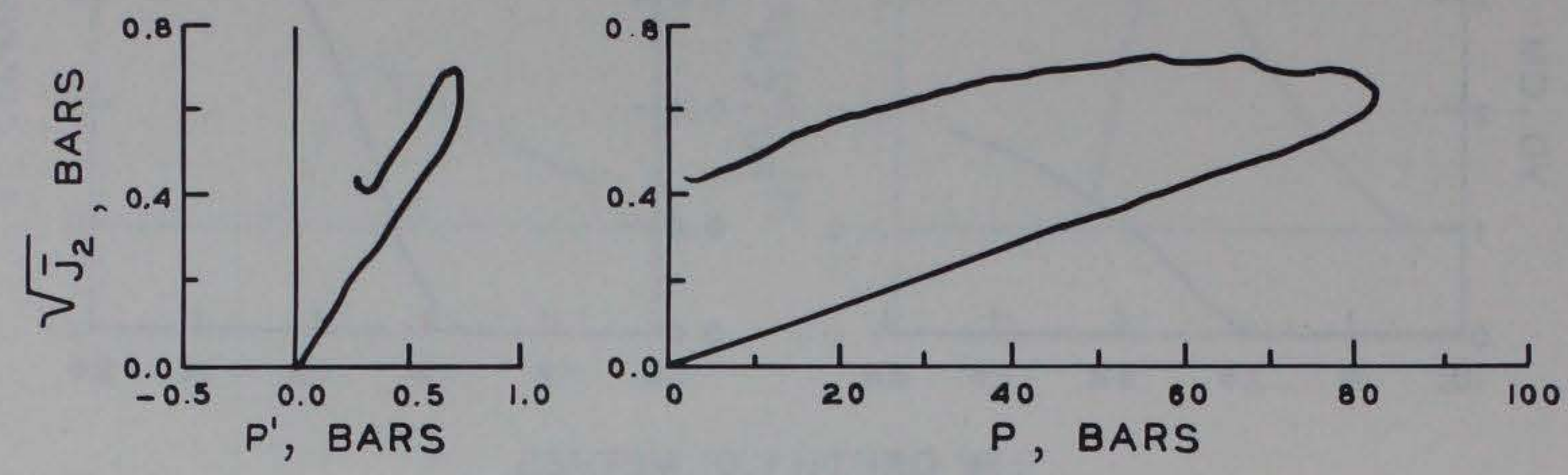

a. DEPTH 1.6 METRES
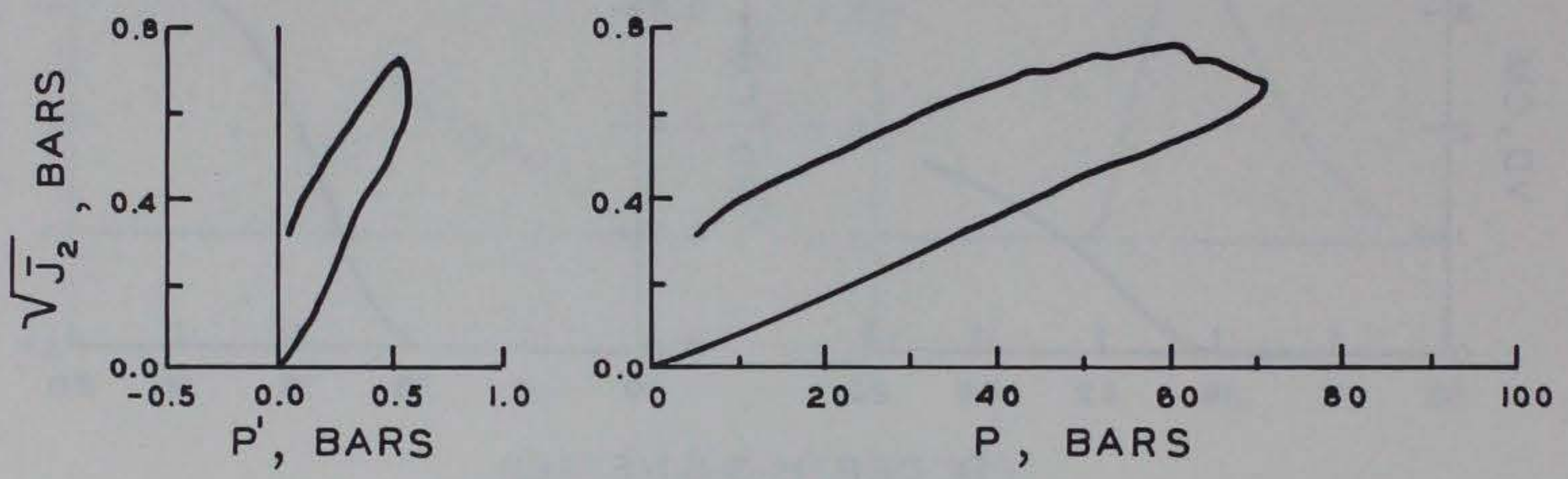

b. DEPTH 3.6 METRES
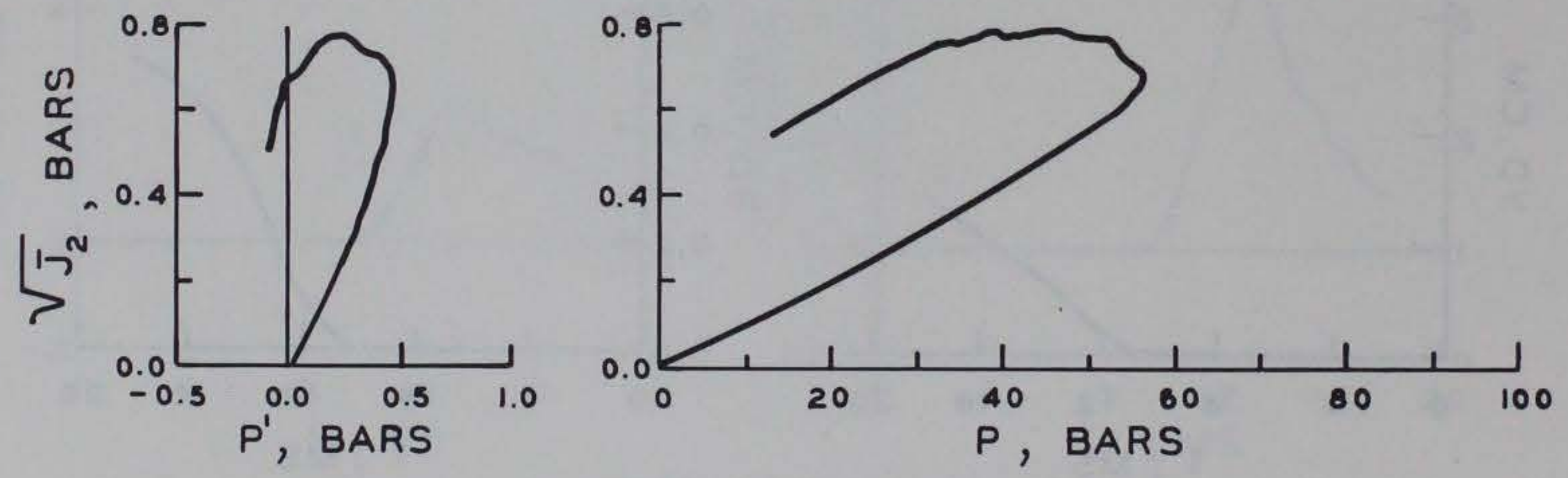

C. DEPTH 7.6 METRES

Figure 7.13 Comparison of total and effective stress paths; range 3.6 metres. 

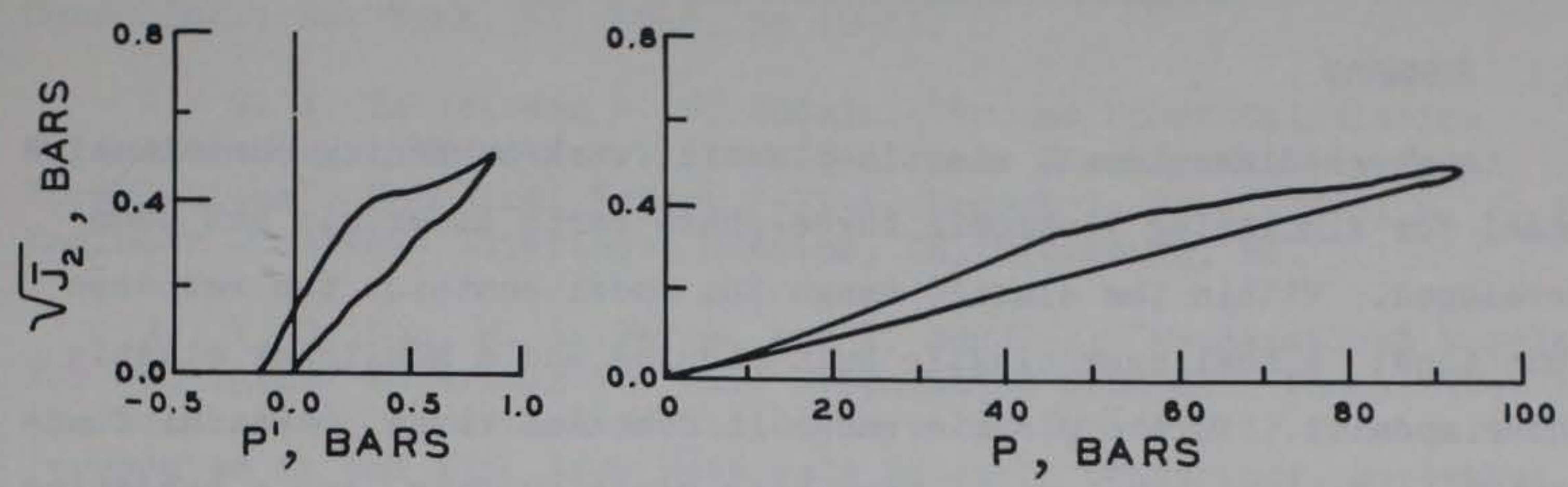

a. DEPTH I. 6 METRES
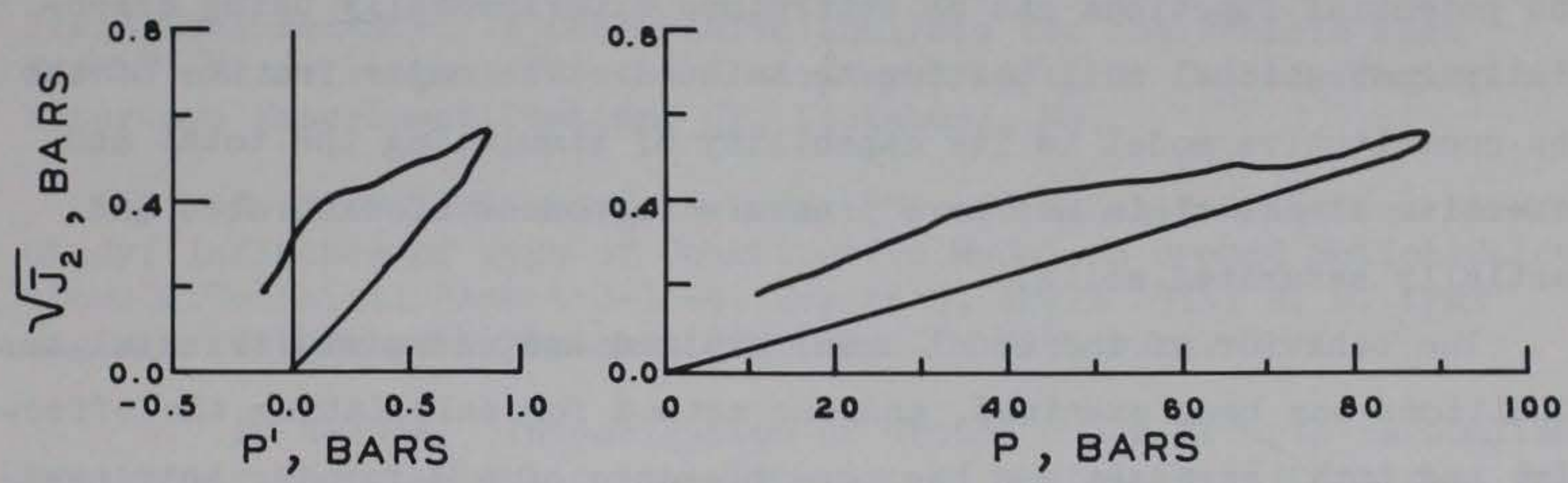

b. DEPTH 3.6 METRES
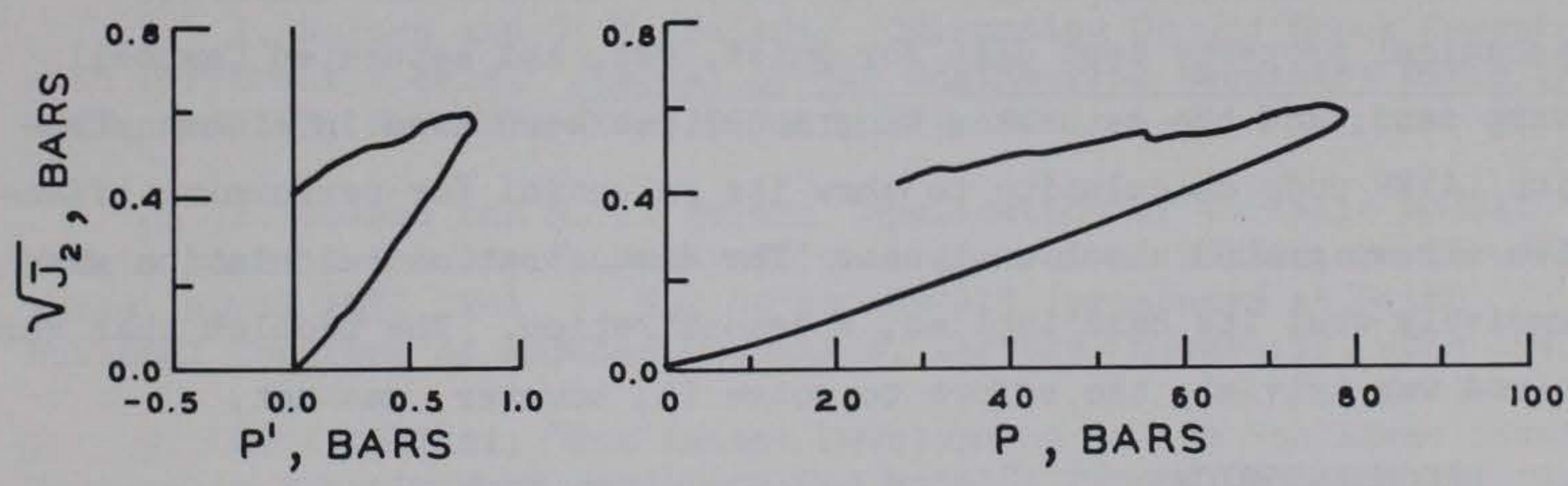

\section{DEPTH 7.6 METRES}

Figure 7.14 Comparison of total and effective stress paths; range 15.6 metres. 
CHAPTER 8

SUMMARY AND RECOMMENDATIONS

\subsection{SUMMARY}

A three-dimensional, elastic-plastic, work-hardening constitutive model for simulating isotropic three-phase earth materials has been developed. Within the elastic range the model contains two response functions: a nonlinear elastic bulk modulus and a nonlinear elastic shear modulus. In the plastic range it contains three potential functions: a failure envelope, a hardening yield surface, and a hardening function. The numerical values of the coefficients in these response and potential functions can be determined experimentally using essentially conventional soil testing techniques. The major feature of the new constitutive model is its capability of simulating the total and effective stress-stain and pore pressure responses of saturated and partially saturated soils.

The behavior of the model under drained and undrained triaxial test conditions has been examined, and the method for calculating the effective and total stresses and the pore pressure of a deforming multiphase soil subjected to given total stress or strain paths has been explained.

The new model has been fit to a set of drained and undrained mechanical property test data for moist, wet, and saturated Campbell Swamp sand; and the saturated sand model has been used in a demonstration LAYER code calculation to show its potential for performing effective stress ground shock analyses. The demonstration calculation was precisely what its name implied, a demonstration. The problem that was solved was trivial; the effort to solve it, however, was not.

\subsection{RECOMMENDATIONS}

It is recommended that the new model be verified through calculations against a wide variety of field events executed at wet sites. These efforts should also include calculations with current single-phase (total stress) constitutive models so that the benefits of effective stress ground shock analyses can be assessed. 


\section{REFERENCES}

1. D. W. Taylor; Fundamentals of Soil Mechanics; John Wiley and Sons, Inc.; New York, NY; 1948; pp 12-21.

2. G. Y. Baladi and P. F. Hadala; "Ground Shock Calculation Parameter Study; Effect of Various Nonlinear Elastic-Plastic Model Formulations"; Technical Report S-71-4, Report 1, April 1971; U. S. Army Engineer Waterways Experiment Station, CE, Vicksburg, MS.

3. I. Nelson, M. L. Baron, and I. Sandler; "Mathematical Models for Geological Materials for Wave Propagation Studies"; Shock Waves and the Mechanical Properties of Solids; Syracuse University Press; 1971 (presented at the 17th Army Materials Research Conference, September 1970).

4. J. S. Zelasko and G. Y. Baladi; "Free-Field Predictions Versus Field Measurements: A Comparative Analysis for the Prairie Flat Event"; Miscellaneous Paper S-71-6, March 1971; U. S. Army Engineer Waterways Experiment Station, CE, Vicksburg, MS.

5. G. Y. Baladi and I. Nelson; "Ground Shock Calculation Parameter Study; Influence of Type of Constitutive Model on Ground Motion Calculations"; Technical Report S-71-4, Report 3, April 1974; U. S. Army Engineer Waterways Experiment Station, CE, Vicksburg, MS.

6. I. Nelson; "Investigation of Ground Shock Effects in Nonlinear Hysteretic Media; Modeling the Behavior of a Real Soil"; Contract Report S-68-1, Report 2, July 1970: U. S. Army Engineer Waterways Experiment Station, CE, Vicksburg, MS.

7. I. Nelson and G. Y. Baladi; "Outrunning Ground Shock Computed with Different Models," Journal of the Engineering Mechanics Division; ASCE, Vol 103, No. EM3, June 1977; pp 377-393.

8. I. Nelson and M. I. Baron; "Application of Variable Moduli Models to Soil Behavior"; International Journal of Solids and Structures, April 1971, Vol. 7, No. 4; pp 399-417 (presented at Sixth National Congress of Applied Mechanics, Harvard University, June 1970).

9. G. Y. Baladi; "The Latest Development in the Nonlinear ElasticNonideally Plastic Work Hardening Cap Model"; Symposium on Plasticity and Soil Mechanics; Cambridge, England; September 1973; pp 51-55.

10. I. S. Sandler, F. L. DiMaggio, and G. Y. Baladi; "Generalized Cap Model for Geological Materials"; Journal of the Geotechnical Engineering Division; ASCE, Vol. 102, No. GT7, Proc Paper 12243, July 1976; pp 683-699. 
11. G. Y. Baladi; "Numerical Implementation of a TransverseIsotropic Inelastic, Work-Hardening Constitutive Model"; Transactions of the 4 th International Conference on Structural Mechanics in Reactor Technology, Vol. M, Methods for Structural Analysis: San Francisco, CA, August 1977.

12. F. L. DiMaggio and I. S. Sandler; "Material Models for Granular Soils"; Journal of the Engineering Mechanics Division; ASCE, Vol. 97, No. EM3; Proc Paper i212; June 1971; pp 935-950.

13. A. Schofield and P. Wroth; Critical State Soil Mechanics; McGraw-Hill; New York, NY; 1968.

14. G. Y. Baladi and B. Rohani; "Liquefaction Potential of Dams and Foundations; Development of an Elastic-Plastic Constitutive Relationship for Saturated Sand"; Research Report S-76-2, Report 3, February 1977; U. S. Army Engineer Waterways Experiment Station, CE, Vicksburg, MS.

15. G. Y. Baladi and B. Rohani; "Liquefaction Potential of Dams and Foundations; Development of a Constitutive Relation for Simulating the Response of Saturated Cohesionless Soil"; Research Report S-76-2, Report 5, August 1978; U. S. Army Engineer Waterways Experiment Station, $\mathrm{CE}$, Vicksburg, MS.

16. K. Terzaghi and R. B. Peck; Soil Mechanics in Engineering Practice; John Wiley and Sons, Inc.; New York, NY, 1948.

17. A. W. Bishop, I. Alpan, G. E. Blight, and I. B. Donald; "Factors Controlling the Strength of Partially Saturated Cohesive Soil"; Proceedings, American Society of Civil Engineers, Research Conference on Shear Strength of Cohesive Soils; 1960; pp 503-505.

18. D. Croney, J. D. Coleman, and W. P. M. Black; "Movement and Distribution of Water in Soil"; Highway Research Board Report 40; 1958, p 226.

19. G. D. Aitchison; "Relationships of Moisture Stress and Effective Stress Functions in Unsaturated Soils"; Pore Pressure and Suction in Soils; London; Butterworth and Co., LTD.

20. G. Y. Baladi; "Ground Shock Calculation Parameter Study; Effects of Various Bottom Boundary Conditions"; Technical Report S-71-4, Report 2, November 1972; U. S. Army Engineer Waterways Experiment Station, CE, Vicksburg, MS.

21. D. C. Drucker; "On Uniqueness in the Theory of Plasticity"; Q. Applied Mathematics, Vol. 14; 1956. 
22. G. H. Handleman, et al.; "On the Mechanical Behavior of Metals in the Strain-Hardening Range"; Q. Applied Mathematics; Vol. 4; 1947; pp 397-407. 


\section{APPENDIX A}

\section{FUNDAMENTAL BASIS OF ELASTIC-PLASTIC CONSTITUTIVE MODELS}

\section{A.I BASIC CONCEPTS FROM CONTINUUM MECHANICS}

From a microscopic point of view, physical bodies are composed of discrete molecules interconnected by internal forces of mutual attraction and repulsion. The concept of stress within a body requires that boundary distances and/or loaded area be large in comparison with distances between molecules and/or the size of the individual molecule. This, in effect, transforms a body composed of discrete molecules into a statistically macroscopic equivalent amenable to mathematical analysis. Since most engineering problems deal with macroscopic phenomena and involve very large boundary distances and loaded areas compared with individual molecules, it appears reasonable and convenient to invoke the mechanics of continua as the basis for analytical consideration of these problems.

The theory of continuous media is built upon two strong foundations: basic balance, and conservation laws and a constitutive theory. The basic balance and conservative laws of any continuum are

1. Conservation of mass

2. Conservation of energy

3. Balance of linear momentum

4. Balance of angular momentum

5. Inadmissibility of decreasing entropy

When thermal effects are neglected and symmetry of the stress tensor is assumed, these basic axioms of continuum mechanics lead to the following continuity equation: ${ }^{1}$

$$
\frac{\partial \rho}{\partial t}+\left(\rho v_{i}\right)_{, i}=0
$$

1 Indices take on a value of 1,2 , or 3 . A repeated index is to be summed over its range. A comma between subscripts represents a derivative. Quantities are referred to rectangular Cartesian coordinates $\mathrm{X}_{i}$. 
and the equations of motion:

$$
\sigma_{i j, j}+F_{i}-\rho a_{i}=0
$$

where

$$
\begin{aligned}
\rho & =\text { mass density } \\
t & =\text { time } \\
v_{i} & =\text { components of velocity vector } \\
\sigma_{i j} & =\sigma_{j i}=\text { symmetrical stress tensor } \\
F_{i} & =\text { components of body force } \\
a_{i} & =\text { components of acceleration vector }
\end{aligned}
$$

Equations A.I and A.2 are called field equations. They constitute four equations that involve ten unknown functions of time and space. Therefore, the system resulting from Equations A.1 and A.2 is indeterminate. These unknown functions are the mass density $p$, the three velocity components $\mathrm{v}_{i}$, and the six independent stress components $\sigma_{i j}$. The body force components $f_{i}$ are known quantities, and the acceleration components $a_{i}$ are expressible in terms of the velocity components $\mathrm{v}_{i}$. To overcome the indeterminacy and make the system complete, six additional expressions relating the ten unknown variables are required. In continuum mechanics such relations are stated by constitutive equations (or material models), which relate stresses to deformation and history of deformation. The difference between constitutive equations and field equations (Equations A.I and A.2) is that the latter contains both space coordinates and time and is applicable to all materials, whereas the former is independent of space coordinates (for homogeneous materials) and represents the intrinsic response of a particular material or class of materials and, as such, is a mathematical idealization of the mechanical behavior of real materials.

The general form of a constitutive equation may be expressed by the following functional form: 


$$
H_{i j}\left(D_{m n}, \Omega_{q p}, \varepsilon_{r s}, \sigma_{k I}, \rho\right)=0
$$

where $\sigma_{k l}$ is the components of stress tensor and the deformation-rate tensor $D_{\mathrm{mn}}$ and the spin tensor $\Omega_{\mathrm{qp}}$ are related to the components of the velocity vector, $v_{i}$, by

$$
D_{m n}=\frac{1}{2}\left(v_{m, n}+v_{n, m}\right)
$$

and

$$
\Omega_{q p}=\frac{l}{2}\left(v_{q, p}-v_{p, q}\right)
$$

and the infinitesimal strain tensor $\varepsilon_{r s}$ is related to the components of the displacement vector $u_{i}$ by

$$
\varepsilon_{r s}=\frac{l}{2}\left(u_{r, s}+u_{s, r}\right)
$$

Equations A.1 through A.3 constitute ten equations involving ten unknown variables. These equations will lead, in conjunction with the kinematic relations given by Equations A. 4 and A.5 and the appropriate boundary conditions, to a complete description for the solution of a boundaryvalue problem.

In general, materials having the same mass and geometry respond differently when subjected to identical external effects. Therefore, a variety of constitutive theories have emerged, each of which describes a limited number of physical phenomena decided on at the outset for a given material. In the following sections the constitutive theory for an elastic-plastic isotropic material is presented.

\section{A.2 GENERAL DESCRIPTION OF ELASTIC-PLASTIC CONSTITUTIVE MODELS}

The basic premise of elastic-plastic constitutive models is the assumption that certain materials are capable of undergoing small plastic (permanent) as well as elastic (recoverable) strains at each 
loading increment. Mathematically, the total strain increment is assumed to be the sum of the elastic and plastic strain increments; i.e.,

$$
d \varepsilon_{i j}=d \varepsilon_{i j}^{E}+d \varepsilon_{i j}^{P}
$$

where

$$
\begin{aligned}
& d \varepsilon_{i j}=\text { components of the total strain increment tensor } \\
& d \varepsilon_{i j}^{E}=\text { components of the elastic strain increment tensor } \\
& d \varepsilon_{i j}^{P}=\text { components of the plastic strain increment tensor }
\end{aligned}
$$

Within the elastic range, the behavior of the material can be described by an elastic constitutive relation of the type

$$
d \varepsilon_{i j}^{E}=C_{i j k l}\left(\sigma_{m n}\right) d \sigma_{k l}
$$

where

$$
\begin{aligned}
& \mathrm{C}_{\mathrm{ijkl}}=\text { material response function } \\
& d \sigma_{\mathrm{kl}}=\text { components of stress increment tensor }
\end{aligned}
$$

The behavior of the material in the plastic range can be described within the framework of the generalized incremental theory of plasticity. The mathematical basis of the theory was established by Drucker (Reference 21), ${ }^{2}$ who introduced the concept of material stability, which has the following implications:

1. Yield surface (loading function) should be convex in stress space.

2. Yield surface and plastic potential should coincide (which results in an "associated" flow rule).

References cited in this appendix are included in the References at the end of the main text. 
3. Work "softening" should not occur.

These three conditions can be summarized mathematically by the following inequality

$$
d \sigma_{i j} d \varepsilon_{i j}^{P} \geq 0
$$

These conditions allow considerable flexibility in the choice of the form of the loading function, 6, for the model, which serves as both a yield surface and the plastic potential. In general, the yield surface may be expressed as

$$
\sigma\left(\sigma_{i j}, k\right)=0
$$

and for isotropic materials the yield surface may be expressed, for example, as

$$
6\left(J_{1}, \sqrt{\bar{J}_{2}}, k\right)=0
$$

where

$$
\begin{aligned}
J_{1} & =\sigma_{n n}=\text { first invariant of the stress tensor } \\
\bar{J}_{2} & =\frac{1}{2} S_{i j} S_{i j}=\text { second invariant of the stress deviation tensor } \\
S_{i j} & =\sigma_{i j}-\left(J_{1} / 3\right) \delta_{i j}=\text { stress deviation tensor } \\
\delta_{i j} & =\text { Kronecker delta }= \begin{cases}1 & i=j \\
0 & i \neq j\end{cases} \\
k & =\text { a hardening parameter }
\end{aligned}
$$

The hardening parameter, $\kappa$, generally can be taken to be a function of the plastic strain tensor, $\varepsilon_{i j}^{P}$. The yield surface of Equation A.9 or A.10 may expand or contract as $K$ increases or decreases, respectively (Figure A.1). 
Conditions 1 through 3 above, taken in conjunction with Equation A.9 or A.10, result in the following plastic flow rule for isotropic materials :

$$
d \varepsilon_{i j}^{P}=\left\{\begin{array}{lll}
d \lambda \frac{\partial f}{\partial \sigma_{i j}} & \text { if } & \sigma=0 \\
0 & \text { if } & \sigma<0
\end{array}\right.
$$

where $\mathrm{d} \lambda$ is a positive scalar factor of proportionality, which is nonzero only when plastic deformations occur and is dependent on the particular form of the loading function.

\section{A.2.1 Elastic Strain Increment Tensor}

For isotropic elastic materials, the strain increment tensor (Equation A.7) takes the following form

$$
d \varepsilon_{i j}^{E}=\frac{d J_{1}}{9 K} \delta_{i, j}+\frac{1}{2 G} d S_{i j}
$$

where

$$
\begin{aligned}
& \mathrm{K}=\text { elastic bulk modulus } \\
& \mathrm{G}=\text { elastic shear modulus }
\end{aligned}
$$

The bulk and shear moduli can be functions of the invariants of the stress tensor. Accordingly, it is assumed that $\mathrm{K}=\mathrm{K}\left(\mathrm{J}_{1}, \bar{J}_{2}, \bar{J}_{3}\right)$ and $G=G\left(J_{1}, \bar{J}_{2}, \bar{J}_{3}\right)$ where $\bar{J}_{3}$ is the third invariant of the stress deviation tensor. Equation A.12 can be written in terms of the hydrostatic and deviatoric components of the strain and stress increment tensors; i.e.,

$$
\begin{aligned}
d \varepsilon_{k \mathrm{k}}^{E} & =\frac{1}{3 \mathrm{~K}\left(\mathrm{~J}_{1}, \bar{J}_{2}, \bar{J}_{3}\right)} d J_{1} \\
d e_{i j}^{E} & =\frac{1}{2 G\left(J_{1}, \bar{J}_{2}, \bar{J}_{3}\right)} d S_{i j}
\end{aligned}
$$


where

$$
\begin{aligned}
& d \varepsilon_{k k}^{E}=\text { increment of elastic volumetric strain } \\
& d e_{i j}^{E}=\text { elastic strain deviation increment tensor }
\end{aligned}
$$

In order not to generate energy or hysteresis within the elastic range, the elastic behavior of the model must be path independent. The material should then possess a positive definite elastic internal energy function $\bar{W}$ which is independent of stress path. The strain energy function can be written as

$$
\begin{aligned}
\bar{W} & =\int_{0}^{\varepsilon_{i j}} \sigma_{i j} d \varepsilon_{i j} \\
& =\int_{0}^{\sigma_{i j}}\left(S_{i j}+\frac{1}{3} J_{1} \delta_{i j}\right)\left[\frac{d J_{1}}{9 K\left(J_{I}, \bar{J}_{2}, \bar{J}_{3}\right)} \delta_{i j}+\frac{d S_{i j}}{2 G\left(J_{1}, \bar{J}_{2}, \bar{J}_{3}\right)}\right] \\
& =\int_{0}^{I} \frac{J_{1}}{9 \mathrm{~K}\left(J_{1}, \bar{J}_{2}, \bar{J}_{3}\right)} d J_{1}+\int_{0}^{i j} \frac{1}{2 G\left(J_{1}, \bar{J}_{2}, \bar{J}_{3}\right)} S_{i j} d S_{i j} \\
& =\int_{0}^{I} \frac{d\left(J_{1}\right)^{2}}{18 K\left(J_{1}, \bar{J}_{2}, \bar{J}_{3}\right)}+j_{0}^{2} \frac{d \bar{J}_{2}}{2 G\left(J_{1}, \bar{J}_{2}, \bar{J}_{3}\right)}
\end{aligned}
$$

In order for $\bar{W}$ to be independent of stress path, the integrals in Equation A.14 have to depend only on the current values of $J_{1}$ and $\bar{J}_{2}$. Therefore, the bulk and shear moduli have, to be expressed as

$$
\begin{aligned}
& K=K\left(J_{1}\right) \\
& G=G\left(\bar{J}_{2}\right)
\end{aligned}
$$


Further, $K$ and $G$ must always be positive. Since during elastic deformation the hardening parameter $(\kappa)$ is constant, the bulk and shear moduli can also be expressed as

$$
\begin{aligned}
& K=K\left(J_{1}, K\right) \\
& G=G\left(\bar{J}_{2}, K\right)
\end{aligned}
$$

\section{A.2.2 Plastic Strain Increment Tensor}

The plastic strain increment tensor is given by Equation A.ll where the loading function $f$ is given by Equation A.9 or A.10. The hardening parameter in Equation A.9 or A.10 could be taken as being equal to the plastic volumetric strain $\varepsilon_{k k}^{P}$; thus

$$
\kappa=\varepsilon_{k k}^{P}
$$

The use of Equation A.17 will allow the yield surface to expand as well as to contract (Figure A.I). The plastic loading criteria for the function $\delta$ are given as

$$
\frac{\partial f}{\partial \sigma_{i j}} d \sigma_{i j} \begin{cases}>0 & \text { for loading } \\ =0 & \text { for neutral loading } \\ <0 & \text { for unloading }\end{cases}
$$

Because $d \varepsilon_{i . j}^{P}=0$ during unloading or neutral loading, as well as for $b<0$, Equations A.12 and/or A.13 are used to determine the purely elastic strain changes. The prescription that neutral loading produces no plastic strain is called the continuity condition. Its satisfaction leads to coincidence of the elastic and plastic constitutive laws during neutral loading (References 21 and 22 ).

Like the elastic behavior, the plastic stress-strain relation can be expressed in terms of the hydrostatic and deviatoric components of 
strain. Applying the chain rule of differentiation to the right-hand side of Equation A.1l yields

$$
d \varepsilon_{i, j}^{P}=d \lambda\left(\frac{\partial f}{\partial J_{1}} \frac{\partial J_{1}}{\partial \sigma_{i, j}}+\frac{\partial f}{\partial \sqrt{J_{2}}} \frac{\partial \sqrt{J_{2}}}{\partial \sigma_{i j}}\right)
$$

or

$$
d \varepsilon_{i j}^{P}=d \lambda\left(\frac{\partial f}{\partial J_{1}} \delta_{i j}+\frac{1}{2 \sqrt{J_{2}}} \frac{\partial f}{\partial \sqrt{J_{2}}} S_{i j}\right)
$$

Multiplying both sides of Equation A.19 by $\delta_{i j}$ gives

$$
d \varepsilon_{k k}^{P}=3 d \lambda \frac{\partial f}{\partial J_{1}}
$$

The deviatoric component of the plastic strain increment tensor $d_{i j}^{P}$ can be written as

$$
\mathrm{de}_{i j}^{\mathrm{P}}=d \varepsilon_{i j}^{\mathrm{P}}-\frac{1}{3} d \varepsilon_{k k}^{P} \delta_{i, j}
$$

Substitution of Equations A.19 and A.20 into Equation A.21 yields

$$
d e_{i j}^{P}=\frac{d \lambda}{2 \sqrt{J_{2}}} \frac{\partial f}{\partial{\sqrt{J_{2}}}_{2}} S_{i, j}
$$

In order to use Equation A.19 or Equations A.20 and A.22, the proportionality factor $\mathrm{d} \lambda$ must be determined. This can be accomplished in the following manner. From Equations A.10 and A.17 the total derivative of 6 becomes

$$
a f=\frac{\partial f}{\partial J_{1}} d J_{1}+\frac{1}{2 \sqrt{J_{2}}} \frac{\partial \hbar}{\partial \sqrt{J}_{2}} S_{i j} d S_{i j}+\frac{\partial f}{\partial \varepsilon_{k k}^{P}} d \varepsilon_{k k}^{P}=0
$$


In view of Equations A.13 and A.20, Equation A.23 becomes

$$
3 K d \varepsilon_{k k}^{E} \frac{\partial f}{\partial J_{1}}+\frac{G d e_{i, j}^{E}}{\sqrt{J_{2}}} \frac{\partial f}{\partial \sqrt{J_{2}}} S_{i . i}+3 d \lambda \frac{\partial f}{\partial J_{1}} \frac{\partial f}{\partial \varepsilon_{k k}^{P}}=0
$$

Substituting Equation A.6 into Equation A.24 results in

$$
3 K\left(d \varepsilon_{k k}-d \varepsilon_{k k}^{P}\right) \frac{\partial f}{\partial J_{1}}+\frac{G}{\sqrt{J_{2}}}\left(d e_{i j}-d e_{i j}^{P}\right) \frac{\partial f}{\partial \sqrt{J_{2}}} S_{i j}=-3 d \lambda \frac{\partial f}{\partial J_{1}} \frac{\partial f}{\partial \varepsilon_{k k}^{P}} \text { (A.25) }
$$

or

$3 K d \varepsilon_{k k} \frac{\partial f}{\partial J_{1}}+\frac{G}{\sqrt{J_{2}}} \frac{\partial f}{\partial \sqrt{J_{2}}} S_{i j} d e_{i j}=3 K d \varepsilon_{k k}^{P} \frac{\partial f}{\partial J_{1}}+\frac{G}{\sqrt{J_{2}}} \frac{\partial f}{\partial \sqrt{J_{2}}} S_{i j} d e_{i j}^{P}$

$$
-3 d \lambda \frac{\partial f}{\partial J_{1}} \frac{\partial f}{\partial \varepsilon_{k k}^{P}}
$$

Substituting the values of $\mathrm{de}_{\mathrm{kk}}^{\mathrm{P}}$ and $\mathrm{de}_{i j}^{\mathrm{P}}$ from Equations $\mathrm{A} .20$ and A.22, respectively, into Equation $A .26$ yields

$$
\begin{aligned}
3 K d \varepsilon_{k k} \frac{\partial f}{\partial J_{1}}+\frac{G}{\sqrt{J_{2}}} \frac{\partial f}{\partial \sqrt{J_{2}}} S_{i j} d e_{i j} & =9 K d \lambda\left(\frac{\partial f}{\partial J_{1}}\right)^{2}+G d \lambda\left(\frac{\partial f}{\partial \sqrt{J}_{2}}\right)^{2} \\
& -3 d \lambda \frac{\partial f}{\partial J_{1}} \frac{\partial f}{\partial \varepsilon_{k k}^{P}}
\end{aligned}
$$

Solving for $\mathrm{d} \lambda$ gives 


$$
d \lambda=\frac{3 K \frac{\partial f}{\partial J_{1}} d \varepsilon_{k k}+\frac{G}{\sqrt{J_{2}}} \frac{\partial f}{\partial \sqrt{J}_{2}} S_{i j} d e_{i j}}{9 K\left(\frac{\partial f}{\partial J_{1}}\right)^{2}+G\left(\frac{\partial f}{\partial \sqrt{J_{2}}}\right)^{2}-3 \frac{\partial f}{\partial J_{1}} \frac{\partial f}{\partial \varepsilon_{k k}^{P}}}
$$

\section{A.2.3 Total Strain Increment Tensor}

The total strain increment tensor can be obtained by combining Equations A.6, A.12, A.19, and A.28:

$$
\begin{aligned}
d \varepsilon_{i j} & =\frac{d J_{1}}{9 K} \delta_{i j}+\frac{d S_{i j}}{2 G} \\
& +\left[\frac{3 K \frac{\partial f}{\partial J_{I}} d \varepsilon_{k k}+\frac{G}{\sqrt{J_{2}}} \frac{\partial f}{\partial \sqrt{J_{2}}} S_{m n}}{9 K\left(\frac{\partial f}{\partial J_{I}}\right)^{2}+G\left(\frac{\partial \hbar}{\partial \sqrt{J_{2}}}\right)^{2}-3 \frac{\partial f}{\partial J_{1}} \frac{\partial f}{\partial \varepsilon_{k k}}}\right]\left(\frac{\partial f}{\partial J_{1}} \delta_{i j}+\frac{1}{2 \sqrt{J_{2}}} \frac{\partial f}{\partial \sqrt{J_{2}}} S_{i j}\right)
\end{aligned}
$$

Similarly, the stress increment tensor can be written as

$$
d \sigma_{i j}=K d \varepsilon_{k k} \delta_{i j}+2 G d e_{i j}
$$

$$
-\left[\frac{3 K \frac{\partial f}{\partial J_{1}} d \varepsilon_{k k}+\frac{G}{\sqrt{J_{2}}} \frac{\partial f}{\partial \sqrt{J}_{2}} S_{m n} d e_{m n}}{9 K\left(\frac{\partial f}{\partial J_{1}}\right)^{2}+G\left(\frac{\partial f}{\partial \sqrt{J_{2}}}\right)^{2}-3 \frac{\partial f}{\partial J_{1}} \frac{\partial f}{\partial \varepsilon_{k k}^{P}}}\right]\left(3 K \frac{\partial f}{\partial J_{1}} \delta_{i j}+G \frac{\partial f}{\partial \sqrt{J}_{2}} \frac{S_{i, j}}{\sqrt{J_{2}}}\right)
$$

Equation A.29 or Equation A.30 is the general constitutive equation for an elastic-plastic isotropic material. To use either of these equations it is necessary only to specify the functional forms of $K$, $G$, and $\delta$ and, of course, to determine experimentally the numerical values of the coefficients in these functions. 


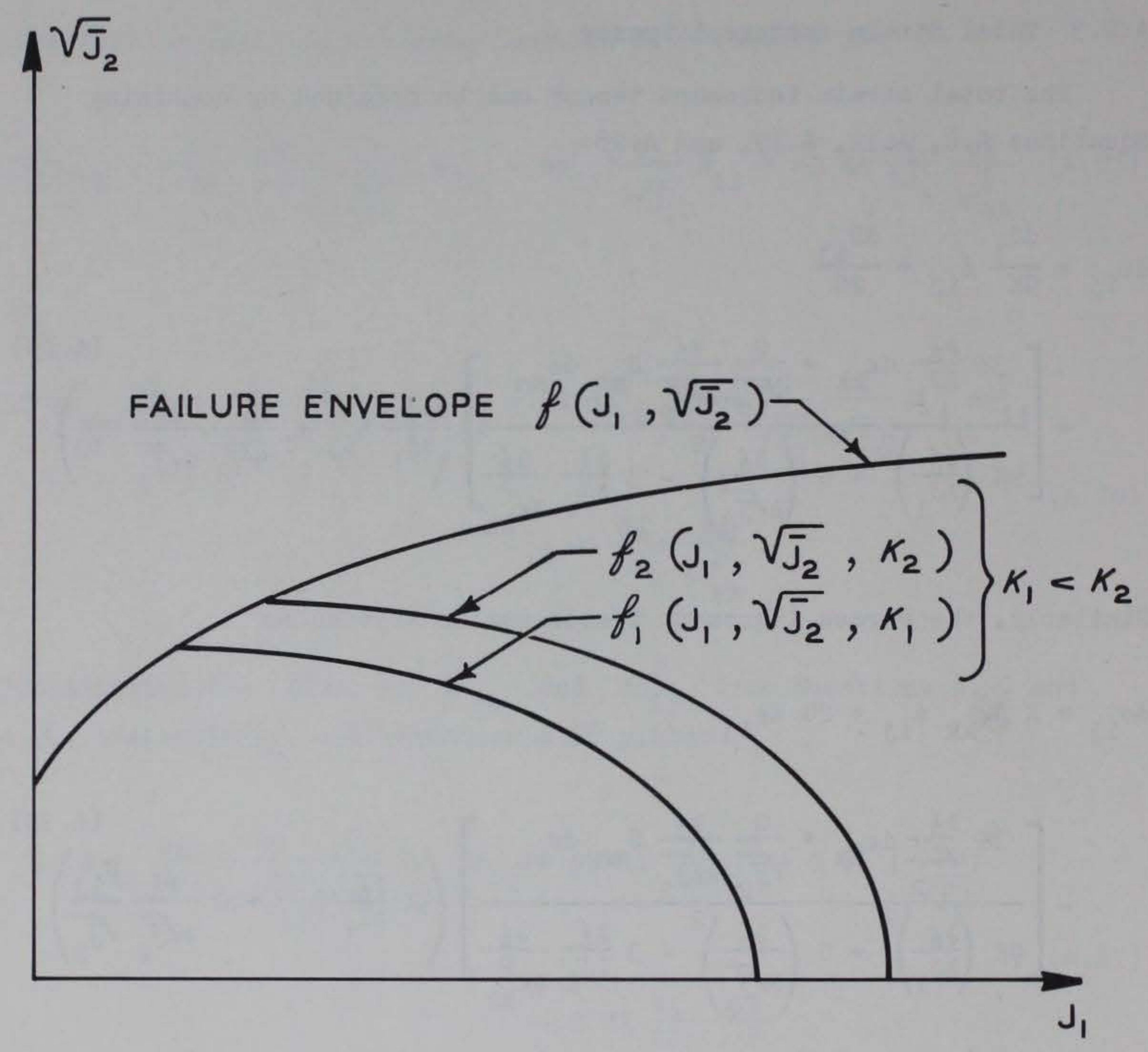

Figure A.1 Typical yield surface for an elastic-plastic strain-hardening model. 


\section{APPENDIX B: NOTATION}

$a_{i}$ Components of acceleration vector

$A$, B, and C Material constants; appear in the equation of the failure envelope

$C_{i j k l} \quad$ Elastic compliances of the material

d Phase duration; appears in application of the model

$\mathrm{d} \lambda$ Positive scalar factor of proportionality; appears in the flow rule

$D_{1} D_{1} \quad$ Material constants; appear in the hardening function

$\mathrm{D}_{\mathrm{mn}} \quad$ Deformation-rate tensor

$e_{i j} \quad$ Strain deviation tensor

$e_{i j}^{E} \quad$ Elastic strain deviation tensor

$e_{i j}^{P} \quad$ Plastic strain deviation tensor

f Failure envelope

6 Loading function

F Strain-hardening elliptic cap

$\mathrm{F}_{i}$ Components of body force

G Elastic shear modulus

$\mathrm{G}_{i} \quad$ Initial elastic shear modulus

$G_{1}, G_{2}, G_{3}, G_{4} \quad$ Material constants in shear modulus formulation

$\mathrm{I}_{2}^{\mathrm{P}} \quad$ Second invariant of the plastic strain deviation tensor

$\mathrm{J}_{1} \quad$ First invariant of the stress tensor

$J_{1}^{\prime} \quad$ First invariant of the effective stress tensor

$\bar{J}_{2}^{\prime}, \bar{J}_{2} \quad$ Second invariant of the effective or total stress deviation tensor, respectively

$\bar{J}_{3} \quad$ Third invariant of the stress deviation tensor

K Elastic bulk modulus

$\mathrm{K}_{\mathrm{i}} \quad$ Initial elastic bulk modulus 


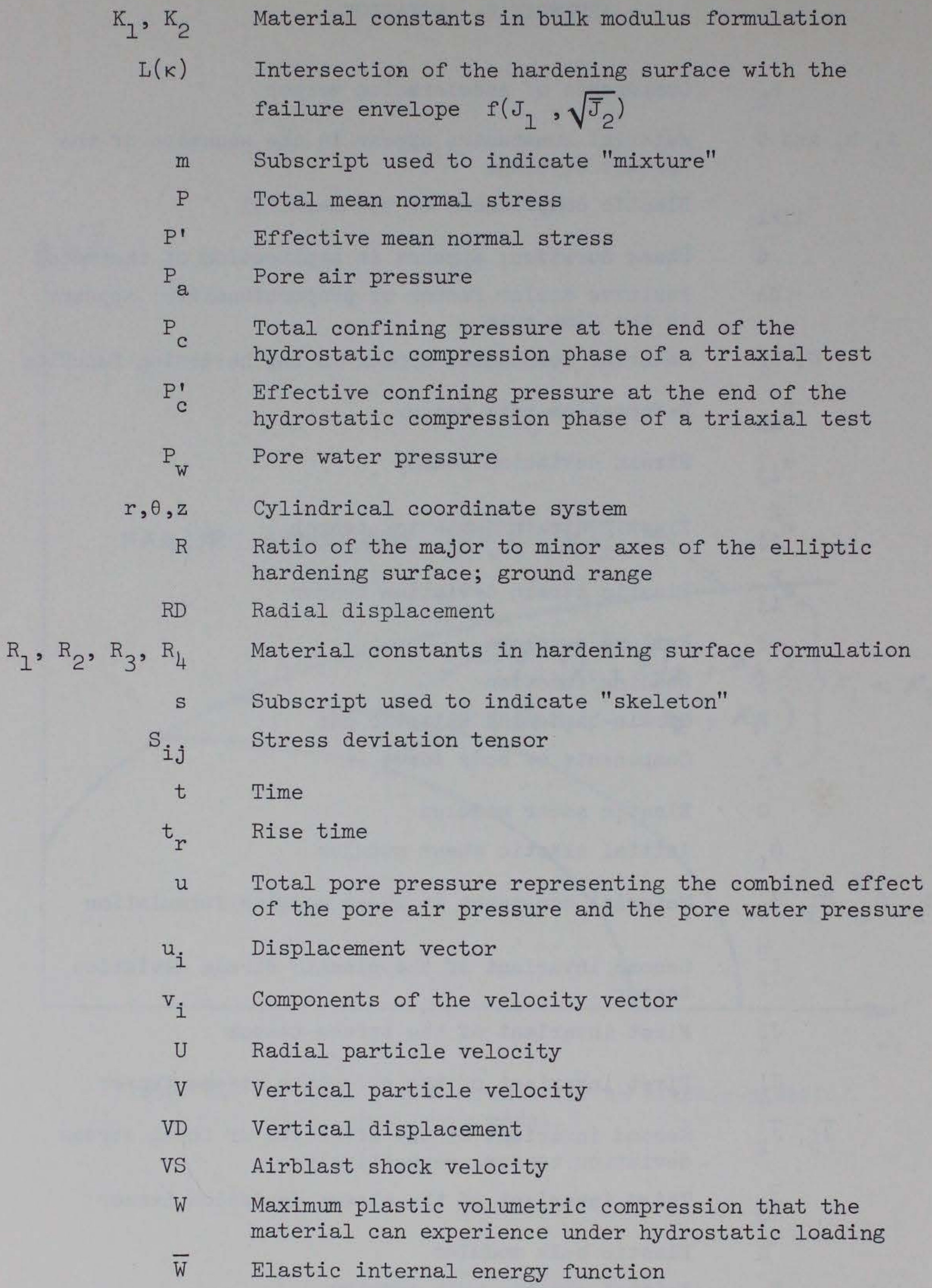

RD Radial displacement

$R_{1}, R_{2}, R_{3}, R_{4} \quad$ Material constants in hardening surface formulation

s Subscript used to indicate "skeleton"

$\mathrm{S}_{i j} \quad$ Stress deviation tensor

t Time

$t_{r} \quad$ Rise time

$u \quad$ Total pore pressure representing the combined effect of the pore air pressure and the pore water pressure

$u_{i} \quad$ Displacement vector

$v_{i} \quad$ Components of the velocity vector

U Radial particle velocity

V Vertical particle velocity

VD Vertical displacement

VS Airblast shock velocity

W Maximum plastic volumetric compression that the material can experience under hydrostatic loading

$\bar{W} \quad$ Elastic internal energy function 


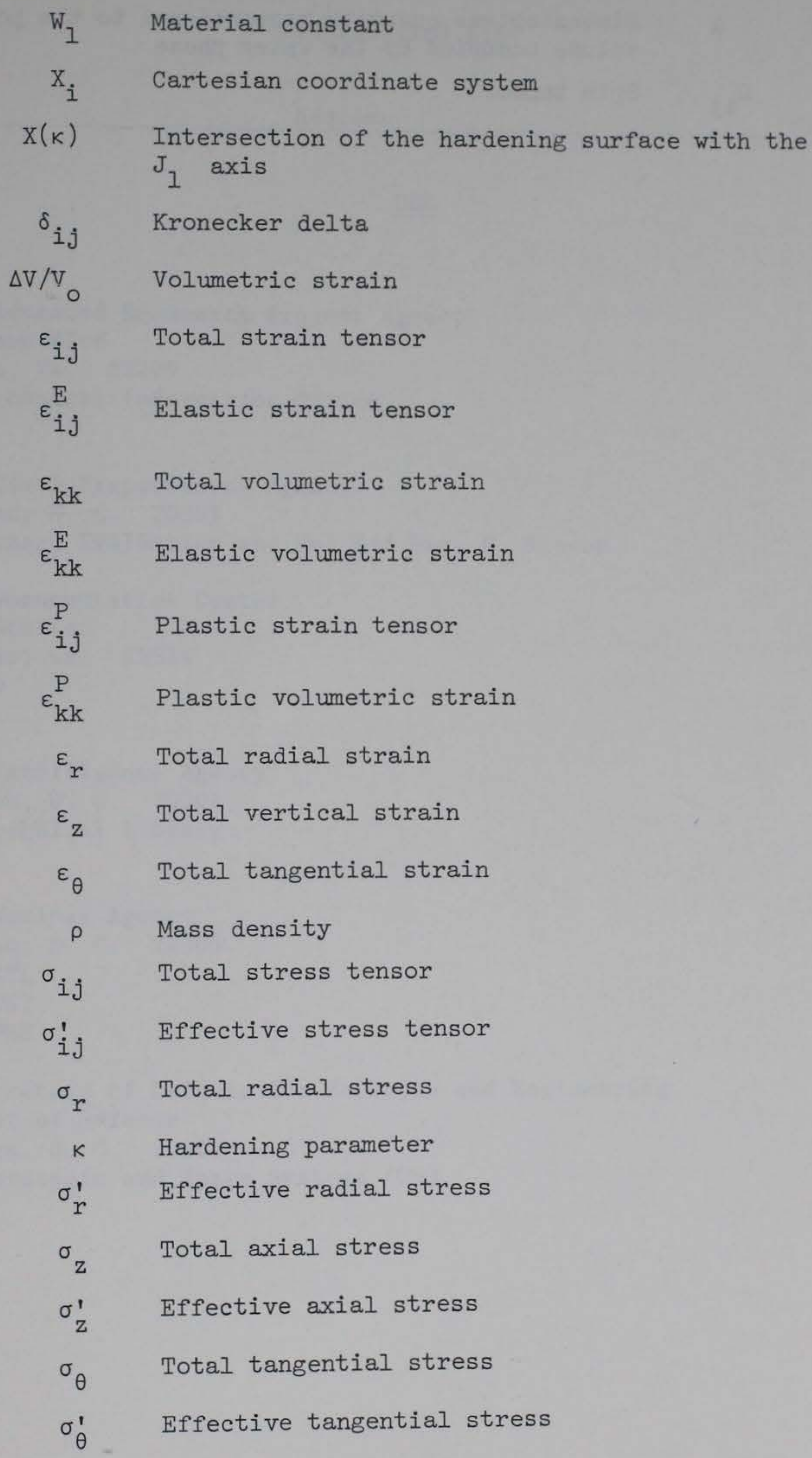


x Dimensionless quantity proportional to the pore volume occupied by the water phase

$\Omega_{i j} \quad$ Spin tensor 


\section{DOD}

\section{Director}

Defense Advanced Reasearch Project Agency 1400 Wilson Blvd

Arlington, Va. 22209

ATTN: Technical Information Office

Director

Defense Civil Preparedness Agency

Washington, D. C. 20301

ATTN: Hazard Evaluation and Vul Red Div, G. Sisson

Defense Documentation Center

Cameron Station

Alexandria, Va. 22314

ATTN : DD

Director

Defense Intelligence Agency

Washington, D. C. 20301

ATTN: Technical Library

Director

Defense Nuclear Agency

Washington, D. C. 20305

ATTN: TITL

DDST

SPSS

Under Secretary of Defense for Research and Engineering

Department of Defense

Washington, D. C. 20301

ATTN: Strategic and Space Systems (OS) 


\section{DEPARTMENT OF THE ARMY}

\section{Director}

BMD Advanced Technology Center

Department of the Army

P. 0. Box 1500, Huntsville, Ala. 35807

ATTN : ATC-T

Chief of Engineers

Department of the Army

Washington, D. C. 20314

ATTN : DAEN-MPE-T (D. Reynolds)

DAEN-RDM

DAEN-RDL

DAEN-ASI - L

Commander

Harry Diamond Laboratories

Department of the Army

2800 Powder Mill Road

Adelphi, Md. 20783

ATTN: DELHD-I-TL (Tech Lib)

Director

U. S. Army Ballistic Research Laboratories

Aberdeen Proving Ground, Md. 21005

ATTN: DRDAR-TSB-S (Tech Lib)

Commander

U. S. Army Engineer Center

Fort Belvoir, Va. 22060

ATTN : DT-LRC

Division Engineer

U. S. Army Engineer Division, Huntsville

P. 0. Box 1600, West Station

Huntsville, Ala. 35807

ATTN: HNDED-SR 


\section{DEPARTMENT OF THE ARMY (Continued)}

Division Engineer

U. S. Army Engineer Division, Ohio River

P. 0. Box 1159

Cincinnati, Ohio 45201

ATTN: ORDAS-L (Tech Lib)

Division Engineer

U. S. Army Engineer Division, Missouri River

P. 0. Box 103, Downtown Station

Omaha, Nebr. 68101

ATTN: Library

Commander

U. S. Army Material \& Mechanics Research Center

Watertown, Mass. 02172

ATTN: Technical Library

Commander

U. S. Army Materiel Development and Readiness Command 5001 Eisenhower Avenue

Alexandria, Va. 22333

ATTN: DRXAM-TL (Tech Lib)

Commander

U. S. Army Nuclear \& Chemical Agency

7500 Backlick Road

Building 2073

Springfield, Va. 22150

ATTN : Library

Commander/Director

U. S. Army Cold Regions Research and Engineering Laboratory

P. 0. Box 282

Hanover, N. H. 03755

ATTN : Library

Director

U. S. Army Construction Engineering Research Laboratory

P. 0. Box 4005

Champaign, I11. 61820

ATTN: Library 


\title{
DEPARTMENT OF THE NAVY
}

\author{
Officer-in-Charge \\ Naval Construction Battalion Center \\ Civil Engineering Laboratory \\ Port Hueneme, Calif. 93041 \\ ATTN: Code L08A (Library) \\ Code L51 (J. Ferrito) \\ Code L51 (J. Crawford)
}

Commander

Naval Facilities Engineering Command

Washington, D. C. 20390

ATTN: Code 09M22C (Tech Lib)

Superintendent

Naval Postgraduate School

Monterey, Calif. 93940

ATTN: Code 0142 (Library)

Officer-in-Charge

Naval Surface Weapons Center

White Oak Laboratory

Silver Spring, Md. 20910

ATTN: Technical Library

Commander

Naval Surface Weapons Center

Dahlgren, Va. 22448

ATTN: Technical Library \& Information Services Branch

Office of Naval Research

Arlington, Va. 22217

ATTN: Code 715 (Tech Lib)

\section{DEPARTMENT OF THE AIR FORCE}

Air Force Institute of Technology

Air University

Wright-Patterson AFB, Ohio 45433

ATTN: Library 


\section{DEPARTMENT OF THE AIR FORCE (Continued)}

Air Force Weapons Laboratory, AFSC

Kirtland AFB, N. Mex 87117

ATTN: DE M. Plamondon

DES R. Jolley

DES J. Thomas

SUL

Deputy Chief of Staff

Research, Development, \& acq.

Department of the Air Force

Washington, D. C. 20330

ATTN : AFRDQSM

Space \& Missile Systems Organization/MN

Air Force Systems Command

Norton AFB, Calif. 92409

ATTN: MNNXH (D. Gage)

MNNXH (M. Del Vecchio)

Vela Seismological Center

312 Montgomery Street

Alexandria, Va. 22314

ATTN: G. Ullrich

\section{DEPARTMENT OF ENERGY}

Nuclear Regulatory Commission

Directorate of Licensing Regulations

Washington, D. C. 20545

ATTN: Site Analysis $\mathrm{Br}$ (L. Heller)

Lawrence Livermore Laboratory

P. 0. Box 808

Livermore, Calif. 94550

ATTN: Technical Information Dept., Library

Oak Ridge National Laboratory

Nuclear Division

X-10 Lab Records Division

P. O. Box X, Oak Ridge, Tenn. 37830

ATTN: Central Research Library 


\section{DEPARTMENT OF ENERGY (Continued)}

Sandia Laboratories

P. 0. Box 5800

Albuquerque, N. Mex. 87115

ATTN: Div 5531 (W. Brown)

Div 5532 (J. Lipkin)

Div 5621 (M. Hightower)

Div 5533 (A. Chabai)

\section{DEPARTMENT OF DEFENSE CONTRACTORS}

Aerospace Corp.

P. O. Box 92957

Los Angeles, Calif. 9009

ATTN: Technical Information Services

Agbabian Associates

250 N. Nash Street

El Segundo, Calif. 90245

ATTN: M. Agbabian

Applied Theory, Inc.

1010 Westwood Blvd

Los Angeles, Calif. 90024

ATTN: J. Trulio

Boeing Co.

P. 0. Box 3707

Seattle, Wash. 98124

ATTN: Aerospace Library

California Research \& Technology, Inc. 6269 Variel Avenue

Woodland Hills, Calif. 91364

ATTN: Library

S. Shuster

$\mathrm{K}$. Kreyenhagen

California Research \& Technology, Inc. 4049 First Street

Livermore, Calif. 94550

ATTN: D. Orphal 


\section{DEPARTMENT OF DEFENSE CONTRACTORS (Continued)}

Civil Systems, Inc.

RFD 1

South Royalton, Vt. 05068

ATTN: S. Blouin

Civil Systems, Inc.

P. 0. Box 2083

Midland, Tex. 79702

ATTN: S. Melzer

Civil Systems, Inc.

2201 San Pedro, NE

Albuquerque, N. Mex. 87110

ATTN: J. Bratton

Eric H. Wang

Civil Engineering Research Facility

University of New Mexico

University Station

P. 0. Box 25

Albuquerque, N. Mex. 87131

ATTN: J. Shinn

J. Kovarna

P. Lodde

Fugro National, Inc.

P. 0. Box 17145

Long Beach, Calif. 90807

ATTN: D. Anderson

General Electric Co.-Tempo

816 State Street (P. O. Drawer QQ)

Santa Barbara, Calif. 93102

ATTN: DASIAC

IIT Research Institute

$10 \mathrm{~W}$. 35th Street

Chicago, I11. 60616

ATTN: Documents Library 


\section{DEPARTMENT OF DEFENSE CONTRACTORS (Continued)}

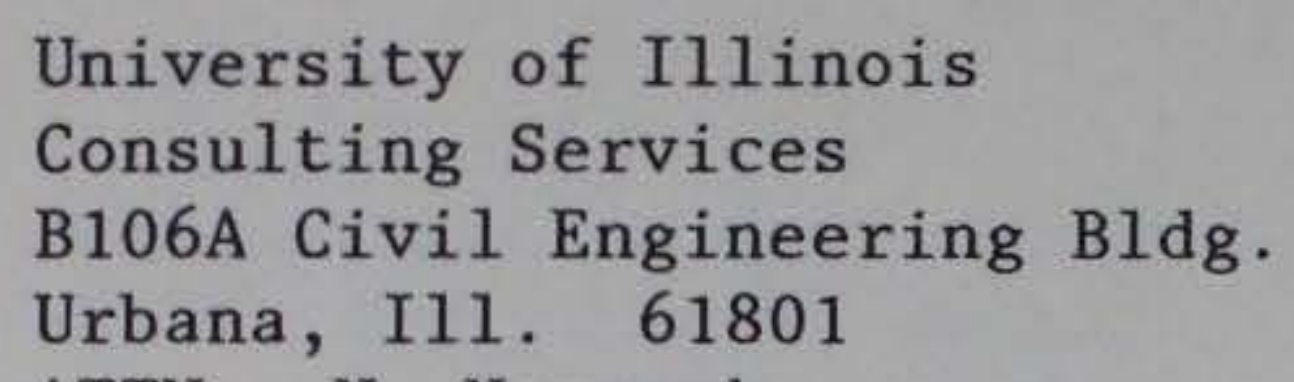

J. H. Wiggins Co., Inc.

1650 S. Pacific Coast Highway

Redondo Beach, Calif. 90277

ATTN : J. Collins

Merritt Cases, Inc.

P. 0. Box 1206

Redlands, Calif. 92373

ATTN : Library

Physics International Co.

2700 Merced Street

San Leandro, Calif. 94577

ATTN: Technical Library

J. Thomsen

Pacifica Technology

P. 0. Box 148

Del Mar, Calif. 92014

ATTN: Technical Library

R\&D Associates

P. 0. Box 9695

Marina Del Rey, Calif. 90291

ATTN: R. Port

Technical Information Center

R\&D Associates

1401 Wilson Blvd., Suite 500

Arlington, Va. 22209

ATTN: H. Cooper

Science Applications, Inc.

P. 0. Box 2351

La Jolla, Calif. 92038

ATTN: Technical Library 


\section{DEPARTMENT OF DEFENSE CONTRACTORS (Continued)}

\section{SRI International}

333 Ravenswood Ave.

Menlo Park, Calif. 94025

ATTN: Y. Gupta

Technical Library

Systems, Science \& Software, Inc.

P. 0. Box 1620

La Jolla, Calif. 92038

ATTN: Library

Terra Tek, Inc.

420 Wakara Way

Salt Lake City, Utah 84108

ATTN : Library

A. Abou-sayed

TRW Defense \& Space Systems Group

One Space Park

Redondo Beach, Calif. 90278

ATTN: Technical Information Center

N. Lipner

Weidlinger Assoc., Consulting Engineers 110 E. 59th Street

New York, N. Y. 10022

ATTN: M. Baron

I. Sandler

Weidlinger Assoc., Consulting Engineers 3000 Sand Hill Road

Menlo Park, Calif. 94025

ATTN: J. Isenberg 